University of Tennessee Health Science Center

UTHSC Digital Commons

$12-2015$

\title{
Genetic Control of Survival and Weight Loss during Pneumonic Burkholderia pseudomallei (Bp) Infection
}

\author{
Felicia D. Emery \\ University of Tennessee Health Science Center
}

Follow this and additional works at: https://dc.uthsc.edu/dissertations

Part of the Bacteria Commons, Bacterial Infections and Mycoses Commons, Medical Immunology Commons, and the Medical Microbiology Commons

\section{Recommended Citation}

Emery, Felicia D. , "Genetic Control of Survival and Weight Loss during Pneumonic Burkholderia pseudomallei (Bp) Infection" (2015). Theses and Dissertations (ETD). Paper 73. http://dx.doi.org/ 10.21007/etd.cghs.2015.0084.

This Dissertation is brought to you for free and open access by the College of Graduate Health Sciences at UTHSC Digital Commons. It has been accepted for inclusion in Theses and Dissertations (ETD) by an authorized administrator of UTHSC Digital Commons. For more information, please contact jwelch30@uthsc.edu. 


\title{
Genetic Control of Survival and Weight Loss during Pneumonic Burkholderia pseudomallei (Bp) Infection
}

\begin{abstract}
Burkholderia pseudomallei (Bp) is a saprophytic, gram-negative aerobe and the causative agent of the disease melioidosis. Melioidosis is an infectious disease that occurs in humans and animals and is prevalent in Southeast Asia, northern Australia and other tropical areas. Transmission occurs through direct contact with the organism via ingestion, inhalation, or through open wounds and skin abrasions. Clinical presentation is extremely variable and can range from acute septicemia with bacterial dissemination to distant sites, to an isolated pulmonary infection. Treatment of melioidosis can be problematic because it is often difficult to diagnose and $\mathrm{Bp}$ is resistant to a diverse group of antibiotics. Even with treatment, the mortality rate of melioidosis is 20 to $50 \%$.

While this pathogen is not widespread in the United States, it is a significant U.S. health issue because of its high potential for use as a biological weapon. The US Centers for Disease Control and Prevention (CDC) and The Department of Health and Human Services (DHHS) has recognized Bp as a Tier 1 Select Agent, meaning there is no effective vaccine against this high morbidity/mortality disease. Furthermore, according the CDC, other factors including aerosol infectivity, the severity of infection, and the global distribution of this pathogen makes it a potential bioterrorism agent that poses a threat to national security, if intentionally released into populated areas.
\end{abstract}

There has been little investigation into the role of host genetic background as it relates to susceptibility and/or resistance to Bp infection. It has been known for some time that inbred and recombinant inbred mice exhibit differences in susceptibility to many intracellular pathogens and are thought to provide excellent models for acute and chronic human melioidosis. Therefore, this project set out to identify host genetic elements that contribute to differential immune responsiveness and/or susceptibility to a Bp infection using a murine pneumonic challenge model. There is a high potential for discovery of host genes/genetic networks that confer resistance or sensitivity to this dangerous and emerging pathogen using inbred and BXD mouse strains as an in vivo modeling system of melioidosis.

We have utilized recombinant inbred BXD mice and a powerful array of complementary computer-based modeling algorithms and databases collectively known as GeneNetwork. We infected parental mice and 32 BXD strains with 50-100 CFU of Bp (strain 1026b) and monitored survival and weight retention each day over an eleven-day time course. Initial studies revealed that Bp infection elicits phenotypically distinct innate immune responses in terms of survival and weight loss following pneumonic infection in parental and BXD mice. Using the computational tools in GeneNetwork, we performed genome-wide linkage analysis of our survival and weight loss phenotypic data to identify that survival is a complex trait involving loci on chromosomes 5 and 7 and weight retention involves loci on chromosome 12 . We then analyzed and ranked several potential candidate genes within the significant and/or suggestive interval on these chromosomes that appear to correlate with differential susceptibility to Bp infection. Several genes have intriguing connections with innate immunity, regulation of Nf-k $\beta$, apoptosis, cell cycle regulation, nervous system development, calcium homeostasis, lipid transport, host cell growth and development, and autophagy.

To date, there have been few published studies that have identified specific host genetic elements that correlate with resistance and/or susceptibility to the acute form of melioidosis. Therefore, the identification of key host genetic factors that control resistance or susceptibility to Bp is of much importance. Results generated from this work will increase our understanding of the interactions between $\mathrm{Bp}$ and its genetically diverse hosts, which will enhance the understanding of Bp pathogenesis and increase the biological knowledge to help guide the progression and development of preventative and 
therapeutic measures to a Bp infection as well as other high morbidity/mortality respiratory pathogens.

\section{Document Type}

Dissertation

Degree Name

Doctor of Philosophy (PhD)

\section{Program}

Biomedical Sciences

\section{Research Advisor}

Mark A. Miller, Ph.D.

\section{Keywords}

BXD mice, Quantitative Trait Loci Mapping, Burkholderia pseudomallei

\section{Subject Categories}

Bacteria | Bacterial Infections and Mycoses | Diseases | Medical Immunology | Medical Microbiology | Medical Sciences | Medicine and Health Sciences | Organisms 


\title{
GENETIC CONTROL OF SURVIVAL AND WEIGHT LOSS DURING
} PNEUMONIC BURKHOLDERIA PSEUDOMALLEI (BP) INFECTION

\author{
A Dissertation \\ Presented for \\ The Graduate Studies Council \\ The University of Tennessee \\ Health Science Center
}

\author{
In Partial Fulfillment \\ Of the Requirements for the Degree \\ Doctor of Philosophy \\ From The University of Tennessee
}

By

Felicia D. Emery

December 2015 
Chapters 3 and 5 (C) 2014 by John Wiley and Sons.

All other material (c) 2015 by Felicia D. Emery. All rights reserved. 


\section{DEDICATION}

To Calvin and Betty Emery, my parents and my foundation. Your words of encouragement and push for tenacity ring in my ears. Both of you have been my best cheerleaders.

To my sisters, Corinthia and Genesia Emery, you have never left my side and are very special to me.

To my grandparents, Alene Comena and Louis Emery, I know you are watching from heaven and will always be in my heart.

To my friend, George R. Buckner, Jr., your encouraging words and wisdom will be a source of inspiration for me now and always.

Words cannot express how much I love you all. 


\section{ACKNOWLEDGEMENTS}

I would like to express my deep appreciation and gratitude to my advisor, Dr. Mark A. Miller, for my graduate training and affording me the opportunity to work in your lab. Your patient guidance, mentorship and support have been invaluable. Thank you for encouraging my research, and allowing me to grow as a scientist and a teacher. Your advice on both research as well as my career has been priceless, and I appreciate your genuinely good nature and your down-to-earth humility. I am truly grateful to have had you as my graduate mentor.

Many thanks to my committee members, Drs. Elizabeth Fitzpatrick, Tony Marion, Yan Cui and Robert W. Williams, for being more than generous with your expertise and precious time. Thank you for the thought provoking suggestions, direction, and counsel during my graduate career. I would also like to thank my former lab member, Jyothi Parvathareddy. Your help in every aspect of my research was imperative to my completion of this degree, and I appreciate all the time you invested helping me to master techniques that were crucial to my project. Thank you for being there for me and lending your support whenever and wherever needed. Additionally, I would like to thank all of the faculty and staff in the Molecular Sciences Building and the Microbiology, Immunology and Biochemistry (MIB) Department for your support. Many thanks to the RBL staff for their assistance and for providing a safe BSL-3 work environment.

I must acknowledge Dr. Gerry Byrne for allowing me to train under the T32 Bacterial Pathogenesis Training Grant and Dr. Sadia Mahdi for your assistance during my tenure on the training grant. The training and professional development opportunities I received were second to none. I want to give a special thanks to the administration and staff of the College of Graduate Health Sciences for the Bridge funding and personal assistance while completing this journey. I would also like to thank the Southern Regional Education Board (SREB) for awarding me a Dissertation Fellowship during my last year of graduate school. I appreciate all of the support provided during the writing process.

Thank you to my fellow graduate students in the MIB Track for their support and feedback. A very special thanks to my friends Beth L. Berkow, Sandra Lester, and Tarsha Harris --we met the first day of graduate school and the rest is history. Thanks for being by my side every step of the way, and always giving me reasons to cheer. Also, many thanks to Elise Brown and Dr. Leah Wright--your support, guidance and friendship were vital to me during this journey. Lastly, I would like to thank Ashutosh Pandey for all of your time and assistance with our QTL mapping studies. 


\begin{abstract}
Burkholderia pseudomallei $(B p)$ is a saprophytic, gram-negative aerobe and the causative agent of the disease melioidosis. Melioidosis is an infectious disease that occurs in humans and animals and is prevalent in Southeast Asia, northern Australia and other tropical areas. Transmission occurs through direct contact with the organism via ingestion, inhalation, or through open wounds and skin abrasions. Clinical presentation is extremely variable and can range from acute septicemia with bacterial dissemination to distant sites, to an isolated pulmonary infection. Treatment of melioidosis can be problematic because it is often difficult to diagnose and $B p$ is resistant to a diverse group of antibiotics. Even with treatment, the mortality rate of melioidosis is 20 to $50 \%$.

While this pathogen is not widespread in the United States, it is a significant U.S. health issue because of its high potential for use as a biological weapon. The US Centers for Disease Control and Prevention (CDC) and The Department of Health and Human Services (DHHS) has recognized $B p$ as a Tier 1 Select Agent, meaning there is no effective vaccine against this high morbidity/mortality disease. Furthermore, according the CDC, other factors including aerosol infectivity, the severity of infection, and the global distribution of this pathogen makes it a potential bioterrorism agent that poses a threat to national security, if intentionally released into populated areas.
\end{abstract}

There has been little investigation into the role of host genetic background as it relates to susceptibility and/or resistance to $B p$ infection. It has been known for some time that inbred and recombinant inbred mice exhibit differences in susceptibility to many intracellular pathogens and are thought to provide excellent models for acute and chronic human melioidosis. Therefore, this project set out to identify host genetic elements that contribute to differential immune responsiveness and/or susceptibility to a $B p$ infection using a murine pneumonic challenge model. There is a high potential for discovery of host genes/genetic networks that confer resistance or sensitivity to this dangerous and emerging pathogen using inbred and BXD mouse strains as an in vivo modeling system of melioidosis.

We have utilized recombinant inbred BXD mice and a powerful array of complementary computer-based modeling algorithms and databases collectively known as GeneNetwork. We infected parental mice and 32 BXD strains with 50-100 CFU of $B p$ (strain 1026b) and monitored survival and weight retention each day over an eleven-day time course. Initial studies revealed that $B p$ infection elicits phenotypically distinct innate immune responses in terms of survival and weight loss following pneumonic infection in parental and BXD mice. Using the computational tools in GeneNetwork, we performed genome-wide linkage analysis of our survival and weight loss phenotypic data to identify that survival is a complex trait involving loci on chromosomes 5 and 7 and weight retention involves loci on chromosome 12 . We then analyzed and ranked several potential candidate genes within the significant and/or suggestive interval on these chromosomes that appear to correlate with differential susceptibility to $B p$ infection. Several genes have intriguing connections with innate immunity, regulation of $\mathrm{Nf}-\mathrm{k} \beta$, 
apoptosis, cell cycle regulation, nervous system development, calcium homeostasis, lipid transport, host cell growth and development, and autophagy.

To date, there have been few published studies that have identified specific host genetic elements that correlate with resistance and/or susceptibility to the acute form of melioidosis. Therefore, the identification of key host genetic factors that control resistance or susceptibility to $B p$ is of much importance. Results generated from this work will increase our understanding of the interactions between $B p$ and its genetically diverse hosts, which will enhance the understanding of $B p$ pathogenesis and increase the biological knowledge to help guide the progression and development of preventative and therapeutic measures to a $B p$ infection as well as other high morbidity/mortality respiratory pathogens. 


\section{TABLE OF CONTENTS}

CHAPTER 1. INTRODUCTION ......................................................................................

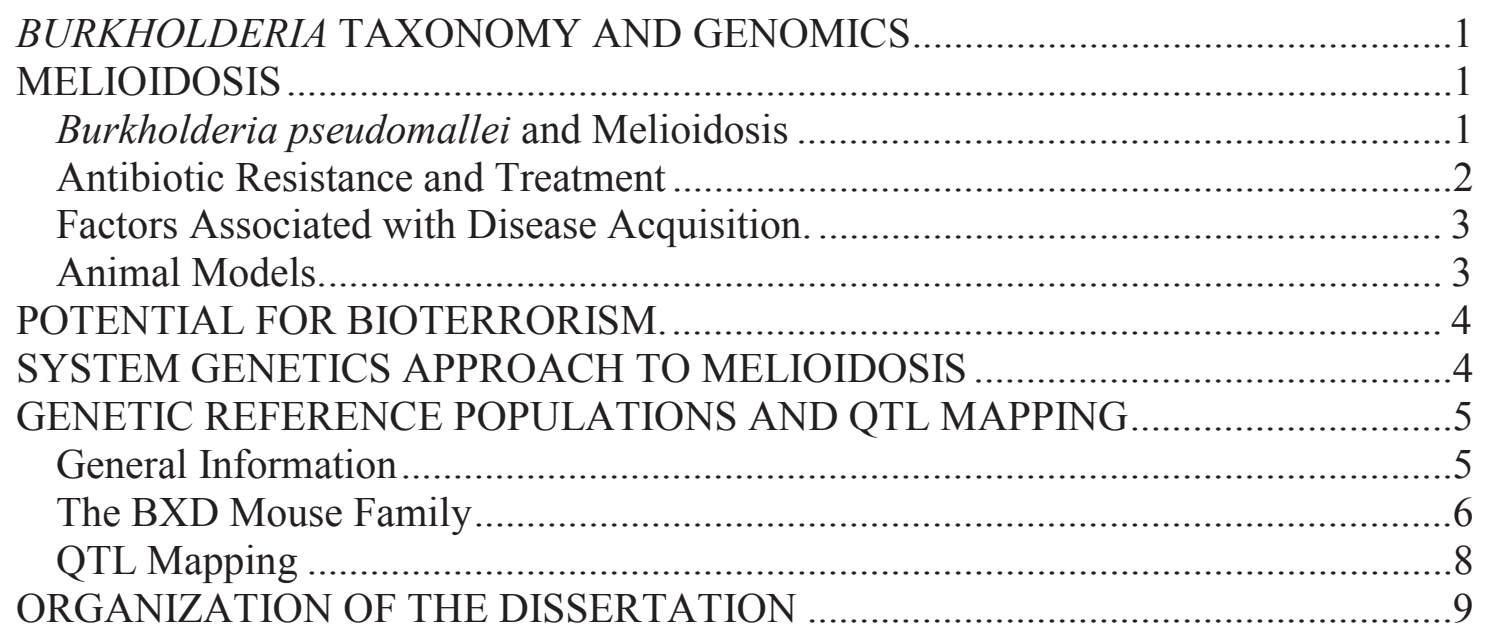

CHAPTER 2. MATERIALS AND METHODS........................................................11

BACTERIAL STRAINS AND GROWTH CONDITIONS ......................................11

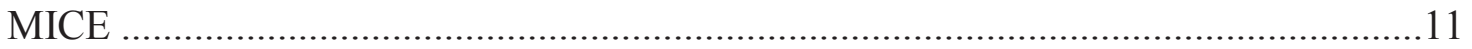

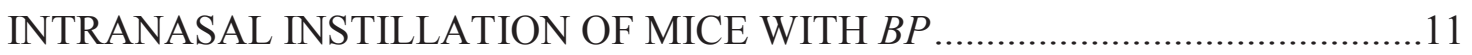

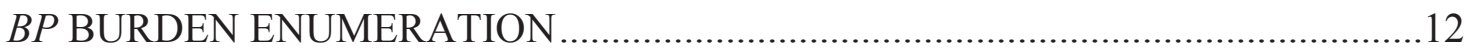

MONITORING OF MICE POST CHALLENGE ....................................................... 12

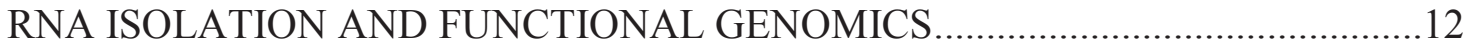

GENOME-WIDE LINKAGE ANALYSIS ............................................................ 13

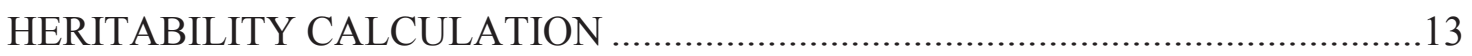

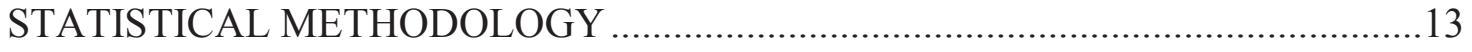

CHAPTER 3. GENETIC CONTROL OF WEIGHT LOSS DURING PNEUMONIC BURKHOLDERIA PSEUDOMALLEI INFECTION......................14

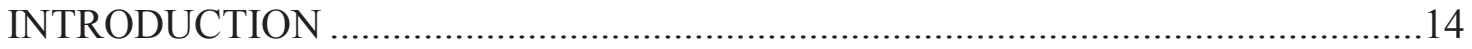

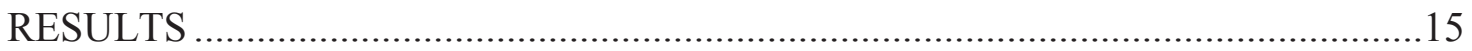

Heritability and Variance of Weight Loss Traits ...................................................20

Identification of Host Loci that Are Covariant with Weight Loss during

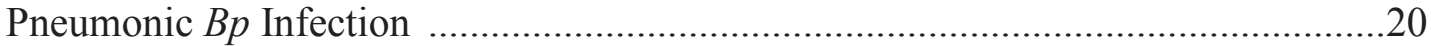

Identification of Candidate Host Genes that May Contribute to Weight Loss

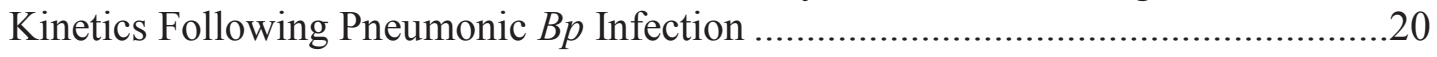

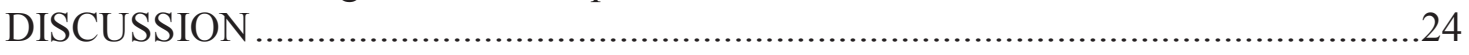

CHAPTER 4. GENETICS OF DIFFERENTIAL SUSCEPTIBILITY TO PNEUMONIC BURKHOLDERIA PSEUDOMALLEI INFECTION.........................37

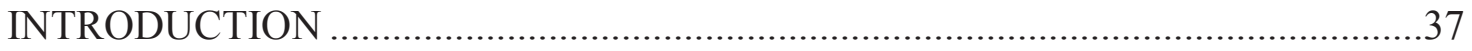

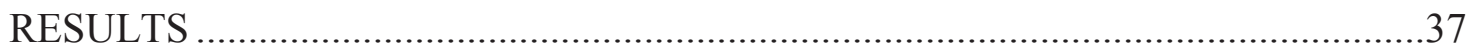

Susceptibility of B6 and D2 Mice to Pneumonic Infection..................................... 37 
Susceptibility of BXD RI Mice to Pneumonic $B p$ Infection ......................................38

Heritability of Survival and Time-to-Death ..............................................................38

Identification of Host Genetic Loci that Influence Survival Following Pneumonic

$B p$ Infection

Identification of Candidate Host Genes that May Contribute to Host

Susceptibility/Resistance Following $B p$ Infection ....................................................40

Identification of Candidate Genes from Expression Profiling Using RNA-Seq.........40

DISCUSSION

\section{CHAPTER 5. EFFICIENT INACTIVATION OF BURKHOLDERIA \\ PSEUDOMALLEI OR FRANCISELLA TULARENSIS IN INFECTED CELLS FOR SAFE REMOVAL FROM BIOSAFETY LEVEL 3 CONTAINMENT

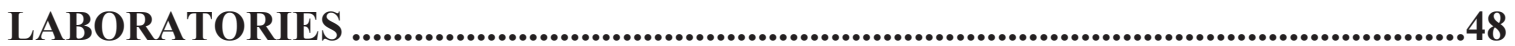

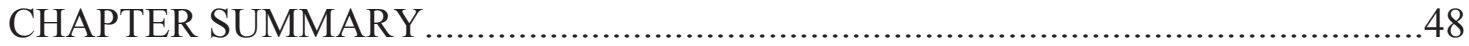

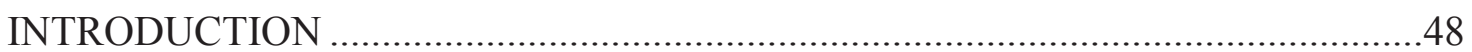

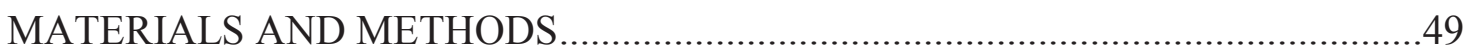

Collection and Differentiation of Murine Bone Marrow Cells ..................................49

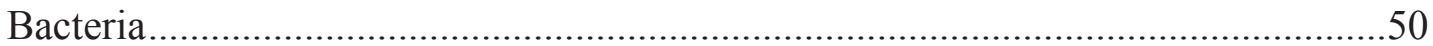

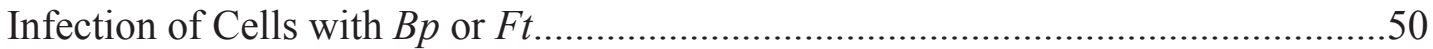

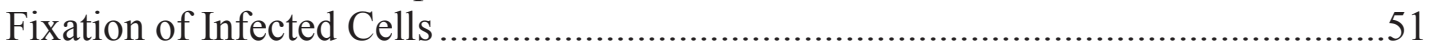

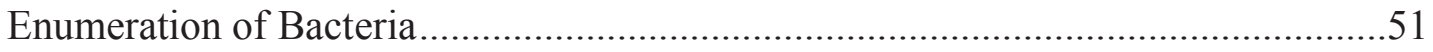

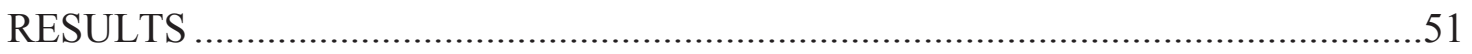

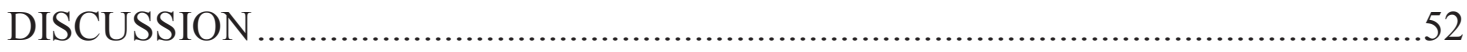

CHAPTER 6. DISCUSSION AND CONCLUSIONS ....................................................59

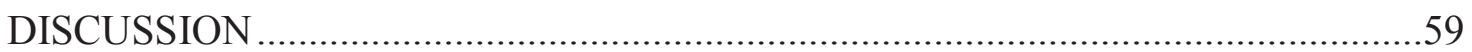

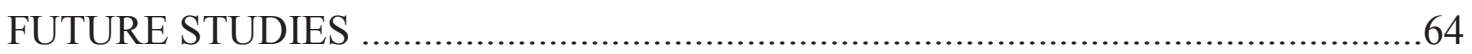

Chromosomes 5 and 7 Are Co-Dependent...........................................................64

The Additive Allele Effect for Survival QTL Analysis ..............................................64

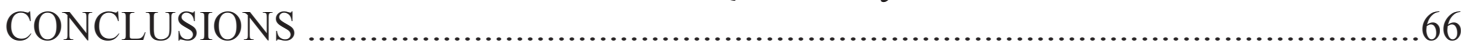

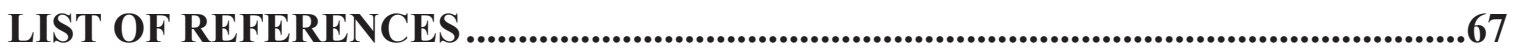

APPENDIX. SUPPLEMENTARY FIGURES AND TABLES.....................................84

VITA 


\section{LIST OF TABLES}

Table 3-1. QTLMINER scores for candidate genes within the day 1 QTL interval (Chr 4): Trait 16332 .......................................................................25

Table 3-2. QTLMINER scores for candidate genes within day 2 QTL intervals (Chrs 2 and 17): Trait 16333 ....................................................................28

Table 3-3. QTLMINER scores for candidate genes within the days 3-4 QTL interval (Chr 12): Trait 16334 and 16335

Table 4-1. QTLMINER scores for candidate genes within the QTL interval for the survival trait (Chrs 5 and 7): Trait 16630

Table 5-1. Number of Burkholderia pseudomallei following paraformaldehyde fixation of infected cell samples (1st 15 minutes of timecourse)

Table 5-2. Number of Francisella tularensis following paraformaldehyde fixation of infected cell samples (1st 15 minutes of timecourse)

Table 5-3. Fold reduction of viable Burkholderia pseudomallei following paraformaldehyde fixation of infected cell samples

Table 5-4. Fold reduction of viable Francisella tularensis following paraformaldehyde fixation of infected cell samples

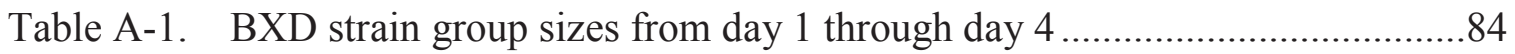

Table A-2. Pathway analysis (Gene Ontology (GO) Description) using genes whose expression is significantly upregulated in resistant BXD mice (BXD50 and BXD70)

Table A-3. Pathway analysis (Gene Ontology (GO) Description) using genes whose expression is significantly upregulated in susceptible BXD mice (BXD9, BXD63 and BXD27) 


\section{LIST OF FIGURES}

Figure 1-1. Breeding scheme used to generate the panel of BXD recombinant inbred strains

Figure 3-1. DBA/2J mice are significantly more susceptible than C57BL/6J mice to Burkholderia pseudomallei....

Figure 3-2. Differential susceptibility of male versus female DBA/2J and BXD mice to pneumonic $B$. pseudomallei infection....

Figure 3-3. Weight loss of BXD genotypes following pneumonic Bp infection

Figure 3-4. Bar graph (by rank) of percentage weight loss on days 1 through 4 postBp infection

Figure 3-5. Principle component analysis, heritability, and correlations among weight loss traits during the early stages of pneumonic melioidosis

Figure 3-6. Genome-wide linkage analysis for percentage weight loss over the 4 days following pneumonic challenge with Burkholderia pseudomallei.......22

Figure 3-7. Detailed maps of the QTLs contributing to weight loss during the early stages of pneumonic $B p$ infection

Figure 4-1. Genome-wide linkage analysis of survival following pneumonic challenge with Burkholderia pseudomallei ....

Figure 4-2. Genome-wide linkage analysis of time-to-death trait following pneumonic challenge with Burkholderia pseudomallei.....

Figure 4-3. Detailed maps of QTLs contributing to survival and candidate genes within these intervals

Figure 5-1. Paraformaldehyde fixation conditions for killing Burkholderia pseudomallei and Francisella tularensis Schu S4 in infected cell samples.

Figure 5-2. Burkholderia pseudomallei is more sensitive than Francisella tularensis to paraformaldehyde treatment.

Figure 6-1. Correlation network for the survival, time-to-death, and weight loss phenotypes following pneumonic $B$. pseudomallei infection.... 
Figure 6-2. Refined QTL analysis with addition of three new BXD genotypes: Genome-wide linkage analysis of survival following pneumonic challenge with Burkholderia pseudomallei.

Figure A-1. Genome-wide linkage analysis for percentage weight loss on days 5-11 post- $B p$ infection. 86 


\section{LIST OF ABBREVIATIONS}

$\begin{array}{ll}\text { AIL } & \text { Advanced Intercrossed Line } \\ \text { B6 } & \text { C57BL/6J } \\ \text { B6NJ } & \text { C57BL/NJ } \\ \text { BMDM } & \text { Bone Marrow Derived Macrophages } \\ \text { Bp } & \text { Burkholderia pseudomallei } \\ \text { BSL-2 } & \text { Biosafety-level 2 } \\ \text { BSL-3 } & \text { Biosafety-level 3 } \\ \text { BXD } & \text { C57BL/6J X DBA/2J } \\ \text { CDC } & \text { Centers for Disease Control and Prevention } \\ \text { Chr(s) } & \text { Chromosome(s) } \\ \text { COBRE } & \text { Committee on Biocontainment and Restricted Entities } \\ \text { CXCL } & \text { Chemokine (C-X-C motif) } \\ \text { D1 } & \text { DBA/1J } \\ \text { D2 } & \text { DBA/2J } \\ \text { DHHS } & \text { Department of Health and Human Services } \\ \text { eQTLs } & \text { Expression Quantitative Trait Loci } \\ \text { Ft } & \text { Francisella tularensis } \\ \text { GI } & \text { Genomic Islands } \\ \text { GN } & \text { GeneNetwork } \\ \text { GRP } & \text { Genetic Reference Population } \\ \text { HLA } & \text { Human Leukocyte Antigen } \\ \text { IACUC } & \text { Institutional Animal Care and Use Committee } \\ \text { IBC } & \text { Institutional Biosafety Committee } \\ \text { Indels } & \text { Insertions and Deletions } \\ \text { ISAC } & \text { International Society for Analytical Cytology } \\ \text { LB } & \text { Luria Broth } \\ \text { LRS } & \text { Likelihood Ratio Statistic } \\ \text { MHC H2 } & \text { Major histocompatibility Complex Histocompatibility-2 } \\ \text { PBS } & \text { Phosphate Buffered Saline } \\ \text { PFA } & \text { Paraformaldehyde } \\ \text { QTL } & \text { Quantitative Trait Locus/Loci } \\ \text { RBL } & \text { Regional Biocontainment Laboratory } \\ \text { RI } & \text { Recombinant Inbred } \\ \text { RIL(s) } & \text { Recombinant Inbred Line(s) } \\ \text { SNP } & \text { Single Nucleotide Polymorphism } \\ \text { SOPs } & \text { Standard Operating Procedures } \\ & \\ & \end{array}$




\section{CHAPTER 1. INTRODUCTION}

\section{BURKHOLDERIA TAXONOMY AND GENOMICS}

Burkholderia pseudomallei $(\mathrm{BP})$ belongs to the Burkholderia genus, which contains over 40 species that inhabit a variety of ecological niches [1]. The majority of species within this genus are non-pathogenic soil-dwelling bacteria, but a few species (including $B p$ ) are highly pathogenic to humans and animals, and can result in severe disease [2]. This includes B. mallei, an obligate mammalian pathogen and the causative agent of glanders. B. mallei primarily affects horses, donkeys and mules, and is extremely virulent in humans [1]. A clinically important species of Burkholderia is B. cenocepacia, which is a major cause of opportunistic infections in cystic fibrosis patients $[1,3]$. This genus also includes the $B p$-like strain $B$. thailandensis, which coexists in the soil in endemic areas, but as described in the literature, it is significantly less pathogenic than $B p$ in hamsters and mice [3, 4].

$B p$ is an organism with a genome of great plasticity. It is also phenotypically versatile, and this is reflective of a highly dynamic genome influenced by processes such as recombination, mutations and gene acquisition through horizontal transfer $[5,6]$. The $B p$ genome (reference strain K96243) is one of the most complex bacterial genomes sequenced to date, and possess two chromosomes of 4.07 and 3.17 megabase pairs [3, 7]. $B p$ shares a common set of 2590 genes ( $86 \%$ of genome) with other members of the Burkholderia genus [3] that encode core functions such as cell growth and metabolism. The other $14 \%$, known as the accessory genome, is variably present across isolates and encodes accessory functions such as adaptation and survival in different environments [3, 8]. The accessory genome also contains multiple genomic islands (GI) that have been acquired through horizontal transfer, and act as a major source of genomic diversity [9]. These GI are likely associated with virulence, antibiotic resistance and the potential for infection. However, more studies are needed to fully understand their association with clinical outcomes $[9,10]$.

\section{MELIOIDOSIS}

\section{Burkholderia pseudomallei and Melioidosis}

$B p$ is a saprophytic, gram-negative aerobe and the causative agent of the disease melioidosis [11]. Melioidosis is an infectious disease that occurs in humans and animals. It is endemic in tropical areas between latitudes $20^{\circ} \mathrm{N}$ and $20^{\circ} \mathrm{S}$ of the equator, but is most often reported in areas of Southeast Asia and Northern Australia [12]. In fact, this disease has emerged as a major public health concern in Northern Australia and Southeast Asia where it is the most common cause of fatal bacteremic pneumonias $[13,14]$ and carries a mortality rate of $20 \%$ and $50 \%$, respectively [7]. 
$B p$ is an environmental pathogen and can be found in niches that predominate in the tropics, such as rice paddies, stagnant waters and moist soils, $[15,16]$. It is thought that these habitats are the major reservoirs from which susceptible hosts acquire infections [16]. Infection can result from percutaneous inoculation, inhalation, or ingestion [3] and manifestations of disease are dependent on host pathogen interactions and are extremely broad. Manifestations can range from rapidly lethal sepsis to chronic low-grade infection, with the most common clinical picture being sepsis with bacterial dissemination to distant sites [11, 17-19]. This picture is frequently associated with pneumonia and formation of abscesses on the liver and spleen [20]. Infection can also manifest in the skin, in bone, joints, soft tissue, or the prostate [19,21-23], and can also cause blood disease, kidney disease, heart disease, and more [20]. This broad spectrum of clinical symptoms has earned $B p$ the nickname "The Great Mimicker", since the clinical symptoms of melioidosis imitate those of many other diseases. As a result, $B p$ infections are frequently misdiagnosed [24] and this is often fatal [3]. Diagnosis is then reliant on proper specimen collection and laboratory identification of the organism [23]. Additionally, melioidosis has been dubbed the "Vietnamese time bomb" [25] because of lengthy disease latency observed in troops of all nationalities who served in areas with endemic disease $[25,26]$. This phenomenon has also been seen in returned travelers to other countries $[25,27,28]$.

\section{Antibiotic Resistance and Treatment}

Melioidosis has an extremely extended progression and cure is difficult without a long course of antibiotic treatment [3]. To make matters worse, $B p$ is inherently resistance to many antibiotics - including penicillin [29, 30], third-generation cephalosporins [29, 31], aminoglycosides [29, 32, 33], rifamycins [28], tetracycline [34$36]$, quinolones $[30,31,34]$ and macrolides $[29,33,35]$, which greatly hinders clinical therapeutic options. According to a recent review by Wiersinga et. al. , "various mechanisms of acquired antibiotic resistance have been identified in $B p$ and include efflux pumps [33], enzymatic inactivation, bacterial-cell-membrane impermeability, alterations in the antibiotic target site, and amino acid changes in penA (the gene encoding the highly conserved class A $\beta$-lactamase)" $[3,37,38]$.

Treatment of melioidosis lasts for 20 weeks and is divided into intravenous and oral phases [3]. The initial intensive phase includes 10 to 14 days of intravenous administration of ceftazidime, meropenem, or imipenem $[3,7,8]$. This is followed up with an oral eradication therapy, usually with trimethoprim-sulfamethoxazole or doxycycline for 3 to 6 months [3]. Despite this prolonged administration of antibiotics, the rate of relapse is about $10 \%$, which increases to almost $30 \%$ if antibiotic therapy is discontinued at 8 weeks or less $[39,40]$. The risk of relapse is also correlated to the initial extent of disease [28]. As compared to children, who generally have a better prognosis, adult patients fare worse and often require life-long follow-up [21, 41]. Unfortunately, melioidosis has high mortality rates (up to 50\%) despite the use of aggressive antimicrobial therapy [1]. 


\section{Factors Associated with Disease Acquisition}

Disease acquisition in endemic regions is associated with environmental and host factors [7]. People with occupational or recreational exposure to contaminated soil or water (rice farmers, military personnel, adventure travelers, eco-tourists, and construction workers [42]) have a higher incidence of disease. This is most common during the rainy season when aerosols are created, which results in repeated inhalation of $B p[43,44]$. Environmental sampling studies reveal there is a positive association between the prevalence of disease and the degree of environmental contamination [7]. In addition to environmental factors, data suggests that host factors play an important role in mounting an immune response against infectious diseases [45] such as melioidosis. While healthy persons can contract melioidosis, most patients in endemic regions have an underlying predisposition [28], which suggests that the immunological status of the patient can influence disease initiation and progression [15]. Specifically, diabetes mellitus (50\% of cases) and chronic renal disease (in 10 to $27 \%$ of cases) are the most common risk factors for melioidosis $[7,15]$. Other risk factors include heavy alcohol use, chronic pulmonary disease, and cancer [3, 21]. Furthermore, since melioidosis is associated with a broad range of clinical presentations, there is a possibility that the route of infection is one of the many factors that may influence disease outcome [46].

It has been established through published genome wide studies that susceptibility to major infectious diseases in humans may be associated with common polymorphisms $[47,48]$. These findings include a correlation between human leukocyte antigen (HLA) polymorphisms and the type and/or intensity of the immune response that develops in response to a $B p$ infection [49]. Additionally, a study by Nuntayunuwat et.al found that polymorphisms in cytokine-related genes maybe be a factor in susceptibility to infection with $B p$ [50]. Such data highlight the importance of investigating the role of host genetic variation with regards to susceptibility to disease [48]. This also leads to the notion that there may be an immunogenetic basis in clearing a $B p$ infection. However, the impact of specific genes or genetic backgrounds in humans that contribute to the susceptibility or resistance to many major diseases [51], including melioidosis, has yet to be determined.

\section{Animal Models}

A variety of animals have been used in experimental models of melioidosis, including chicken [52], rats [53], guinea pigs [54] and inbred mouse strains [55, 56]. The murine infection model has also been used to show both the importance of the host genetic background as well as host responses on the progression of a $B p$ infection [28]. $\mathrm{BALB} / \mathrm{c}$ mice $[57,58]$ and DBA/2J (D2) $[55,59]$ mice are known to be extremely susceptible to the acute form of melioidosis, while C57BL/6 (B6) $[28,55,56,58]$ mice exhibit a heightened level of resistance to the acute form of melioidosis, and tend to develop a chronic form of the disease. The acute melioidosis observed in BALB/c and D2 mice is characterized by significantly higher levels of pro-inflammatory cytokines, including a hyper-production of IFN- $\gamma$. This results in a cellular response that fails to control the infection and contributes to tissue damage and multiple organ failure [56]. In 
contrast, B6 mice develop a chronic infection that is associated with a moderate but transient induction of pro-inflammatory cytokines, allowing the temporary sequestration of $B p$ within phagocytes and induction of an adaptive immune response [56,60]. The heighted level of resistance exhibited in B6 mice is thought to have a genetic basis. Undeniably, these mouse studies illustrate the potential importance of host genetic effects to $B p$ infection by highlighting major differences between distinctive inbred strains [48, $56,61]$.

\section{POTENTIAL FOR BIOTERRORISM}

As a result of $B p$ 's biodefense implications, broad-host-range infectivity and its low infectious dose, the CDC and DHHS have recognized $B p$ as a Tier 1/ Category B Select Agent [37, 62, 63]. According to the CDC, agents within this category are those that are moderately easy to disseminate, have an amenability to aerosolize, result in a severe course of infection and no have effective vaccine. Other factors include the intrinsic antibiotic resistance and global distribution of this pathogen, which makes it a potential bioterrorism agent that poses a threat to national security if intentionally released into populated areas $[64,65]$. While $B p$ is not widespread in the U.S., it is a significant U.S. health issue because of its high potential for use as a biological weapon. In recent years, knowledge on melioidosis has increased tremendously, due to more research groups working with $B p$ as a result of it being recognized as a biological threat agent [66]. Furthermore, the select agent listing of this pathogen subjects all research using $B p$ to strict federal guidelines that govern its acquisition, possession and use. Only trained personnel within a Biosafety Level 3 (BSL-3) facility (or national equivalent) should handle the organism $[19,23]$. This hinders research on $B p$ by those research institutions that lack these containment laboratories.

\section{SYSTEM GENETICS APPROACH TO MELIOIDOSIS}

As described above, melioidosis is associated with a variable clinical presentation. The varying responses have been attributed to heritable variation, which predisposes an individual to certain disease outcomes $[67,68]$. Rather than independently investigate each biochemical, cellular and genetic factor in understanding melioidosis, it is far more efficient to instead utilize recent computational and technological advances to quantitatively examine large numbers of DNA sequence variations, transcript levels, and proteins $[69,70]$. By integrating this comprehensive data, it is possible to identify the commonalties that link the associations between disease and DNA, as well as develop molecular networks by which these links can be traced [70]. As such, it is useful to employ a system genetics approach to identify and characterize genetic loci that contribute to resistance and/or susceptibility to melioidosis.

System genetics is an emerging branch of systems biology that seeks to identify relationships between genetic variants and systems of biological components (i.e.

molecules, cells) in complex traits and disease [71]. Most often, mapping populations are 
used to understand the relationship between phenotype and genotype relative to complex traits. The phenotypic and genotypic data that is generated is compiled into complex networks, which are then used to discriminate genetic variation among the mapping population $[55,72,73]$. This approach provides an informative view into the general framework of complex traits and the flow of biological information [69]. Furthermore, in an attempt to better understand both biology and disease, systems genetics has become a progressively important approach in bridging this gap [69]. The idea is that variations in DNA (i.e. single nucleotide polymorphisms), which associate with a particular disease or response (melioidosis in this case), impact the complex physiological processes involved with the response through molecular and cellular events, tissue, and organismal phenotypes [70]. Statistical methods and computational algorithms can be used to identify associations between multi-level phenotypes and the underlying genetic variants as previously described [74].

\section{GENETIC REFERENCE POPULATIONS AND QTL MAPPING}

\section{General Information}

Genetic reference populations (GRP) are often used in system genetics studies. They are well characterized genetically, and thus are ideal to examine phenotypic traits [69]. Usually, these populations are sets of inbred strains that have been designed to incorporate levels of genetic complexity that mimic aspects of human populations [75]. Furthermore, they are genetically stable and therefore reproducible, thereby enabling extensive replication studies $[75,76]$. As a result, phenotypic data can be obtained over time from various experiments and investigators, and then integrated together [77]. Moreover, one of the initial motivations of using GRP is that researchers do not have to undergo the difficult and costly task of genotyping individuals for each experiment.

Recombinant inbred (RI) mouse strain lines (RILs) are a type of GRP that provide genetic variation for molecular genetic studies and can serve as powerful tools for genetic mapping. Donald Bailey and Ben Taylor first developed and characterized a collection at the Jackson Laboratory in the 1970s [78]. RILs can serve as powerful tools for genetic mapping and are commonly used in linkage studies [79] to map the locations of DNA sequence differences (i.e. quantitative trait loci-discussed later) that contribute to alterations in phenotype in these model organisms. These RILs allow tight experimental control [75] where variance associated with environmental factors and technical errors can be suppressed to low levels; and each recombinant genome is represented by an entire isogenic line [76]. Conventional RILs are created by crossing two inbred parental strains. This crossing initiates the formation of the heterozygous F1 progeny [80], which will be identical to its siblings. The F1 progeny are crossed to produce the F2 generations, which is followed by repeated selfing or sibling mating for 20 or more generations. This breeding scheme makes certain these strains are at least $99 \%$ inbred $[81,82]$. This also ensures fixation of the recombined chromosomes in that, animals from each individual RI strain are genetically identical and homozygous at every locus in their 
genome [80, 83-85]. In other words, this process creates new RILs that: (1) possess two matching copies of every chromosome, (2) are genetically different from one another and (3) have a genome that is a pure mixture of the parental strains [79]. Additionally, RI strains acquire large amounts of recombination as they are created, which is particularly useful for mapping complex traits $[79,84,86]$. Furthermore, phenotypic data from these RILs can be collected by many different research groups, at different ages, and under various environmental conditions [87] and stored in databases for comparison [77, 88].

\section{The BXD Mouse Family}

BXDs (C57BL/6J X DBA/2J) are the largest RI strain panel currently available and represent a commonly used GRP. These strains were derived by crossing B6 and D2 and inbreeding progeny for 20 or more generations [89] resulting in a unique combination of parental alleles between the different progeny strains (Figure 1-1). The BXD RI mapping panel was first generated by Ben Taylor at the Jackson Laboratory [77], producing the first 30 lines and subsequently lines 33-42 [90]. Lines 43-100+, also called the Advanced Intercrossed Lines (AILs), were produced by Williams, Lu and colleagues at The University of Tennessee Health Science Center [84]. Breeding of the AILs is initiated in the same manner as the RI strain sets however, mice of the F2 generation and each subsequent generation are intercrossed for 9-14 generations before initiating inbreeding. As a result, the highly recombinant AIL population incorporates approximately 1.7 times more recombination events [91] as standard RI strains, and a 4$8 \mathrm{X}$ higher level of recombination relative to the $\mathrm{F} 2$ intercross progeny. This level of recombination significantly adds to the power of the BXD RI lines as a whole in achieving a higher mapping precision $[79,92]$.

The BXD strain set is fully genotyped and each line is genetically distinct with a defined and fixed genetic architecture [73]. There are currently over 100 BXD strains for which genotype data is publically available. They have the potential to display a broad range of susceptibilities to a $B p$ infection [89] and also provide high precision mapping [93]. The idea of the use of BXD mouse strains is advantageous because BXD mice incorporate a well-defined level of genetic and phenotypic variation. Furthermore, since each strain has a fixed genome, it is possible to resample a given phenotype multiple times. The BXD panel consists of almost 3,800 informative markers including, single nucleotide polymorphisms (SNPs), polymorphic insertions and deletions (indels) and microsatellites disturbed throughout the genome [91, 94]. This makes the discovery of genetic loci that contribute to quantitative traits relatively fast and straightforward. As stated earlier, data generated using the BXD family of strains is both "cumulative and comparable"[87], where phenotypes can be quantified using the same set of genotypes, representing yet another advantage of this RIL [95]. 


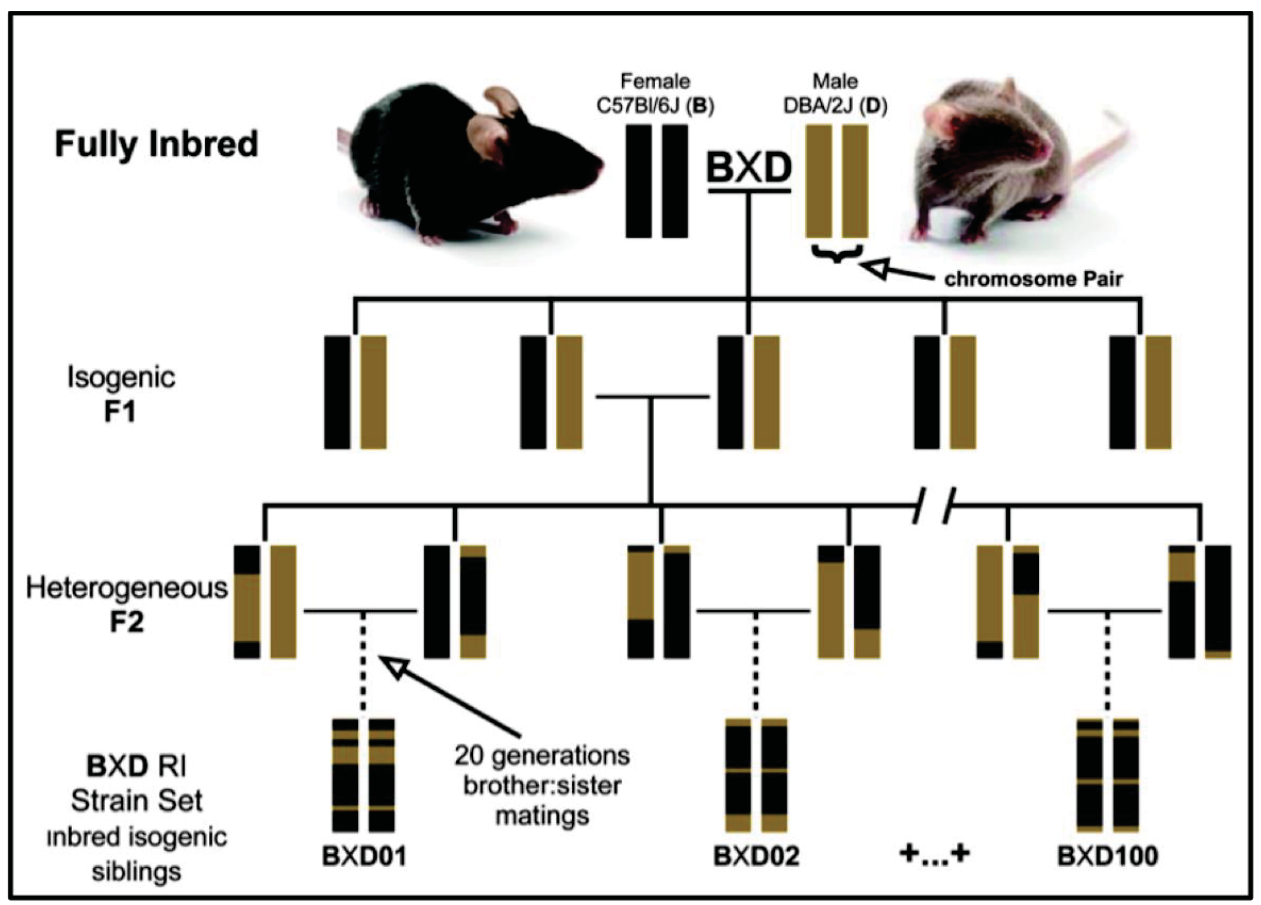

Figure 1-1. Breeding scheme used to generate the panel of BXD recombinant inbred strains.

$\mathrm{BXD}$ recombinant inbred mouse strains that were generated by the inbreeding of $\mathrm{B} 6 \mathrm{x} \mathrm{D} 2$ F1 offspring. 


\section{QTL Mapping}

Allelic variation exists among natural populations and inbred strains, and this is reflective of the segregation of quantitative trait loci (QTLs) [96]. QTLs are stretches of DNA that are closely linked to genes that underlie a phenotype of interest. QTL analysis has been proven to be an invaluable tool to help unravel heritable traits, by enabling researchers to map different quantitative traits back to the genomic location involved in the regulation of these phenotypes.

QTLs are identified by their linkage to polymorphic marker loci (SNPs, indels, microsatellites) [94] that are distributed throughout the genome of the reference population. A large number of these polymorphic loci are required to obtain adequate power for informative QTL mapping. QTLs can be identified through their genetic linkage to visible marker loci with genotypes that can be readily classified [94, 97]. As such, markers that are genetically linked quantitative trait will segregate more often with trait values, whereas unlinked markers will lack an association with the phenotype [94, 98]. The principal goal of a QTL analysis is to identify all QTLs linked to a trait and discern whether phenotypic differences are mainly due to a few loci with large effects, or many loci with small effects [98]. However, QTL mapping usually results in identifying genes that have major effects on the trait [99] but in this instance, sample size is a critical factor [98]. Furthermore, an additional advantage to identifying QTLs are the insights gained into the development and physiology of complex traits on a molecular level [96]. QTL mapping has been used to successfully identify genomic regions underlying a variety of human diseases such as chlamydial infections [100], Influenza [73] and alcoholism [101].

QTL mapping requires a few essential steps: initially, the trait must be measured in the parental (or progenitor) inbred strains that were used to create the GRP that will be used for the study before culminating studies in the RILs (i.e. BXD mice). Since the individuals in GRP have polymorphic genes (i.e. genes that exist in multiple forms), there is a high potential for distinctive strains to exhibit differences in phenotype. Once a differential phenotype is established in the parents and the RILs, the next step is to determine the heritability of the variation in the trait being measured. Heritability describes the genetic influence of the observed variation in the trait, as opposed to variation caused by environmental factors or technical errors. The third step is to prepare the phenotype and genotype data from the individuals for QTL mapping. Once this step is completed, interval mapping can be carried out which will identify any regions of the genome that may contribute to the phenotypic trait that is being measured.

Simultaneously, statistical tests (i.e. permutation tests and bootstrapping) are performed to establish confidence intervals. Once a QTL has been identified, subsequent testing can be used to further resolve the precise location and mechanism of the gene effect [102].

For this study, we used GeneNetwork (GN) to perform our QTL mapping analyses. GN is an extensive online tool that contains a powerful array of complementary computer-based modeling algorithms and databases and uses interval mapping to approximate the location of QTLs throughout the genome [103, 104]. These 
bioinformatics tools allow for the reconstruction of genetic networks that confer resistance and/or susceptibility to many infectious diseases [105]. GN combines a large number of transcriptome and sequence data sets that are acquired from many species including humans, mice and some plants [106]. This allows for rapid integration and analysis of experimentally obtained phenotypes with genetic and gene expression data through QTL mapping. Specifically, once trait data is uploaded into GN, interval mapping can be completed to establish if there is a significant or suggestive linkage between the phenotypic trait of interest and the genotype. Permutation tests are used to calculate the significant $(\mathrm{p}=0.05)$ and suggestive values and are depicted as a likelihood ratio statistic (LRS). The LRS signifies that a particular region of a chromosome contains a gene(s) that is influencing the variation in the phenotypic trait. The higher the LRS, the more likely it is that a gene in that portion of the chromosome is associated with the trait being measured.

\section{ORGANIZATION OF THE DISSERTATION}

The work presented in this dissertation demonstrates the use of a murine model of $B p$ infection and a forward genetics approach to gain a better understanding of the interactions between $B p$ and its hosts. We have identified several host loci that may contribute to resistance and/or susceptibility to a $B p$ infection.

In chapter 3, we exploit a powerful mouse genetics resource that consists of a large family of BXD type recombinant inbred strains, to perform genome-wide linkage analysis of the weight loss phenotype following pneumonic infection with $\mathrm{Bp}$. We initiated this project by infecting parental mice and $32 \mathrm{BXD}$ strains with 50-100 CFU of $B p$ (strain 1026b) and monitored weight retention each day over an eleven-day time course. Using the computational tools in GeneNetwork, we performed linkage analysis to identify intervals on chromosomes $4,2,17$, and 12 that appear to control the weight retention trait. We then analyzed and ranked positional candidate genes in these intervals, several of which have intriguing connections with innate immunity, calcium homeostasis, lipid transport, host cell growth and development, and autophagy.

Based on the insights we gained in chapter 3, we extended our investigation beyond weight retention to examine survival and time-to-death following pneumonic $B p$ infection. The results in chapter 4 show that D2 mice are significantly more susceptible to pneumonic $B p$ infection than B6 mice. We then utilized the BXD RI strain panel to perform genome-wide linkage analysis using survival and time-to-death (following pneumonic infection with 50-100 CFU of $B p 1026 \mathrm{~b}$ ) as phenotypic readouts. The BXD mice displayed a wide range of susceptibilities to pneumonic $B p$ infection and these studies revealed that survival is a complex trait that is dependent on host loci located on chromosomes 5 and 7.

This dissertation also explores the challenges of working with infectious agents (such as $B p$ ) in BSL-3 level containment laboratories. In chapter 5, we characterize the

effectiveness of paraformaldehyde fixation for inactivation of cell samples infected with 
$B p$ and Francisella tularensis $(F t)$. Both of these intracellular pathogens are Tier 1 select agents and require BSL-3 containment. In this study, we tested varying concentrations $(0.5 \%, 1.0 \%, 2.1 \%, 4.2 \%)$ of paraformaldehyde to validate the inactivation kinetics required to completely inactivate these bacteria to allow for removal of samples from a BSL-3 laboratory for flow cytometric analysis using BSL-2 containment practices. We found that these cells are completely inactivated via a 5-minute treatment with $4 \%$ paraformaldehyde and that $B p$ is significantly more sensitive to paraformaldehyde treatment than Ft [107]. 


\section{CHAPTER 2. MATERIALS AND METHODS}

\section{BACTERIAL STRAINS AND GROWTH CONDITIONS}

Burkholderia pseudomallei strain 1026b (Bp) was obtained from BEI Resources Biodefense \& Emerging Infections Research Resources Repository (Manassa, VA). Bp was cultured in LB broth (tryptone [ $10 \mathrm{~g} /$ liter], yeast extract [ $5 \mathrm{~g} /$ liter], and $\mathrm{NaCl}$ $[10 \mathrm{~g} /$ liter $]$ ). Challenge stocks were prepared by performing an overnight culture that was then sub-cultured the following day until mid-log growth phase was achieved $(\mathrm{ABS}=1.0$ at $600 \mathrm{~nm}$ ). Bacteria were then pelleted by centrifugation, resuspended in fresh LB medium containing 20\% glycerol, and frozen in aliquots. These challenge stock aliquots were stored at $-80^{\circ} \mathrm{C}$ until needed. All work with $B p$ was performed under biosafety level-3 (BSL-3) containment according to policies and standard operating procedures approved via the University of Tennessee Health Science Center (UTHSC) Committee On Biocontainment and Restricted Entities (COBRE), a subcommittee of the UTHSC Institutional Biosafety Committee (IBC). The UTHSC has been approved for select agent work by the CDC.

\section{MICE}

$\mathrm{C} 57 \mathrm{BL} / 6 \mathrm{~J}, \mathrm{DBA} / 2 \mathrm{~J}$, and all BXD strains of mice used in these studies were obtained from our in-house breeding colony in the Regional Biocontainment Laboratory (RBL) at UTHSC and were used between the ages of 8-16 weeks. Mice were housed in an AALAC accredited and CDC-select agent program approved facility within an Allentown Biocontainment Unit BCU2000 caging system with gamma-irradiated food and autoclaved water available ad libitum. All experimental protocols involving animals were reviewed and approved by the UTHSC IACUC.

\section{INTRANASAL INSTILLATION OF MICE WITH BP}

Prior to each challenge procedure, an aliquot of frozen challenge stock was thawed and diluted as needed with PBS to reach the required dose of $B p(50-100$ $\mathrm{CFU} /$ dose). Prior to instillation, mice were anesthetized using isoflurane delivered using a SurgiVet ${ }^{\circledR}$ Vaporstick small animal anesthesia machine equipped with a Classic T3 ${ }^{\mathrm{TM}}$ isoflurane vaporizer (Smith Medical, Dublin, $\mathrm{OH}$ ). Mice were exposed to 2.5\% isoflurane delivered in $\mathrm{O}_{2}(2 \mathrm{~L} / \mathrm{min})$ within a 1-liter induction chamber until a state of areflexia was reached. Intranasal administration of each challenge dose $(50 \mu 1$ total volume) was administered immediately after the mouse was removed from the induction chamber by pipetting the inoculum onto the outer edge of the nares. No supplemental anesthesia or oxygen was administered following removal of mice from the induction chamber. Mice were held in a tilted supine position with their heads elevated to between 60 and 75 degrees above their feet during and after instillation (for approximately 1 minute). 


\section{BP BURDEN ENUMERATION}

Determination of $B p$ burdens in the lungs and livers collected from infected mice was performed via dilution plating as previously described [108-110]. Briefly, lungs of $B p$-infected mice were removed aseptically and homogenized (using a closed tissue grinder system, Fisher Scientific, Pittsburgh, PA) in one $\mathrm{ml}$ of sterile PBS, and the final volume was adjusted to $1.25 \mathrm{ml}$ with PBS. To disrupt cells (releasing $B p$ ), $0.25 \mathrm{ml}$ disruption buffer $(2.5 \%$ saponin, $15 \%$ BSA, in PBS) was added with light vortexing. Appropriate dilutions of each sample were then plated in duplicate using an Eddy Jet spiral plater (Neutec Group Inc., Farmingdale, NY) on LB agar plates and incubated at $37^{\circ} \mathrm{C}$ for $48-72$ hours. Colonies were counted using a Flash \& Go automated colony counter (Neutec Group Inc.).

\section{MONITORING OF MICE POST CHALLENGE}

Mice were observed daily for signs of morbidity for a period of 10-11 days post infection. Each mouse was weighed daily as an additional measure of disease progression. Moribund mice were euthanized to prevent unnecessary pain and/or discomfort. Scoring for linkage analyses was as follows: mice that succumbed to acute melioidosis where given a score of " 0 " while those that survived were given a score of "1".

\section{RNA ISOLATION AND FUNCTIONAL GENOMICS}

RNA expression was analyzed in lungs, 24 hours post-infection from resistant (BXD50, BXD70) and susceptible (BXD63, BXD09, BXD27) BXD mice infected with 50-100 CFU of $B p$ 1026b. A minimum of three RNA samples per strain was obtained. For RNA isolation, lungs were immediately suspended in $1 \mathrm{~mL}$ of RNAlater (Qiagen, Valencia CA) and placed in $4^{\circ} \mathrm{C}$. Following homogenization (using a closed tissue grinder system, Fisher Scientific, Pittsburgh, PA) total RNA was prepared from the lungs and submitted to a cleanup protocol using the RNeasy Midi Kit (Qiagen, Valencia CA) following the manufacturer's protocol. Contaminating DNA was removed using a RNAase-Free DNAase Set according to the manufacturer's protocol (Qiagen, Valencia CA).

RNA quality was confirmed by UV spectrophotometry and RNA quantity was confirmed by analysis on an Agilent 2100 bioanalyzer (Agilent Technologies, Santa Clara, CA). Total RNA was processed in the Molecular Resource Center at UTHSC. RNA-seq reads were trimmed to remove low quality 3' ends using Trimmomatic (version 0.32) with the following parameters: TRAILING:15 SLIDINGWINDOW:5:15 MINLEN:35. Reads were aligned to the C57BL/6J reference mouse genome (mm10) using TopHat2 (a splice aware aligner, version 2.0.12) with the following parameters: -library-type fr-firststrand --max-intron-length 300000 --b2-sensitive. HTSeq-count (version 0.6.1) was used with the following parameters: --stranded=reverse $-r$ 'pos' to 
count the number of reads that overlap each transcript in the mouse Ensemble gene model (GRCm38, version 76). The resulting count files were used as input to DESeq2 (version 1.3.69). DESeq2 uses a negative binomial distribution for statistical inference about differential expression of genes. We selected genes that showed differential expression between $x$ and $y$ at FDR of 0.05 .

\section{GENOME-WIDE LINKAGE ANALYSIS}

QTL/interval mapping of BXD weight retention and survival phenotypic data was performed using GeneNetwork (www.genenetwork.org). Interval mapping tests for the presence of QTLs across the entire genome and summarizes the strength of linkage as a likelihood ratio statistic (LRS) [84, 103]. We used a permutation test to establish empirical significance criteria at a genome-wide $p$ value of .05 [100]. The original data sets can be obtained at www.genenetwork.org with the following identification numbers: survival: 16330, time of death: 16331, percentage weight loss Day 1: 16332, Day 2: 16333, Day 3: 16334, Day 4: 16335, and Principle component 1: 16350.

\section{HERITABILITY CALCULATION}

To assess heritability, we computed a single factor ANOVA with the mouse strain as the independent measure and percentage weight loss as the dependent measure. In short, the variance between strains and variance within strains were calculated. The Fstatistic was calculated as the ratio of the variance between strains to the variance within strains. The total variance was calculated as the sum of variance between strains and variance within strains. Heritability was calculated as ratio of variance between strains to the total variance.

\section{STATISTICAL METHODOLOGY}

Statistical analyses for some figures in chapter 3 were performed using GraphPad Prism software (GraphPad Software, La Jolla, CA) as indicated in the figure legend. All other statistical analyses were performed using the algorithms built into GeneNetwork or as described in the text. 


\section{CHAPTER 3. GENETIC CONTROL OF WEIGHT LOSS DURING PNEUMONIC BURKHOLDERIA PSEUDOMALLEI INFECTION*}

\section{INTRODUCTION}

Burkholderia pseudomallei $(B p)$ is a saprophytic, gram-negative aerobe and the causative agent of the disease melioidosis [7]. Melioidosis is an infectious disease that occurs in humans and animals and is prevalent in S.E. Asia, N. Australia and other tropical areas [111]. Transmission occurs through direct contact with the organism via ingestion, inhalation, or through open wounds and skin abrasions [7]. Clinical presentation is extremely variable and can range from acute septicemia with bacterial dissemination to distant sites, to an isolated pulmonary infection $[7,8]$. Treatment of melioidosis can be problematic because it is often difficult to diagnose and $B p$ is resistant to a diverse group of antibiotics [34]. Even with treatment, the mortality rate of melioidosis is 20 to $50 \%$ [21, 112]. Although this pathogen is not endemic in the United States, it is a significant U.S. health issue because of its high potential for use as a biological weapon $[56,113]$. In fact, $B p$ has been classified as a Tier 1 Select Agent by APHIS and DHHS and as a Biodefense category B pathogen by NIAID. Furthermore, other factors including aerosol infectivity, the severity of infection, and the global distribution of this pathogen makes it a potential bioterrorism agent that poses a threat to national security, if intentionally released into populated areas [114].

The basis of the variable progression of melioidosis in $B p$-infected individuals has not been determined, to date. There is evidence that differential susceptibility to $B p$ has an immunogenetic basis. For instance, one study revealed that polymorphisms in cytokine-related genes may be a factor in susceptibility to infection with $B p$ [68]. Another report revealed a correlation between human leukocyte antigen (HLA) polymorphisms and the type and/or intensity of the immune response that develops in response to a $B p$ infection [49]. These findings are not surprising in light of findings that genetic factors play a key role in susceptibility to a wide range of other infectious diseases. Published findings have identified host genetic factors that are critical for variable susceptibility to intracellular parasites [115], viruses [116-120], and both intracellular [74, 100, 121] and extracellular [122] bacterial pathogens. Moreover, recent genome-wide studies have established novel associations between common polymorphisms and susceptibility to several infectious diseases that are responsible for significant morbidity and/or mortality in humans [73, 100, 123, 124].

The murine model of $B$. pseudomallei infection is considered to be an excellent model for both the chronic and acute forms of human melioidosis $[56,60,125]$. Studies

\footnotetext{
*Reprinted with permission. Emery, F.D., et al., Genetic control of weight loss during pneumonic Burkholderia pseudomallei infection. Pathogens and disease, 2014. 71(2): p. 249-64.
} 
in inbred strains of mice have established the importance of the host genetic background on the progression of $B p$ infection. $\mathrm{C} 57 \mathrm{BL} / 6 \mathrm{~J}$ (B6) mice are known to be relatively resistant to the acute form of melioidosis and tend to develop disease that progresses significantly slower than that observed in the much more susceptible BALB/c $[56,60]$ or DBA/2J (D2) [61] inbred strains. To date, there have been few published studies that have identified host-genetic elements that correlate with the progression of melioidosis. In this report, we have used a panel of recombinant inbred (RI) mouse strains, that were generated by inbreeding of B6 x D2 F1 offspring (BXD), to perform genome-wide linkage analysis for the identification of host genetic loci that correlate with the differential weight loss of B6 and D2 parental strains during acute pneumonic melioidosis.

\section{RESULTS}

Our initial studies with a pneumonic challenge model (intranasal instillation) using 50-200 CFU of $B p 1026 \mathrm{~b}$ confirmed the previously published observation [61] that B6 are more resistant than D2 to $B p$ infection (Figure 3-1). Subsequent studies in a cohort of BXD strains (using a challenge dose of 50-100 CFU) revealed a range of susceptibility to melioidosis. Interestingly, female D2 mice (as well as females of several BXD strains) were significantly more resistant to pneumonic Bp infection than their male counterparts (Figure 3-2). This result indicates that there are sex-based host factor(s) that influence the susceptibility/resistance phenotypes of at least some mouse strains to $B p$ infection. Based on these findings, we performed all of the following studies exclusively in male mice.

We performed a series of experiments in which a cohort of $32 \mathrm{BXD}$ strains as well as the B6 and D2 parental strains were challenged via intranasal instillation with 50$100 \mathrm{CFU}$ of $\mathrm{Bp} 1026 \mathrm{~b}$ and then monitored for disease progression by measuring weight loss over the next 11 days (see Table A-1 in Appendix for BXD strain group sizes). Based on survival, the BXD strains could be logically broken into three categories based on their susceptibility to pneumonic $B p$ infection: 1) susceptible, 2) intermediate susceptibility, and 3) resistant. An evaluation of weight loss in these three groups of BXD genotypes predictably revealed that the resistant strains generally lost less weight than the intermediate susceptibility strains, and especially the susceptible BXD strains following infection (Figure 3-3). However, there were several BXD genotypes that did not follow this pattern. For instance BXD9 was highly susceptible to $B p$ infection and all succumbed to infection by day 4 post-infection. Interestingly, these mice lost less of their body weight than most of the strains in the study, including the BXD genotypes that were resistant to $\mathrm{Bp}$. Likewise, BXD81 lost weight slower than the other susceptible strains despite the fact that they all succumbed to melioidosis by day 4 post-infection. In contrast, BXD38 survived the challenge while losing weight faster than any other strain in the study. Moreover, BXD strains within each of these phenotypically distinct subgroups - susceptible, intermediate susceptibility, and resistant - displayed a wide range of weight change kinetics (Figure 3-4). These findings indicated that weight 

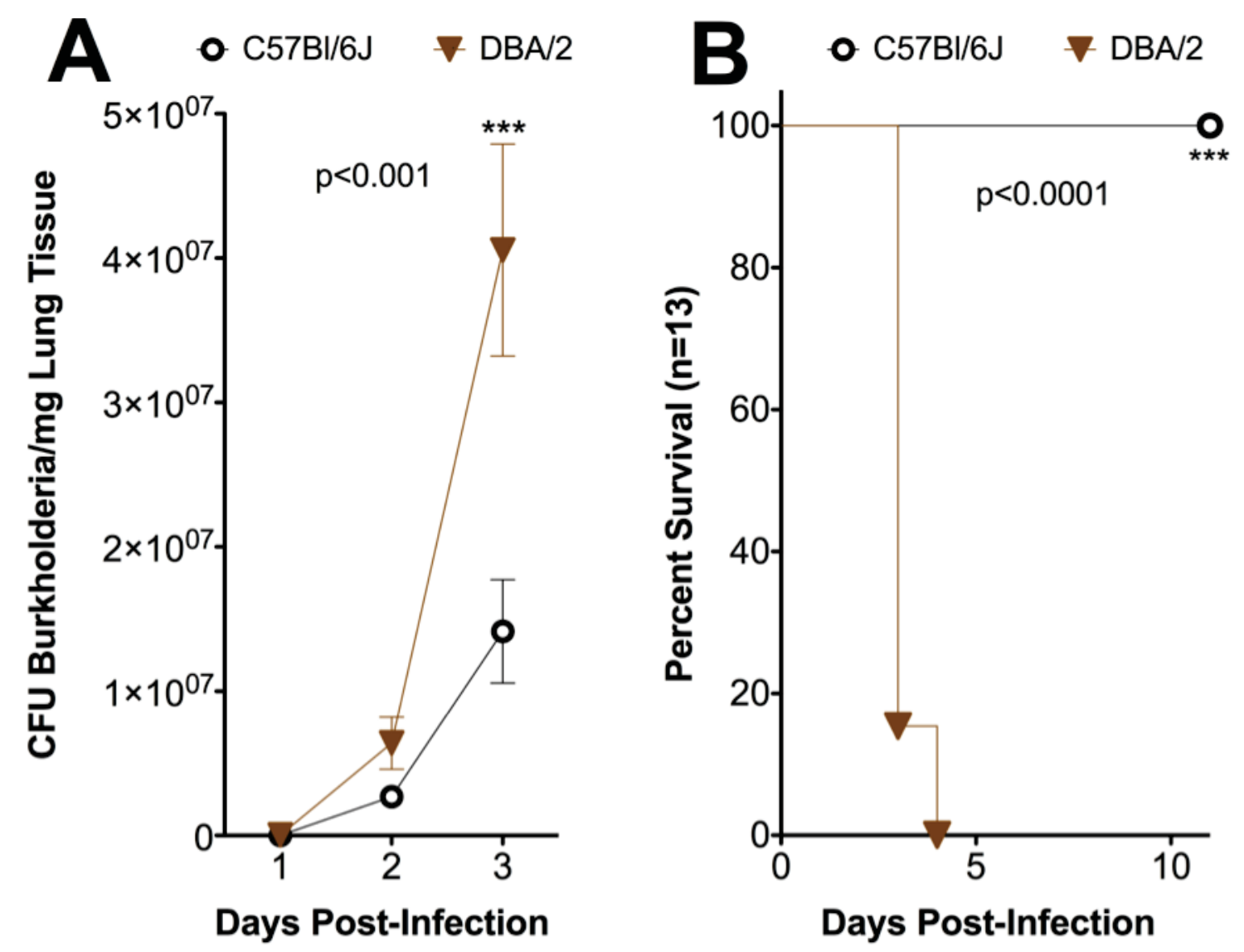

Figure 3-1. DBA/2J mice are significantly more susceptible than C57BL/6J mice to Burkholderia pseudomallei.

Panel A: C57BL/6J and DBA/2J mice (15/strain) were challenged with 50 CFU Bp $1026 \mathrm{~b}$ via intranasal instillation. Mice were sacrificed (5/strain) each day and lungs were collected via sterile dissection. The bacterial burdens in the lungs of each mouse were determined via dilution plating and are reported as CFU/mg of lung tissue. Statistical analysis was performed using a two-way ANOVA with Bonferroni posttests. Panel B: C57BL/6J and DBA/2J mice (13/strain) were challenged with 50-100 CFU Bp 1026b via intranasal instillation and were monitored for survival over the next 11 days. Statistical analyses were performed using Log-Rank (Mantel-Cox) and Gehan-Breslow-Wilcoxon tests. 


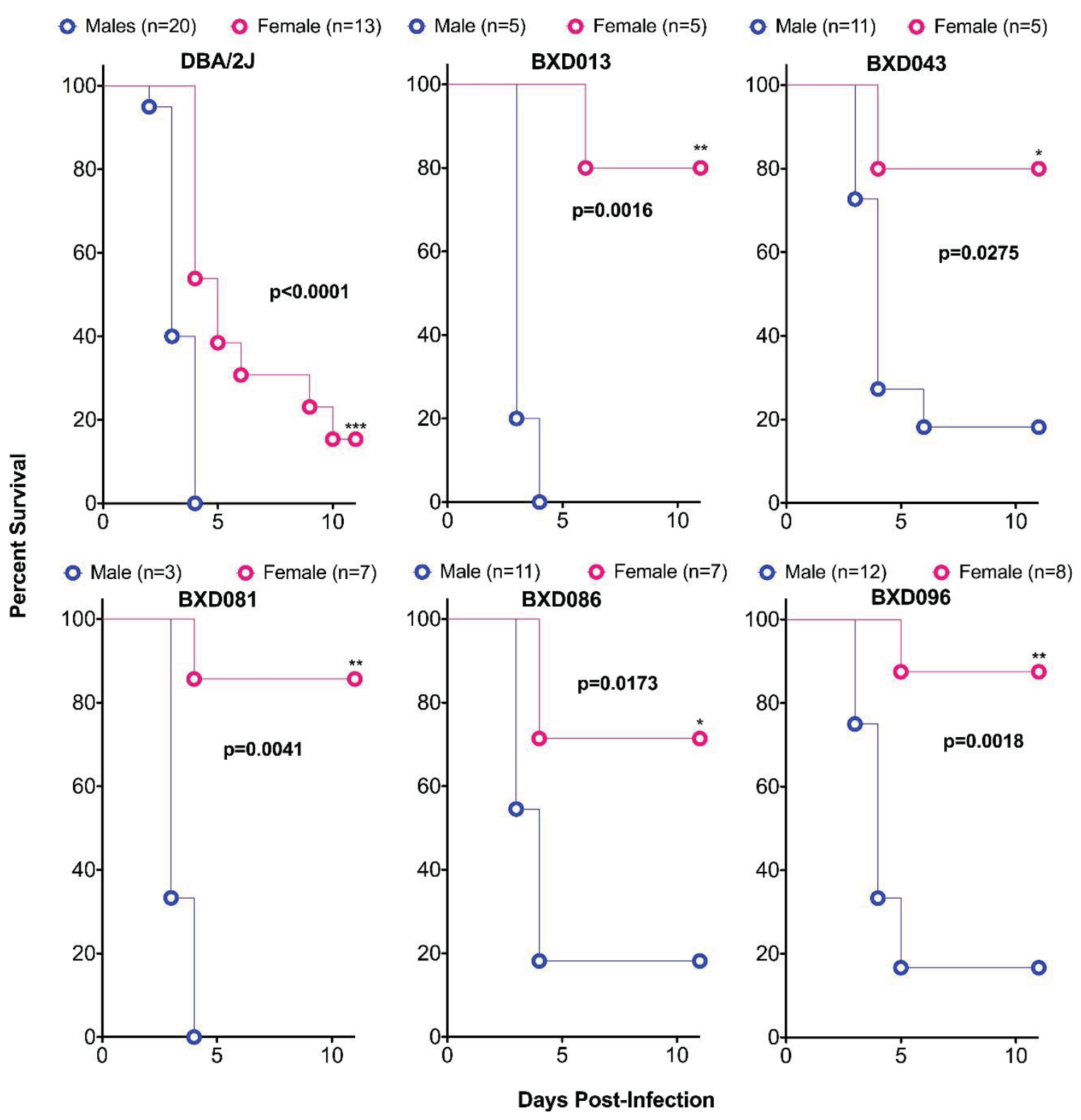

Figure 3-2. Differential susceptibility of male versus female DBA/2J and BXD mice to pneumonic $B$. pseudomallei infection.

The indicated strains of mice were challenged with 50-100 CFU of $B p$ via intranasal instillation and were monitored for survival over an 11-day period. Survival data is displayed in a Kaplan-Meier plot and statistical analyses were performed using Log-Rank (Mantel-Cox) tests. 


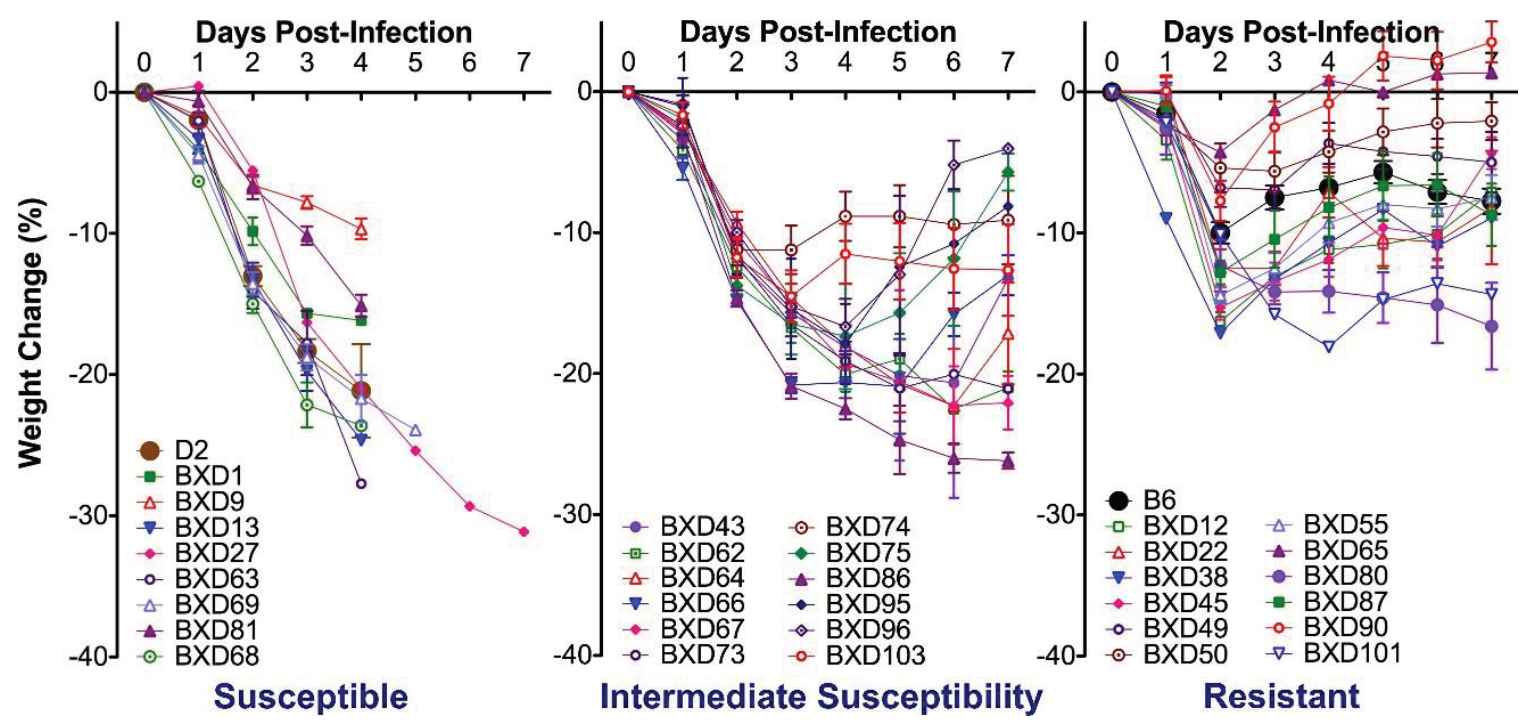

Figure 3-3. Weight loss of BXD genotypes following pneumonic $B p$ infection.

The cohort of BXD mice were weighed daily following intranasal instillation with 50-100 CFU of $B p 1026 \mathrm{~b}$ as a measure of morbidity. For comparative purposes, the data are presented in three panels depending on the susceptibility of each strain to $B p$ infection. The genotypes that all experienced 100\% mortality are shown in the panel labeled "Susceptible". Those that experienced 100\% survival are shown in the panel labeled "Resistant". The genotypes that had at least one survivor or at least one mortality are shown in the panel labelled "Intermediate Susceptibility". The data are plotted as the mean weight loss ( \pm SEM). 

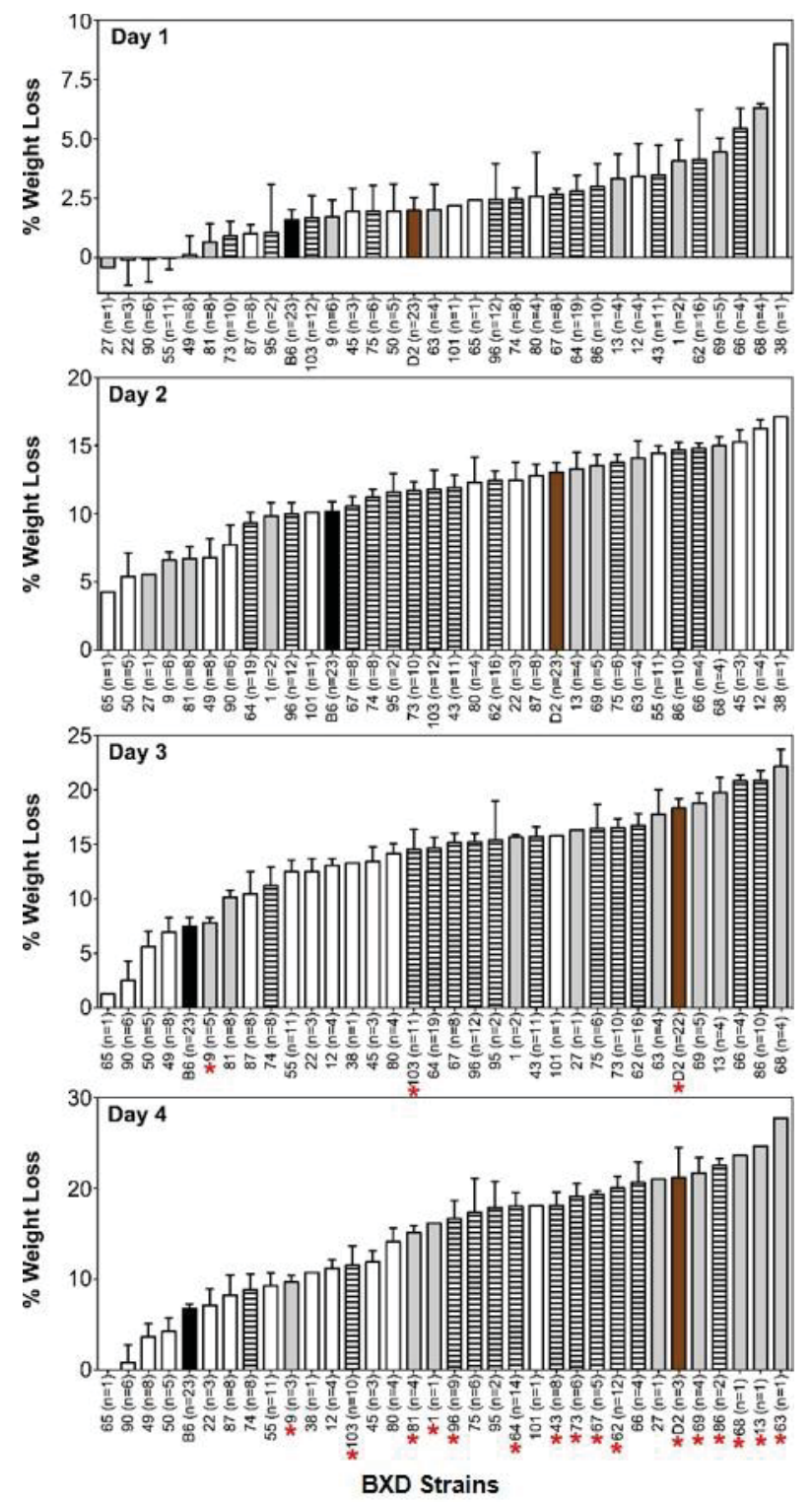

Figure 3-4. Bar graph (by rank) of percentage weight loss on days 1 through 4 post- $B p$ infection.

The BXD and parental mouse cohort were weighed daily after intranasal challenge with 50-100 CFU of $B p 1026 \mathrm{~b}$ as a measure of morbidity and the percentage of weight loss (mean \pm SEM) is shown for each mouse genotype on the indicated day post-infection. The "susceptible" strains (100\% mortality) are indicated with a grey bar, "resistant" strains (100\% survival) are indicated with a white bar, and "intermediate" strains (at least one mouse died) are indicated with crosshatched bars. The parental B6 and D2 mice are indicated with black and brown bars, respectively. Red asterisks indicate that at least one mouse from that genotype succumbed to infection. 
change kinetics generally tracks with disease progression, but is not a completely reliable indicator of susceptibility to pneumonic $B p$ infection.

\section{Heritability and Variance of Weight Loss Traits}

We estimated heritability as the main effect on body weight relative to the starting weight by ANOVA. Heritability increased from day 1 through to day 3-4 from $\sim 70$ to 93\% (Figure 3-5a). Correlations among the four sequential and non-independent weight loss estimates are high, and the first principal component accounts of $\sim 75 \%$ of the total variance (Figure 3-5B and Figure 3-5C), and GeneNetwork Trait 16350 for the eigentrait associated with the principal component.

\section{Identification of Host Loci that Are Covariant with Weight Loss during Pneumonic $B p$ Infection}

We performed genome-wide linkage analysis using weight loss relative to baseline. Mapping results are volatile for days 1 and 2 (Figure 3-6), with suggestive loci on Chr 4 (LRS of $\sim 15$ from 7 to $11 \mathrm{Mb}$ with $B$ alleles contributing to increased weight loss; Figure 3-7A), on distal Chr 2 (LRS of $\sim 12$ from 178 to $182 \mathrm{Mb}$, high $B$ allele; Figure 3-7B), and on proximal Chr 17 (LRS of $\sim 14$ from 6 to $13 \mathrm{Mb}$, high $D$ allele; Figure 3-7C). Two of these suggestive loci have an effect that does not conform to expectation based on parental strain weight loss (D2 high, B6 low). In contrast, we detect a single significant and consistent QTL on Chr 12 for weight loss on days 3 and 4 (and remaining stable over the remaining timecourse: see Figure A-1) that does conform to expectation based on the parental strain difference (Traits 16334 and 16335). This Chr 12 locus peaks between 80 and $87 \mathrm{Mb}$ near the Ttc 9 gene. The LRS peak of 16-18 is near the genome-wide significance threshold. Although it does not affect the position of this peak, the LRS is boosted to 21 by including parental phenotypes (Figure 3-7D). As shown in Figure 3-5, a principal component analysis for weight loss at all days, also supports a single locus on Chr 12 with increased sensitivity being associated with the $D$ allele (Trait 16350).

\section{Identification of Candidate Host Genes that May Contribute to Weight Loss Kinetics Following Pneumonic Bp Infection}

We analyzed each of the loci to identify and evaluate potential candidate genes. We considered and weighted several factors including: (1) mRNA expression levels at or above background in the lungs and spleen, (2) genes that are associated with local genetic control (so called cis eQTLs) in the lung; and (3) genes with one or more nonsynonymous SNPs or indels between the parental B6 and D2 genotypes. These factors were combined into a ranking score scale ( 0 to 4 ) using the QTLminer software [126]. The highest scoring candidates are indicated in Figure 3-7 (right hand panels). 


\begin{tabular}{|c|c|c|c|c|c|c|}
\hline \multicolumn{7}{|c|}{ Heritability of Weight Loss Traits } \\
\hline & $\begin{array}{c}\text { Trait 1: } 16332 \\
\text { Day } 1 \mathrm{~W} / \mathrm{L}\end{array}$ & \multicolumn{2}{|c|}{$\begin{array}{l}\text { Trait 2: } 16333 \\
\text { Day 2 W/L }\end{array}$} & $\begin{array}{c}\text { Trait 3: } 16334 \\
\text { Day } 3 \mathrm{~W} / \mathrm{L}\end{array}$ & \multicolumn{2}{|c|}{$\begin{array}{c}\text { Trait 4: } 16335 \\
\text { Day } 4 \text { W/L }\end{array}$} \\
\hline & $68.8 \%$ & $87.4 \%$ & \multicolumn{2}{|c|}{$92.9 \%$} & \multicolumn{2}{|c|}{$92.7 \%$} \\
\hline \multicolumn{7}{|c|}{ Spearman Rank Correlation (rho) } \\
\hline \multirow{6}{*}{ 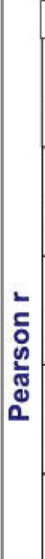 } & Traits & Trait 1 & Trait 2 & Trait 3 & Trait 4 & Trait 5 \\
\hline & $\begin{array}{c}\text { Trait } 1 \text { (16322) } \\
\text { Day } 1 \text { Weight Loss }\end{array}$ & $n=34$ & $\begin{array}{c}0.422 \\
n=34\end{array}$ & $\begin{array}{l}0.503 \\
n=34\end{array}$ & $\begin{array}{c}0.458 \\
n=34\end{array}$ & $\begin{array}{l}0.731 \\
n=34\end{array}$ \\
\hline & $\begin{array}{c}\text { Trait } 2 \text { (16323) } \\
\text { Day } 2 \text { Weight Loss }\end{array}$ & $\begin{array}{l}0.510 \\
n=34\end{array}$ & $n=34$ & $\begin{array}{l}0.511 \\
n=34\end{array}$ & $\begin{array}{c}0.388 \\
n=34\end{array}$ & $\begin{array}{c}0.744 \\
n=34\end{array}$ \\
\hline & $\begin{array}{c}\text { Trait } 3(16324) \\
\text { Day } 3 \text { Weight Loss }\end{array}$ & $\begin{array}{c}0.422 \\
n=34\end{array}$ & $\begin{array}{l}0.647 \\
n=34\end{array}$ & $n=34$ & $\begin{array}{l}0.946 \\
n=34\end{array}$ & $\begin{array}{l}0.886 \\
n=34\end{array}$ \\
\hline & $\begin{array}{c}\text { Trait } 4 \text { (16325) } \\
\text { Day } 4 \text { Weight Loss }\end{array}$ & $\begin{array}{c}0.324 \\
n=34\end{array}$ & $\begin{array}{l}0.437 \\
n=34\end{array}$ & $\begin{array}{l}0.921 \\
n=34\end{array}$ & $n=34$ & $\begin{array}{c}0.822 \\
n=34\end{array}$ \\
\hline & $\begin{array}{c}\text { Trait } 5(16350) \\
\text { PC1 }\end{array}$ & $\begin{array}{l}0.648 \\
n=34\end{array}$ & $\begin{array}{c}0.790 \\
n=34\end{array}$ & $\begin{array}{l}0.944 \\
n=34\end{array}$ & $\begin{array}{l}0.855 \\
n=34\end{array}$ & $n=34$ \\
\hline
\end{tabular}

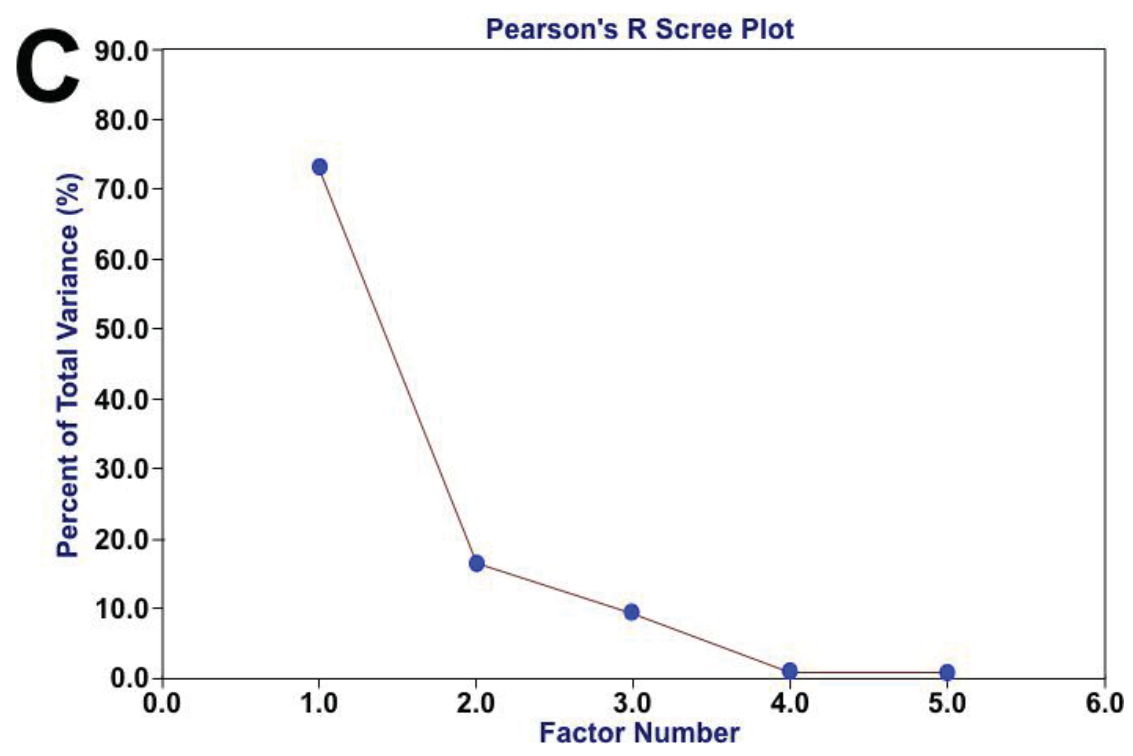

Figure 3-5. Principal component analysis, heritability, and correlations among weight loss traits during the early stages of pneumonic melioidosis.

Panel A: Heritability of weight loss increases from day 1 to day 4. Panel B: A correlation matrix of Pearson (lower left) and Spearman rank (upper right) correlations, along with the first principal component (PC). The numbers listed in orange or red text indicate correlation indices of 0.5-0.7 and 0.7 to 1.0, respectively. Panel C: Pearson's Scree plot shows that the first PC accounts for approximately $75 \%$ of the strain variance in weight loss. 

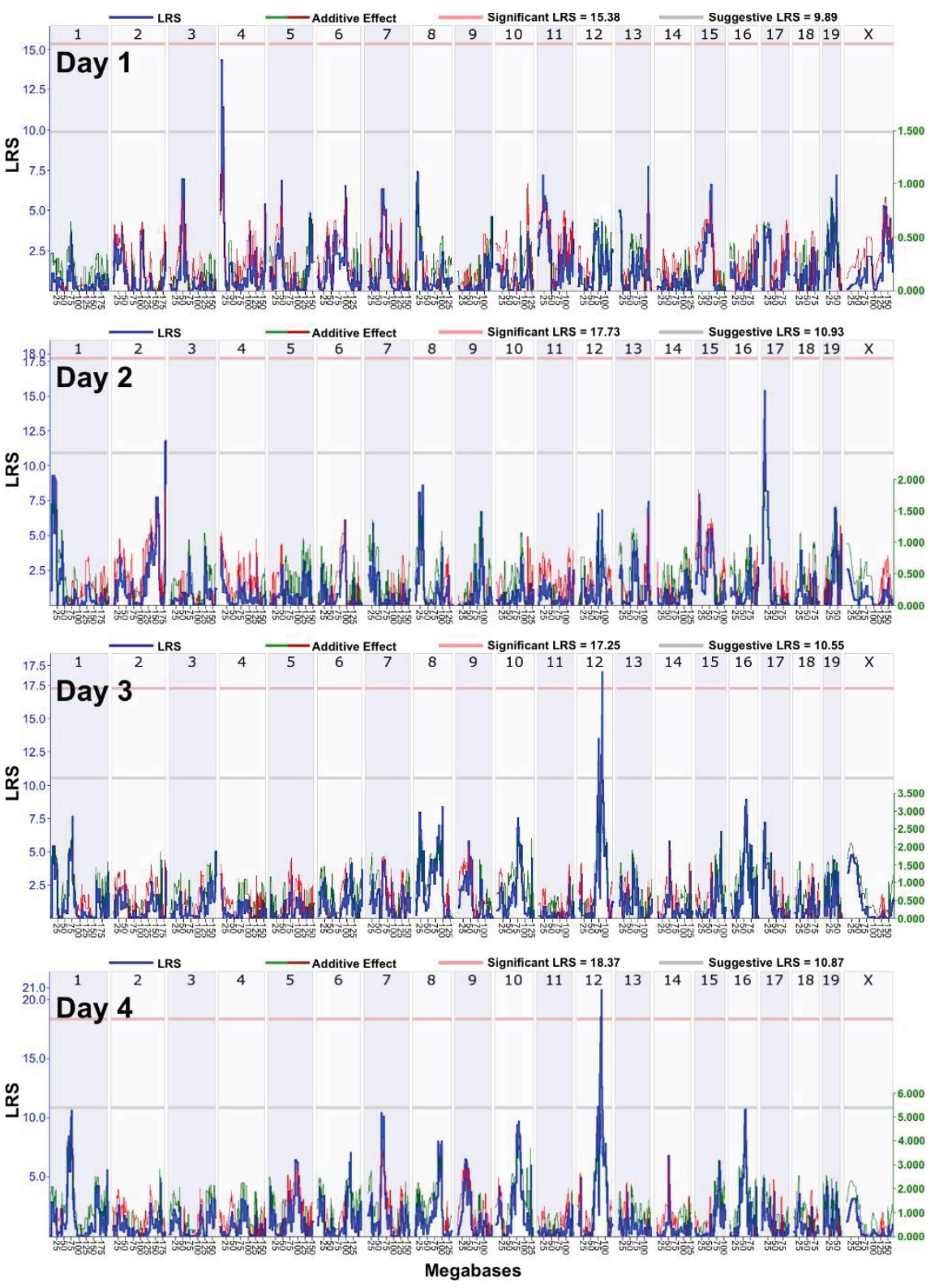

Figure 3-6. Genome-wide linkage analysis for percentage weight loss over the 4 days following pneumonic challenge with Burkholderia pseudomallei.

Genome-wide interval maps of percentage weight loss of all BXD genotypes and parental strains at each time point are shown as indicated. The blue line indicates LRS scores across the entire genome. Thin red and green lines indicate that B6 or D2 alleles increase trait values, respectively. The mouse chromosomes are identified in the upper $\mathrm{x}$-axis, the lower $\mathrm{x}$-axis shows the physical map in mega bases for each chromosome, and the $y$-axis represents the LRS score. Thick red and grey horizontal lines indicate the genome-wide significance threshold $(p<0.05)$ or suggestive threshold $(p<0.63)$, respectively. 

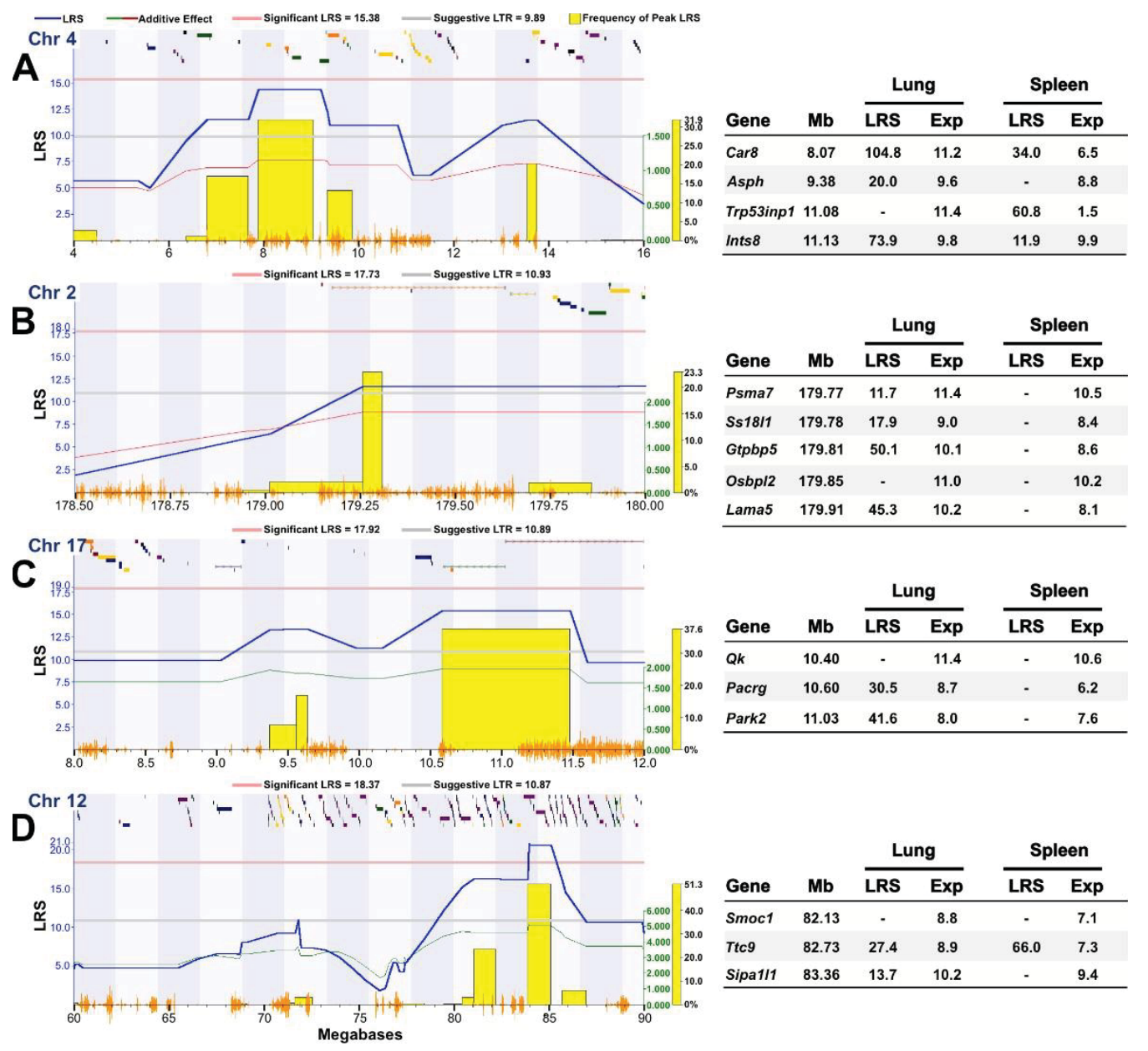

Figure 3-7. Detailed maps of the QTLs contributing to weight loss during the early stages of pneumonic $B p$ infection.

The critical intervals on Chrs 4 (Panel A), 2 (Panel B), 17 (Panel C) and 12 (Panel D) were identified based on bootstrap analysis (frequencies of peak LRS indicated with yellow bars) and peak shapes. The critical intervals for candidate gene analysis for each chromosome were: Chr 4: 7-14 Mb, Chr 2: 179.25-180 Mb, Chr. 17: 9.5-11.5 Mb, Chr. 12: $80-86 \mathrm{Mb}$. The density of SNPs present in the BXD strains is indicated by orange chatter along the $\mathrm{x}$-axis. The multicolored chatter along the top of the graph represent the open reading frames within the interval. The blue line indicates LRS scores across the entire genome. Thin red and green lines indicate that B6 or D2 alleles increase trait values, respectively. The mouse chromosomes are identified in the upper x-axis, the lower $\mathrm{x}$-axis shows the physical map in mega bases for each chromosome, and the y-axis represents the LRS score. Thick red and grey horizontal lines indicate the genome-wide significance threshold $(\mathrm{p}<0.05)$ or suggestive threshold $(\mathrm{p}<0.63)$, respectively. Right hand panels: The highest ranking candidate genes within each interval (according to QTLminer scores) are indicated along with their LRS score and their relative expression levels in normative tissues. 
More comprehensive lists of candidates for each of the QTLs are shown by day and trait identifiers in Tables 3-1, 3-2, and 3-3.

\section{DISCUSSION}

Both humans and distinct inbred mouse strains display a range of disease progression following Burkholderia pseudomallei infection. In this study, we employed a panel of recombinant inbred BXD genotypes to identify regions of the murine genome that are responsible for their variable weight loss during the course of $B p$ infection. We performed genome-wide linkage analysis using percentage weight loss over a four-day time course following pneumonic infection with $B p 1026 \mathrm{~b}$ to identify host genes responsible for differential progression of melioidosis. We found that the weight loss trait is controlled in a time-dependent manner by a significant QTL on Chr 12 and several suggestive loci on chromosomes 2, 4, and 17. The locus on Chr 12 is likely to be the single primary factor responsible for differential weight loss following infection. Interestingly, in a parallel study in which we have used survival as the key outcome phenotype, we identified a highly significant QTL on Chr 5, with no contribution from Chr 12.

Analysis of weight loss phenotypes over the course of infection yielded some interesting findings. First, the cohort of BXD genotypes displayed a wide range of weight loss kinetics that often did not always correlate with survival. For instance, BXD9 lost weight more slowly than other strains, yet all of these animals succumbed to melioidosis on or before day 4. In contrast, several genotypes that lost much more weight (and lost it more rapidly) than BXD9 fell into the resistant category (100\% survival). These findings clearly showed that weight loss is not an ideal indicator for determining the ultimate fate of $\mathrm{Bp}$-infected mice. It seems likely that other infection models would display a similar lack of correlation between weight loss kinetics and eventual mortality, a point that should be shared with IACUC committees that require sacrifice of infected animals once they reach an arbitrary percentage of weight loss.

Another interesting finding is the volatile nature of the set of three suggestive QTLs detected only during the early stages of infection. These loci may be a sampling artifact, but it is also possible that different phases of infection expose different gene loci. The locus on chromosome 4 is only detected "acutely" at 24 hours post-infection. Similarly, the two suggestive loci on day 2 are not even hinted at either on day 1 or day 3 . In contrast, the QTL that we detect on days 3 and 4 is consistent, and is also detected when mapping with the weight loss "eigentrait" that summarizes weight loss across all days. These findings suggest that weight loss following $B p$ infection may be a dynamic phenotype that involves different host genes over the course of infection/disease. Interestingly, a recently reported genome wide study of host response to H1N1 influenza infection also identified multiple QTLs (different from those identified here) that appear to control weight loss kinetics in a time-dependent fashion [73]. 
Table 3-1. QTLMINER scores for candidate genes within the day 1 QTL interval (Chr 4): Trait 16332.

\begin{tabular}{|c|c|c|c|c|c|c|c|}
\hline $\begin{array}{c}\text { Gene } \\
\text { Symbol }\end{array}$ & Mb & $\begin{array}{c}\text { Gene } \\
\text { Designation }\end{array}$ & $\begin{array}{c}\text { Biological } \\
\text { Processes/Functions }\end{array}$ & $\begin{array}{c}\text { nsSNPs } \\
\text { (B6 vs. } \\
\text { D2) }\end{array}$ & $\begin{array}{c}\text { InDels in } \\
\text { BXD } \\
\text { Mice }\end{array}$ & $\begin{array}{c}\text { Cis- } \\
\text { Regulated } \\
\text { in Lung }\end{array}$ & $\begin{array}{l}\text { QTL } \\
\text { Miner } \\
\text { Score } \\
(1-4)\end{array}$ \\
\hline \multicolumn{8}{|c|}{ Chromosome 4} \\
\hline Car8 & 8.07 & $\begin{array}{l}\text { carbonic } \\
\text { anhydrase } 8\end{array}$ & $\begin{array}{l}\text { phosphoinositide- } \\
\text { mediated signaling, one- } \\
\text { carbon metabolic } \\
\text { process }\end{array}$ & 184 & 9 & Yes & 4 \\
\hline Ints 8 & 11.13 & $\begin{array}{l}\text { integrator } \\
\text { complex } \\
\text { subunit } 8\end{array}$ & & 35 & 4 & Yes & 4 \\
\hline Asph & 9.38 & $\begin{array}{l}\text { aspartate-beta- } \\
\text { hydroxylase }\end{array}$ & $\begin{array}{l}\text { oxidation reduction, } \\
\text { face morphogenesis, } \\
\text { palate development, } \\
\text { peptidyl-amino acid } \\
\text { modification, limb } \\
\text { morphogenesis, negative } \\
\text { regulation of cell } \\
\text { proliferation } \\
\text { pattern specification } \\
\text { process, peptidyl- } \\
\text { aspartic acid } \\
\text { hydroxylation }\end{array}$ & 47 & 35 & Yes & 4 \\
\hline $\begin{array}{l}\text { Trp53in } \\
\text { p1 }\end{array}$ & 11.08 & $\begin{array}{l}\text { transformation } \\
\text { related protein } \\
53 \text { inducible } \\
\text { nuclear protein } \\
1\end{array}$ & $\begin{array}{l}\text { apoptosis, cell cycle } \\
\text { arrest, response to } \\
\text { stress, induction of } \\
\text { apoptosis }\end{array}$ & 18 & 1 & No & 3 \\
\hline Plekhf2 & 10.92 & $\begin{array}{l}\text { pleckstrin } \\
\text { homology } \\
\text { domain } \\
\text { containing, } \\
\text { family F (with } \\
\text { FYVE } \\
\text { domain) } \\
\text { member } 2\end{array}$ & $\begin{array}{l}\text { phospholipid binding, } \\
\text { metal ion binding }\end{array}$ & 10 & 1 & No & 3 \\
\hline $\begin{array}{l}2610301 \\
\text { B20Rik }\end{array}$ & 10.80 & $\begin{array}{l}\text { RIKEN cDNA } \\
2610301 B 20 \\
\text { gene }\end{array}$ & unknown & 17 & 3 & Yes & 3 \\
\hline Rbm35a & 11.26 & $\begin{array}{l}\text { RNA binding } \\
\text { motif protein } \\
35 \mathrm{~A}\end{array}$ & $\begin{array}{l}\text { mRNA processing, } \\
\text { RNA splicing, } \\
\text { regulation of RNA } \\
\text { splicing }\end{array}$ & 22 & 2 & No & 3 \\
\hline $\begin{array}{l}5730591 \\
\text { J02Rik }\end{array}$ & 9.70 & $\begin{array}{l}\text { RIKEN cDNA } \\
5730591 \mathrm{~J} 02 \\
\text { gene }\end{array}$ & unknown & 72 & 5 & Yes & 3 \\
\hline Ccne2 & 11.12 & cyclin E2 & $\begin{array}{l}\text { cell cycle, cell division, } \\
\text { regulation of cell cycle, } \\
\text { DNA replication } \\
\text { initiation }\end{array}$ & 4 & 2 & No & 2 \\
\hline Runxlt1 & 13.67 & $\begin{array}{l}\text { runt-related } \\
\text { transcription } \\
\text { factor } 1 ; \\
\text { translocated } \\
\text { to, } 1 \text { (cyclin } \\
\text { D-related) }\end{array}$ & $\begin{array}{l}\text { transcription, regulation } \\
\text { of transcription, DNA- } \\
\text { dependent fat cell } \\
\text { differentiation, } \\
\text { regulation of DNA } \\
\text { binding }\end{array}$ & 8 & 8 & No & 2 \\
\hline
\end{tabular}


Table 3-1. (Continued).

\begin{tabular}{|c|c|c|c|c|c|c|c|}
\hline $\begin{array}{l}\text { Gene } \\
\text { Symbol }\end{array}$ & Mb & $\begin{array}{c}\text { Gene } \\
\text { Designation }\end{array}$ & $\begin{array}{c}\text { Biological } \\
\text { Processes/Functions }\end{array}$ & $\begin{array}{l}\text { nsSNPs } \\
\text { (B6 vs. } \\
\text { D2) }\end{array}$ & $\begin{array}{l}\text { InDels in } \\
\text { BXD } \\
\text { Mice }\end{array}$ & $\begin{array}{c}\text { Cis- } \\
\text { Regulated } \\
\text { in Lung }\end{array}$ & $\begin{array}{l}\text { QTL } \\
\text { Miner } \\
\text { Score } \\
(1-4) \\
\end{array}$ \\
\hline Chd7 & 8.62 & $\begin{array}{l}\text { chromodomai } \\
\mathrm{n} \text { helicase } \\
\text { DNA binding } \\
\text { protein } 7\end{array}$ & $\begin{array}{l}\text { transcription, chromatin } \\
\text { modification, regulation } \\
\text { of transcription, } \\
\text { chromatin assembly or } \\
\text { disassembly, adult } \\
\text { walking behavior, heart } \\
\text { morphogenesis, female } \\
\text { genitalia development, } \\
\text { camera-type eye } \\
\text { development } \\
\text { blood vessel } \\
\text { development, blood } \\
\text { circulation, adult heart } \\
\text { development,nose } \\
\text { development, embryonic } \\
\text { hindlimb } \\
\text { morphogenesis, palate } \\
\text { development, positive } \\
\text { regulation of } \\
\text { multicellular organism } \\
\text { growth, in utero } \\
\text { embryonic development, } \\
\text { sensory perception of } \\
\text { sound } \\
\text { ear morphogenesis, } \\
\text { inner ear morphogenesis } \\
\text { locomotory behavior }\end{array}$ & 6 & 0 & No & 2 \\
\hline Tox & 6.61 & $\begin{array}{l}\text { thymocyte } \\
\text { selection- } \\
\text { associated } \\
\text { HMG box } \\
\text { gene }\end{array}$ & $\begin{array}{l}\text { DNA binding, T-cell } \\
\text { devolopment }\end{array}$ & 0 & 5 & Yes & 2 \\
\hline $\begin{array}{l}\text { E13001 } \\
\text { 6E03Rik }\end{array}$ & 11.49 & $\begin{array}{l}\text { RIKEN cDNA } \\
\text { E130016E03 } \\
\text { gene }\end{array}$ & $\begin{array}{l}\text { DNA repair, } \\
\text { transcription, regulation } \\
\text { of transcription, double- } \\
\text { strand break repair via } \\
\text { homologous } \\
\text { recombination, response } \\
\text { to DNA damage } \\
\text { stimulus, response to } \\
\text { drug, response to } \\
\text { ionizing radiation }\end{array}$ & 28 & 3 & No & 2 \\
\hline Dpy19l4 & 11.19 & $\begin{array}{l}\text { dpy-19-like } 4 \\
\text { (C. elegans) }\end{array}$ & $\begin{array}{l}\text { C-mannosylation of } \\
\text { tryptophan residues }\end{array}$ & 18 & 3 & unknown & 2 \\
\hline $\begin{array}{l}1700123 \\
\text { O12Rik }\end{array}$ & 10.44 & $\begin{array}{l}\text { RIKEN cDNA } \\
1700123012 \\
\text { gene }\end{array}$ & unknown & 6 & 14 & No & 2 \\
\hline $\operatorname{RlBp}_{1} 1 l$ & 9.20 & $\begin{array}{l}\text { retinaldehyde } \\
\text { binding } \\
\text { protein 1-like } \\
1\end{array}$ & transport & 25 & 7 & unknown & 2 \\
\hline
\end{tabular}


Table 3-1. (Continued).

\begin{tabular}{|c|c|c|c|c|c|c|c|}
\hline $\begin{array}{c}\text { Gene } \\
\text { Symbol }\end{array}$ & $\mathbf{M b}$ & $\begin{array}{c}\text { Gene } \\
\text { Designation }\end{array}$ & $\begin{array}{c}\text { Biological } \\
\text { Processes/Functions }\end{array}$ & $\begin{array}{c}\text { nsSNPs } \\
\text { (B6 vs. } \\
\text { D2) }\end{array}$ & $\begin{array}{l}\text { InDels in } \\
\text { BXD } \\
\text { Mice }\end{array}$ & $\begin{array}{c}\text { Cis- } \\
\text { Regulated } \\
\text { in Lung }\end{array}$ & $\begin{array}{l}\text { QTL } \\
\text { Miner } \\
\text { Score } \\
\text { (1-4) }\end{array}$ \\
\hline $\begin{array}{l}4930412 \\
\text { C18Rik }\end{array}$ & 9.70 & $\begin{array}{l}\text { RIKEN cDNA } \\
4930412 \text { C18 } \\
\text { gene }\end{array}$ & unknown & 80 & 5 & unknown & 2 \\
\hline Rab2 & 8.46 & $\begin{array}{l}\text { RAB2, } \\
\text { member RAS } \\
\text { oncogene } \\
\text { family }\end{array}$ & $\begin{array}{l}\text { GDP binding, GTP } \\
\text { binding }\end{array}$ & 5 & 12 & unknown & 2 \\
\hline $\begin{array}{l}2310030 \\
\text { No2Rik }\end{array}$ & 10.98 & $\begin{array}{l}\text { RIKEN cDNA } \\
2310030 \text { N02 } \\
\text { gene }\end{array}$ & unknown & 7 & 1 & unknown & 2 \\
\hline $\begin{array}{l}\text { 1110037 } \\
\text { F02Rik }\end{array}$ & 11.41 & $\begin{array}{l}\text { RIKEN cDNA } \\
1110037 \mathrm{~F} 02 \\
\text { gene }\end{array}$ & $\begin{array}{l}\text { RNA splicing, mRNA } \\
\text { processing }\end{array}$ & 26 & 9 & unknown & 2 \\
\hline Rbm $12 b$ & 12.07 & $\begin{array}{l}\text { RNA binding } \\
\text { motif protein } \\
12 \mathrm{~B}\end{array}$ & $\begin{array}{l}\text { RNA binding, } \\
\text { nucleotide binding }\end{array}$ & 5 & 0 & No & 1 \\
\hline$G d f 6$ & 9.77 & $\begin{array}{l}\text { growth } \\
\text { differentiation } \\
\text { factor } 6\end{array}$ & $\begin{array}{l}\text { growth, BMP signaling } \\
\text { pathway }\end{array}$ & 1 & 0 & No & 1 \\
\hline $\begin{array}{l}\operatorname{LOC} 242 \\
317\end{array}$ & 10.37 & $\begin{array}{l}\text { similar to L- } \\
\text { lactate } \\
\text { dehydrogenase } \\
\text { A chain } \\
\text { (LDH-A) } \\
\text { (LDH muscle } \\
\text { subunit) } \\
\text { (LDH-M) }\end{array}$ & unknown & 0 & 1 & unknown & 1 \\
\hline $\begin{array}{l}\text { A63003 } \\
\text { 4I12Rik }\end{array}$ & 11.10 & $\begin{array}{l}\text { RIKEN cDNA } \\
\text { A630034I12 } \\
\text { gene }\end{array}$ & unknown & 0 & 2 & unknown & 1 \\
\hline $\begin{array}{l}1700123 \\
\text { M08Rik }\end{array}$ & 11.89 & $\begin{array}{l}\text { RIKEN cDNA } \\
1700123 \mathrm{M} 08 \\
\text { gene }\end{array}$ & unknown & 0 & 1 & unknown & 1 \\
\hline
\end{tabular}


Table 3-2. QTLMINER scores for candidate genes within day 2 QTL intervals (Chrs 2 and 17): Trait 16333.

\begin{tabular}{|c|c|c|c|c|c|c|c|}
\hline $\begin{array}{c}\text { Gene } \\
\text { Symbol }\end{array}$ & Mb & $\begin{array}{c}\text { Gene } \\
\text { Designation }\end{array}$ & $\begin{array}{c}\text { Biological } \\
\text { Processes/Functions }\end{array}$ & $\begin{array}{c}\text { nsSNPs } \\
\text { (B6 vs. } \\
\text { D2) }\end{array}$ & $\begin{array}{l}\text { InDels } \\
\text { in } \\
\text { BXD } \\
\text { Mice }\end{array}$ & $\begin{array}{c}\text { Cis- } \\
\text { Regulated } \\
\text { in Lung }\end{array}$ & $\begin{array}{c}\text { QTL } \\
\text { Miner } \\
\text { Score } \\
(1-4)\end{array}$ \\
\hline \multicolumn{8}{|c|}{ Chromosome 2} \\
\hline Lama5 & 179.91 & $\begin{array}{l}\text { laminin, } \\
\text { alpha } 5\end{array}$ & $\begin{array}{l}\text { cell adhesion, regulation } \\
\text { of cell migration, } \\
\text { regulation of cell } \\
\text { adhesion,regulation of } \\
\text { embryonic development } \\
\text { hair follicle development, } \\
\text { muscle organ development } \\
\text { lung development, } \\
\text { branching involved in } \\
\text { ureteric bud } \\
\text { morphogenesis, organ } \\
\text { morphogenesis, cilium } \\
\text { assembly } \\
\text { neural crest cell } \\
\text { migration,branching } \\
\text { morphogenesis of a } \\
\text { tube,morphogenesis of a } \\
\text { polarized epithelium, } \\
\text { regulation of cell } \\
\text { proliferation, } \\
\text { morphogenesis of } \\
\text { embryonic epithelium, } \\
\text { odontogenesis of dentine- } \\
\text { containing tooth } \\
\text { branching involved in } \\
\text { salivary gland } \\
\text { morphogenesis }\end{array}$ & 58 & 5 & Yes & 4 \\
\hline GtpBp5 & 179.81 & $\begin{array}{l}\text { GTP binding } \\
\text { protein } 5\end{array}$ & $\begin{array}{l}\text { ribosome maturation } \\
\text { process, GTPase }\end{array}$ & 8 & 1 & Yes & 4 \\
\hline Psma7 & 179.77 & $\begin{array}{l}\text { proteasome } \\
\text { (prosome, } \\
\text { macropain) } \\
\text { subunit, } \\
\text { alpha type } 7\end{array}$ & $\begin{array}{l}\text { proteolysis involved in } \\
\text { cellular protein catabolic } \\
\text { process, ubiquitin- } \\
\text { dependent protein } \\
\text { catabolic process }\end{array}$ & 2 & 0 & Yes & 3 \\
\hline OsBpl2 & 179.85 & $\begin{array}{l}\text { oxysterol } \\
\text { binding } \\
\text { protein-like } \\
2\end{array}$ & $\begin{array}{l}\text { transport, lipid transport, } \\
\text { steroid metabolic process }\end{array}$ & 8 & 5 & No & 3 \\
\hline Ss $18 l 1$ & 179.78 & $\begin{array}{l}\text { synovial } \\
\text { sarcoma } \\
\text { translocation } \\
\text { gene on } \\
\text { chromosome } \\
\text { 18-like } 1\end{array}$ & $\begin{array}{l}\text { transcription, chromatin } \\
\text { modification, regulation of } \\
\text { transcription, regulation of } \\
\text { transcription, DNA- } \\
\text { dependent } \\
\text { dendrite development }\end{array}$ & 18 & 0 & Yes & 3 \\
\hline$C d h 4$ & 179.18 & cadherin 4 & $\begin{array}{l}\text { cell adhesion, axon } \\
\text { guidance, positive } \\
\text { regulation of axon } \\
\text { extension, heterophilic } \\
\text { cell-cell adhesion, } \\
\text { homophilic cell adhesion }\end{array}$ & 14 & 57 & No & 2 \\
\hline
\end{tabular}


Table 3-2. (Continued).

\begin{tabular}{|c|c|c|c|c|c|c|c|}
\hline $\begin{array}{l}\text { Gene } \\
\text { Symbol }\end{array}$ & $\mathbf{M b}$ & $\begin{array}{c}\text { Gene } \\
\text { Designation }\end{array}$ & $\begin{array}{c}\text { Biological } \\
\text { Processes/Functions }\end{array}$ & $\begin{array}{l}\text { nsSNPs } \\
\text { (B6 vs. } \\
\text { D2) }\end{array}$ & $\begin{array}{l}\text { InDels } \\
\text { in } \\
\text { BXD } \\
\text { Mice }\end{array}$ & $\begin{array}{l}\text { Cis- } \\
\text { Regulated } \\
\text { in Lung }\end{array}$ & $\begin{array}{l}\text { QTL } \\
\text { Miner } \\
\text { Score } \\
(1-4)\end{array}$ \\
\hline Taf $4 a$ & 179.65 & $\begin{array}{l}\text { TAF4A } \\
\text { RNA } \\
\text { polymerase } \\
\text { II, TATA } \\
\text { box binding } \\
\text { protein } \\
\text { (TBP)- } \\
\text { associated } \\
\text { factor }\end{array}$ & $\begin{array}{l}\text { transcription from RNA } \\
\text { polymerase II promoter, } \\
\text { ovarian follicle } \\
\text { development, regulation of } \\
\text { transcription from RNA } \\
\text { polymerase II promoter }\end{array}$ & 3 & 0 & No & 2 \\
\hline Adrm1 & 179.91 & $\begin{array}{l}\text { adhesion } \\
\text { regulating } \\
\text { molecule } 1\end{array}$ & $\begin{array}{l}\text { proteasomal ubiquitin } \\
\text { receptor, regulation of } \\
\text { deubiquitinating enzyme }\end{array}$ & 9 & 0 & No & 2 \\
\hline Hrh3 & 179.83 & $\begin{array}{l}\text { histamine } \\
\text { receptor H } 3\end{array}$ & $\begin{array}{l}\text { G-protein coupled } \\
\text { receptor protein signaling } \\
\text { pathway, signal } \\
\text { transduction,negative } \\
\text { regulation of adenylate } \\
\text { cyclase activity, elevation } \\
\text { of cytosolic calcium ion } \\
\text { concentration, learning } \\
\text { memory, negative } \\
\text { regulation of glutamate } \\
\text { secretion, negative } \\
\text { regulation of gamma- } \\
\text { aminobutyric acid } \\
\text { secretion, regulation of } \\
\text { norepinephrine secretion, } \\
\text { negative regulation of } \\
\text { serotonin secretion } \\
\text { response to organic cyclic } \\
\text { substance, eating behavior } \\
\text { drinking behavior, } \\
\text { negative regulation of } \\
\text { blood pressure, positive } \\
\text { regulation of epithelial cell } \\
\text { proliferation, cognition }\end{array}$ & 3 & 0 & No & 1 \\
\hline $\begin{array}{l}4930449 \\
\text { I21Rik }\end{array}$ & 179.39 & $\begin{array}{l}\text { RIKEN } \\
\text { cDNA } \\
4930449121 \\
\text { gene }\end{array}$ & unknown & 0 & 1 & No & 1 \\
\hline
\end{tabular}

\section{Chromosome 17}

Pacrg

10.60 Park2 co-

Functions within a

36

19

Yes

regulated multiprotein E3 ubiquitin

ligase complex 
Table 3-2. (Continued).

\begin{tabular}{|c|c|c|c|c|c|c|c|}
\hline $\begin{array}{l}\text { Gene } \\
\text { Symbol }\end{array}$ & Mb & $\begin{array}{c}\text { Gene } \\
\text { Designation }\end{array}$ & $\begin{array}{c}\text { Biological } \\
\text { Processes/Functions }\end{array}$ & $\begin{array}{l}\text { nsSNPs } \\
\text { (B6 vs. } \\
\text { D2) }\end{array}$ & $\begin{array}{c}\text { InDels } \\
\text { in } \\
\text { BXD } \\
\text { Mice } \\
\end{array}$ & $\begin{array}{c}\text { Cis- } \\
\text { Regulated } \\
\text { in Lung }\end{array}$ & $\begin{array}{c}\text { QTL } \\
\text { Miner } \\
\text { Score } \\
(1-4) \\
\end{array}$ \\
\hline$Q k$ & 10.40 & quaking & $\begin{array}{l}\text { vasculogenesis, cell } \\
\text { differentiation, transport, } \\
\text { regulation of translation, } \\
\text { multicellular organismal } \\
\text { development, RNA } \\
\text { splicing, mRNA transport, } \\
\text { mRNA processing, axon } \\
\text { ensheathment, } \\
\text { myelination, muscle cell } \\
\text { differentiation, long-chain } \\
\text { fatty acid biosynthetic } \\
\text { process }\end{array}$ & 2 & 1 & No & 3 \\
\hline Pdel0a & 8.99 & $\begin{array}{l}\text { phosphodiest } \\
\text { erase } 10 \mathrm{~A}\end{array}$ & $\begin{array}{l}\text { signal transduction, cAMP } \\
\text { catabolic process, cGMP } \\
\text { catabolic process }\end{array}$ & 8 & 10 & No & 2 \\
\hline
\end{tabular}


Table 3-3. QTLMINER scores for candidate genes within the days 3-4 QTL interval (Chr 12): Traits 16334 and 16335.

\begin{tabular}{|c|c|c|c|c|c|c|c|}
\hline $\begin{array}{c}\text { Gene } \\
\text { Symbol }\end{array}$ & Mb & $\begin{array}{c}\text { Gene } \\
\text { Designation }\end{array}$ & $\begin{array}{c}\text { Biological } \\
\text { Processes/Functions }\end{array}$ & $\begin{array}{l}\text { nsSNPs } \\
\text { (B6 vs. } \\
\text { D2) }\end{array}$ & $\begin{array}{l}\text { InDels } \\
\text { in } \\
\text { BXD } \\
\text { Mice }\end{array}$ & $\begin{array}{l}\text { Cis- } \\
\text { Regulated } \\
\text { in Lung }\end{array}$ & $\begin{array}{l}\text { QTL } \\
\text { Miner } \\
\text { Score } \\
(1-4)\end{array}$ \\
\hline \multicolumn{8}{|l|}{ Chromosome 12} \\
\hline Sipa1l1 & 83.36 & $\begin{array}{l}\text { signal- } \\
\text { induced } \\
\text { proliferation- } \\
\text { associated } 1 \\
\text { like } 1\end{array}$ & $\begin{array}{l}\text { regulation of synaptic } \\
\text { plasticity, regulation } \\
\text { of small GTPase } \\
\text { mediated signal } \\
\text { transduction, } \\
\text { regulation of dendrite } \\
\text { morphogenesis }\end{array}$ & 3 & 7 & Yes & 4 \\
\hline Ttc9 & 82.73 & $\begin{array}{l}\text { tetratricopepti } \\
\text { de repeat } \\
\text { domain } 9\end{array}$ & protein folding & 38 & 3 & Yes & 4 \\
\hline Smocl & 82.13 & $\begin{array}{l}\text { SPARC } \\
\text { related } \\
\text { modular } \\
\text { calcium } \\
\text { binding } 1\end{array}$ & $\begin{array}{l}\text { extracellular matrix } \\
\text { organization, positive } \\
\text { regulation of cell- } \\
\text { substrate adhesion }\end{array}$ & 18 & 15 & No & 3 \\
\hline$A \cot 2$ & 85.33 & $\begin{array}{l}\text { acyl-CoA } \\
\text { thioesterase } 2\end{array}$ & $\begin{array}{l}\text { lipid metabolic } \\
\text { process, acyl-CoA } \\
\text { metabolic process, } \\
\text { very-long-chain fatty } \\
\text { acid catabolic process }\end{array}$ & 5 & 0 & No & 2 \\
\hline Psen 1 & 85.03 & presenilin 1 & $\begin{array}{l}\text { regulation of resting } \\
\text { membrane potential, } \\
\text { negative regulation of } \\
\text { neuron apoptosis, } \\
\text { protein maturation by } \\
\text { peptide bond cleavage, } \\
\text { regulation of synaptic } \\
\text { transmission, } \\
\text { glutamatergic } \\
\text { neurogenesis, skeletal } \\
\text { system } \\
\text { morphogenesis, T cell } \\
\text { activation during } \\
\text { immune response, } \\
\text { brain morphogenesis, } \\
\text { dorsal/ventral neural } \\
\text { tube patterning, } \\
\text { hemopoietic } \\
\text { progenitor cell } \\
\text { differentiation; } \\
\text { myeloid leukocyte } \\
\text { differentiation, } \\
\text { endoplasmic } \\
\text { reticulum, calcium ion } \\
\text { homeostasis, Cajal- } \\
\text { Retzius cell } \\
\text { differentiation, T cell } \\
\text { receptor signaling } \\
\text { pathway, thymus } \\
\text { development, positive } \\
\text { regulation of apoptosis }\end{array}$ & 0 & 1 & No & 2 \\
\hline
\end{tabular}


Table 3-3. (Continued).

\begin{tabular}{|c|c|c|c|c|c|c|c|}
\hline $\begin{array}{c}\text { Gene } \\
\text { Symbol }\end{array}$ & Mb & $\begin{array}{c}\text { Gene } \\
\text { Designation }\end{array}$ & $\begin{array}{c}\text { Biological } \\
\text { Processes/Functions }\end{array}$ & $\begin{array}{c}\text { nsSNPs } \\
\text { (B6 vs. } \\
\text { D2) }\end{array}$ & $\begin{array}{l}\text { InDels } \\
\text { in } \\
\text { BXD } \\
\text { Mice } \\
\end{array}$ & $\begin{array}{l}\text { Cis- } \\
\text { Regulated } \\
\text { in Lung }\end{array}$ & $\begin{array}{c}\text { QTL } \\
\text { Miner } \\
\text { Score } \\
(1-4) \\
\end{array}$ \\
\hline$R b m 25$ & 84.97 & $\begin{array}{l}\text { RNA binding } \\
\text { motif protein } \\
25\end{array}$ & $\begin{array}{l}\text { apoptosis, RNA } \\
\text { splicing, mRNA } \\
\text { processing }\end{array}$ & 0 & 1 & No & 2 \\
\hline Nek9 & 86.64 & $\begin{array}{l}\text { NIMA (never } \\
\text { in mitosis } \\
\text { gene a)- } \\
\text { related } \\
\text { expressed } \\
\text { kinase } 9\end{array}$ & $\begin{array}{l}\text { cell cycle, cell } \\
\text { division, mitosis, } \\
\text { protein amino acid } \\
\text { phosphorylation }\end{array}$ & 2 & 0 & No & 2 \\
\hline $\begin{array}{l}2410016006 R \\
i k\end{array}$ & 85.29 & $\begin{array}{l}\text { RIKEN } \\
\text { cDNA } \\
2410016006 \\
\text { gene }\end{array}$ & $\begin{array}{l}\text { transcription, } \\
\text { oxidation reduction, } \\
\text { regulation of } \\
\text { transcription, } \\
\text { chromatin } \\
\text { remodeling, } \\
\text { ribosome biogenesis, } \\
\text { chromatin } \\
\text { modification, } \\
\text { negative regulation } \\
\text { of osteoblast, } \\
\text { differentiation, } \\
\text { negative regulation } \\
\text { of transcription, } \\
\text { DNA-dependent, } \\
\text { histone H3-K4 } \\
\text { demethylation, } \\
\text { histone H3-K36 } \\
\text { demethylation }\end{array}$ & 1 & 0 & No & 2 \\
\hline Zfyvel & 84.89 & $\begin{array}{l}\text { zinc finger, } \\
\text { FYVE } \\
\text { domain } \\
\text { containing } 1\end{array}$ & biological process & 1 & 0 & No & 2 \\
\hline Rgs6 & 83.72 & $\begin{array}{l}\text { regulator of } \\
\text { G-protein } \\
\text { signaling } 6\end{array}$ & $\begin{array}{l}\text { signal transduction, } \\
\text { negative regulation } \\
\text { of signal } \\
\text { transduction, } \\
\text { intracellular } \\
\text { signaling cascade } \\
\text { G-protein coupled } \\
\text { receptor protein } \\
\text { signaling pathway } \\
\text { positive regulation of } \\
\text { neuron } \\
\text { differentiation }\end{array}$ & 9 & 31 & No & 2 \\
\hline Pcnx & 82.96 & $\begin{array}{l}\text { pecanex } \\
\text { homolog } \\
\text { (Drosophila) }\end{array}$ & biological process & 2 & 0 & No & 2 \\
\hline Map $3 k 9$ & 82.83 & $\begin{array}{l}\text { mitogen- } \\
\text { activated } \\
\text { protein kinase } \\
\text { kinase kinase } \\
9\end{array}$ & $\begin{array}{l}\text { protein amino acid } \\
\text { phosphorylation, cell } \\
\text { death } \\
\text { positive regulation of } \\
\text { apoptosis }\end{array}$ & 1 & 0 & No & 2 \\
\hline
\end{tabular}


Table 3-3. (Continued).

\begin{tabular}{|c|c|c|c|c|c|c|c|}
\hline $\begin{array}{c}\text { Gene } \\
\text { Symbol }\end{array}$ & Mb & $\begin{array}{c}\text { Gene } \\
\text { Designation }\end{array}$ & $\begin{array}{c}\text { Biological } \\
\text { Processes/Functions }\end{array}$ & $\begin{array}{c}\text { nsSNPs } \\
\text { (B6 vs. } \\
\text { D2) }\end{array}$ & $\begin{array}{c}\text { InDels } \\
\text { in BXD } \\
\text { Mice }\end{array}$ & $\begin{array}{l}\text { Cis- } \\
\text { Regulated } \\
\text { in Lung }\end{array}$ & $\begin{array}{c}\text { QTL } \\
\text { Miner } \\
\text { Score } \\
(1-4) \\
\end{array}$ \\
\hline Adam4 & 82.52 & $\begin{array}{l}\text { a disintegrin } \\
\text { and } \\
\text { metallopepti } \\
\text { dase domain } \\
4\end{array}$ & $\begin{array}{l}\text { integrin-mediated } \\
\text { signaling pathway }\end{array}$ & 3 & 0 & No & 2 \\
\hline Synj $2 B p$ & 82.59 & $\begin{array}{l}\text { synaptojanin } \\
2 \text { binding } \\
\text { protein }\end{array}$ & $\begin{array}{l}\text { endocytosis, } \\
\text { cytoplasm } \\
\text { organization, protein } \\
\text { targeting, Rho } \\
\text { protein signal } \\
\text { transduction, } \\
\text { regulation of } \\
\text { endocytosis, } \\
\text { intracellular } \\
\text { distribution of } \\
\text { mitochondria }\end{array}$ & 3 & 0 & No & 2 \\
\hline Tmed 10 & 86.68 & $\begin{array}{l}\text { transmembra } \\
\text { ne emp24- } \\
\text { like } \\
\text { trafficking } \\
\text { protein } 10 \\
\text { (yeast) }\end{array}$ & $\begin{array}{l}\text { transport, vesicle- } \\
\text { mediated transport, } \\
\text { protein transport } \\
\text { intracellular protein } \\
\text { transport, regulated } \\
\text { secretory pathway, } \\
\text { vesicle targeting, to, } \\
\text { from or within Golgi }\end{array}$ & 1 & 0 & No & 2 \\
\hline Ylpm1 & 86.34 & $\begin{array}{l}\text { YLP motif } \\
\text { containing } 1\end{array}$ & $\begin{array}{l}\text { reduction of } \\
\text { telomerase activity } \\
\text { differentiation of } \\
\text { embryonic stem cells }\end{array}$ & 2 & 0 & No & 2 \\
\hline Jundm 2 & 86.94 & $\begin{array}{l}\text { Jun } \\
\text { dimerization } \\
\text { protein } 2\end{array}$ & $\begin{array}{l}\text { transcription, } \\
\text { regulation of } \\
\text { transcription, DNA- } \\
\text { dependent, negative } \\
\text { regulation of } \\
\text { transcription from } \\
\text { RNA polymerase II } \\
\text { promoter }\end{array}$ & 1 & 0 & No & 2 \\
\hline Rps6kl1 & 86.48 & $\begin{array}{l}\text { ribosomal } \\
\text { protein S6 } \\
\text { kinase-like } 1\end{array}$ & $\begin{array}{l}\text { protein amino acid } \\
\text { phosphorylation }\end{array}$ & 0 & 1 & No & 1 \\
\hline
\end{tabular}


Table 3-3. (Continued).

\begin{tabular}{|c|c|c|c|c|c|c|c|}
\hline $\begin{array}{c}\text { Gene } \\
\text { Symbol }\end{array}$ & $\mathbf{M b}$ & $\begin{array}{c}\text { Gene } \\
\text { Designation }\end{array}$ & $\begin{array}{c}\text { Biological } \\
\text { Processes/Functions }\end{array}$ & $\begin{array}{c}\text { nsSNPs } \\
\text { (B6 vs. } \\
\text { D2) }\end{array}$ & $\begin{array}{l}\text { InDels } \\
\text { in } \\
\text { BXD } \\
\text { Mice }\end{array}$ & $\begin{array}{c}\text { Cis- } \\
\text { Regulated } \\
\text { in Lung }\end{array}$ & $\begin{array}{c}\text { QTL } \\
\text { Miner } \\
\text { Score } \\
(1-4)\end{array}$ \\
\hline$V s \times 2$ & 85.91 & $\begin{array}{l}\text { visual system } \\
\text { homeobox } 2\end{array}$ & $\begin{array}{l}\text { transcription, regulation } \\
\text { of transcription, } \\
\text { multicellular organismal } \\
\text { development, DNA- } \\
\text { dependent positive } \\
\text { regulation of cell } \\
\text { proliferation, positive } \\
\text { regulation of transcription } \\
\text { from RNA polymerase II } \\
\text { promoter, negative } \\
\text { regulation of cell } \\
\text { proliferation, cell fate } \\
\text { commitment, retina } \\
\text { morphogenesis in } \\
\text { camera-type eye, retinal } \\
\text { bipolar neuron } \\
\text { differentiation, camera- } \\
\text { type eye development }\end{array}$ & 0 & 1 & No & 1 \\
\hline$A \cot 5$ & 85.41 & $\begin{array}{l}\text { acyl-CoA } \\
\text { thioesterase } 5\end{array}$ & $\begin{array}{l}\text { acyl-CoA metabolic } \\
\text { process, lipid } \\
\text { metabolic process, } \\
\text { saturated } \\
\text { monocarboxylic acid } \\
\text { metabolic process, } \\
\text { long-chain fatty acid } \\
\text { metabolic process, } \\
\text { very-long-chain fatty } \\
\text { acid metabolic } \\
\text { process, unsaturated } \\
\text { monocarboxylic acid } \\
\text { metabolic process }\end{array}$ & 2 & 0 & No & 1 \\
\hline Acot3 & 85.39 & $\begin{array}{l}\text { acyl-CoA } \\
\text { thioesterase } 3\end{array}$ & $\begin{array}{l}\text { lipid metabolic } \\
\text { process, unsaturated } \\
\text { monocarboxylic acid } \\
\text { metabolic process, } \\
\text { long-chain fatty acid } \\
\text { metabolic process, } \\
\text { very-long-chain fatty } \\
\text { acid metabolic } \\
\text { process, saturated } \\
\text { monocarboxylic acid } \\
\text { metabolic process, } \\
\text { acyl-CoA metabolic } \\
\text { process }\end{array}$ & 4 & 0 & No & 1 \\
\hline Acot 4 & 85.38 & $\begin{array}{l}\text { acyl-CoA } \\
\text { thioesterase } 4\end{array}$ & $\begin{array}{l}\text { acyl-CoA metabolic } \\
\text { process, succinyl-CoA } \\
\text { metabolic process, } \\
\text { lipid metabolic } \\
\text { process, short-chain } \\
\text { fatty acid metabolic } \\
\text { process, dicarboxylic } \\
\text { acid metabolic process }\end{array}$ & 1 & 0 & No & 1 \\
\hline Tmem90a & 86.02 & $\begin{array}{l}\text { transmembrane } \\
\text { protein } 90 \mathrm{a}\end{array}$ & $\begin{array}{l}\text { response to biotic } \\
\text { stimulus }\end{array}$ & 1 & 0 & No & 1 \\
\hline
\end{tabular}


The H1N1 study identified a QTL on Chr 10 that was linked only with the day 1 weight loss trait, and they concluded that much of the weight loss was transient and associated with the stress of anesthesia prior to intranasal instillation. Our findings support a similar conclusion for the day 1 weight loss trait. Although the QTLs identified in the two studies are on different chromosomes, this conclusion is feasible because our studies utilized inhaled isoflurane for anesthesia, while the studies by Nedelko et. al. used injectable anesthesia (ketamine/xylazine). Another stressor that could account for variation of the weight loss trait could be introduction of liquid vehicle (PBS) into the lungs during intranasal instillation. Again, the identification of loci on different chromosomes (Chrs 4 and 10) in our and the Nedelko et. al. studies, respectively, is

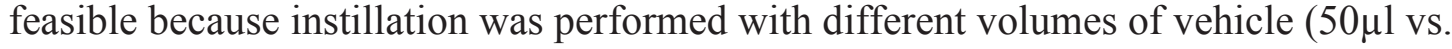
$20 \mu 1$, respectively).

We used QTLminer to analyze these QTL intervals and to identify genes that are promising positional and biological candidate genes. Three candidate genes with high QTLminer scores were identified within the significant QTL on chromosome 12 that was observed on days 3 and 4 post-infection. One of these genes (Sipall1) encodes a protein that is thought to be involved in several processes that impact innate immunity: (1) positive regulation of RAP2A GTPase activity, (2) reorganization of the actin cytoskeleton and recruitment of DLG4 to F-actin, and (3) regulation of dendritic spine morphogenesis. Ttc 9 is a hormonally regulated gene in breast cancer cells and may play a role in cancer cell invasion and metastasis [127]. The final candidate gene (Smoc1) encodes a putative regulator of osteoblast differentiation in bone marrow stromal cells [128] and plays a critical role in ocular and limb development in mice and humans through the modulation of BMP signaling $[129,130]$. The heritability of the day 3 and day 4 weight loss traits approached 93\%, indicating that these traits are likely to be genetically controlled. Moreover, principal component analysis revealed that the QTL on Chr 12 contributed $>70 \%$ of the total weight loss variability in the cohort, indicating that a gene(s) within this interval is the most important genetic factor in weight loss kinetics.

Although the loci that were identified on days 1 and 2 post-infection contribute $30 \%$ or less to weight loss, we also examined them for gene candidates. There were four high value candidates associated with the day $1 \mathrm{Chr} 4$ locus. Car 8 encodes a protein that is designated as carbonic anhydrase VIII, despite its lack of carbonic anhydrase activity. Mice carrying non-functional Car 8 mutations suffer from neurological defects [131]. The Asph gene is expressed from two promoters and undergoes extensive alternative splicing, resulting in a set of aspartate beta-hydroxylases that have distinct functional properties. The longest isoform hydroxylates aspartic acid or asparagine residues in the epidermal growth factor-like domains of several proteins, including protein $\mathrm{C}$, coagulation factors VII, IX, and X, and the complement factors C1R and C1S. ASPH is also thought to play an important role in calcium homeostasis [132]. Trp53inpl encodes an antiproliferative and proapoptotic protein (tumor protein p53-inducible nuclear protein 1) that is involved in cell stress responses by acting as a dual regulator of transcription and autophagy [133135]. TRP53INP1 protein also reduces cell migration by regulating expression of SPARC, a regulator of cell growth through interactions with the extracellular matrix and cytokines. Inst8 encodes one component of a complex (integrator complex) that 
associates with RNA polymerase II and is involved in the processing of small nuclear RNAs [136]. It remains unclear how any of the candidate genes within the Chr 4 interval might be involved in weight loss kinetics during the initial stages of melioidosis.

There were several high-scoring candidate genes from the suggestive QTLs that were observed on day 2 post-infection. Lama5 ( $\mathrm{Chr} 2$ ) encodes a protein that is thought to mediate the attachment, migration and organization of cells into tissues during embryonic development. GtpBp5 (Chr 2) encodes a putative GTPase that may play a role in the regulation of processes such as protein synthesis, nuclear transport, membrane trafficking, and signal transduction $[137,138]$. The gene product of $S s 18 l 1(\mathrm{Chr} 2)$ is a transcriptional activator that is required for calcium-dependent dendritic growth and branching in cortical neurons. Psma7 (Chr 2) encodes a member of the peptidase T1A family that functions as a $20 \mathrm{~S}$ core alpha proteasome subunit and participates in cytoplasmic protein degradation and recycling, while $O s B p l 2$ encodes a member of the oxysterol-binding protein family of intracellular lipid receptors, known as oxysterol binding protein-like 2 [139]. Two of the high-priority candidate genes on chromosome 17, Park2 and Pacrg, share a bidirectional promoter and are co-regulated in various tissues. Their gene products are involved in the degradation of misfolded or damaged proteins as well as in autophagy and mitophagy, and have a strong association with the development of Parkinson's disease [140] [141, 142]. Interestingly, single nucleotide polymorphisms of Park2 and Pacrg are also associated with leprosy susceptibility in the Chinese population [143]. The other high scoring candidate gene on chromosome 17 was $Q k$, a gene that encodes an RNA-binding protein that plays a central role in myelination; dysfunction of this gene may result in myelin and/or oligodendrocyte dysfunction in schizophrenia [144]. It is difficult to predict the role of any of these genes in weight loss kinetics, but because the heritability of the Day 2 weight loss trait is approximately $87 \%$ (compared to $68.8 \%$ for the day 1 weight loss trait), it is much more likely that genes from one or both of these QTLs exert some control over weight loss during melioidosis.

Our findings indicate that weight loss kinetics during acute pneumonic $B p$ infection is a heritable and dynamic trait that is controlled by several host loci in a time dependent fashion. A significant QTL on Chr 12 (between 80 and $87 \mathrm{Mb}$ ) appears to be the most important genetic factor, while loci on chromosomes 2, 4, and 17 also contribute to weight loss. The strongest candidate genes are involved in processes that could be critical for immune processes, such as regulation of GTPase activity, reorganization of actin cytoskeleton, hydroxylation of coagulation factors and complement components, and autophagy. Several of the other strong candidates are involved in developmental processes that include osteoblast differentiation, regulation of cell growth and migration, tissue development during embryonic development, limb development, and myelination. 


\section{CHAPTER 4. GENETICS OF DIFFERENTIAL SUSCEPTIBILITY TO PNEUMONIC BURKHOLDERIA PSEUDOMALLEI INFECTION}

\section{INTRODUCTION}

In humans, infection with $B p$ can cause a rapidly developing acute form of melioidosis or there can be an extended latency period (that can last for many years) before the patient becomes symptomatic. In fact, $B p$ infection has been described as the "Vietnamese time bomb" due to reports that some US servicemen developed melioidosis up to six decades after their exposure to the bacterium in Vietnam [26, 145-147]. Humans and animals exhibit a broad range of clinical presentations following infection with $B p$, but the host factors that contribute to the different forms of melioidosis remain unclear. Although no causal relationship has been determined, pre-existing host conditions in humans (such as renal dysfunction, diabetes mellitus, and alcoholism) are considered to be risk factors for the disease [7]. As previously mentioned, associations have been demonstrated between the clinical presentation of melioidosis and either the host's HLA haplotype [49] or the allelic forms of some cytokine-related genes expressed by the host [50]. These findings suggest that host genetic factors determine (at least in part) the susceptibility of individual patients to the various clinical presentations of this disease.

The murine infection model has been used to establish the importance of host genetic background on the progression of $B p$ infection, which is considered to be an excellent model for both the acute and chronic forms of human melioidosis [56, 60, 125]. $\mathrm{BALB} / \mathrm{c}[56,60]$ and $\mathrm{D} 2[61]$ mice are known to be extremely susceptible to the acute form of melioidosis, while B6 mice $[56,60]$ are relatively resistant to the acute form of the disease and instead tend to develop disease that progresses at a much slower rate. In this report, we have utilized a panel of BXD mice to perform genome-wide linkage analysis to identify host genetic loci that correlate with the differential susceptibilities of B6 and D2 parental strains to acute melioidosis.

\section{RESULTS}

\section{Susceptibility of B6 and D2 Mice to Pneumonic Bp Infection}

As previously mentioned in Chapter 3, our initial studies with a pneumonic challenge model (intranasal instillation) confirmed the previously published observation $[55,61]$ that $\mathrm{B} 6$ mice are more resistant than $\mathrm{D} 2$ mice to $B p$ infection. We performed time course studies to kinetically evaluate the permissiveness of B6 vs. D2 mice to replication of $B p$ in vivo. We found that following intranasal instillation of 50-100 CFU of $B p$ strain 1026b, D2 mice experienced significantly higher $(\mathrm{p}<0.001)$ bacterial burdens in their lungs than B6 mice (see Figure 3-1A in Chapter 3). We also used survival as a readout to examine the relative susceptibility of $\mathrm{B} 6 \mathrm{vs}$. D2 mice to pneumonic $B p$ infection. Following intranasal instillation with 50-100 CFU of $B p 1026 \mathrm{~b}$, we found that 
D2 mice were significantly more susceptible to $B p$ infection than B6 mice $(p<0.0001)$ as they succumbed to infection by day 4 post-infection, while B6 mice survived the infection (see Figure 3-1B in Chapter 3). Subsequent studies showed that the same results were obtained with challenge doses of up to $200 \mathrm{CFU} /$ mouse (data not shown).

\section{Susceptibility of BXD RI Mice to Pneumonic $B p$ Infection}

To identify host genetic elements that are covariant with the variable susceptibility of murine hosts to pneumonic $B p$ infection, we initiated forward genetics studies with a cohort of BXD strains using survival of pneumonic infection as the phenotypic readout. Groups of male mice from 32 BXD strains were challenged with 50$100 \mathrm{CFU}$ of $\mathrm{Bp} 1026 \mathrm{~b}$ (from a diluted frozen stock) via intranasal instillation and then monitored for survival. B6 and D2 mice were included in each of the 20 experiments that were performed, and the D2 mice were always the last group to be challenged to ensure the "potency" of the challenge stock throughout the instillation process. Strains that succumbed to acute melioidosis where given a score of " 0 " and mice that survived the challenge with $B p$ were given a score of " 1 ". We found that several of the BXD strains were highly susceptible to $B p$ (similar to D2 mice), others were relatively resistant to $B p$ (similar to B6 mice), and several strains displayed intermediate phenotypes

(Figure 4-1A).

\section{Heritability of Survival and Time-to-Death}

Our data indicate that there are significant differences observed amongst the different BXD strains for survival and time-to-death. Since all mice used in this study were bred and housed in the same environment, it is likely that the observed differences in these phenotypes are mainly due to genetic variation. A heritability analysis summarizes how much of the variation in a trait is due to variation in genetic factors (as opposed to environmental or technical errors) and this value can range from 0 to $100 \%$. The heritability of our survival and time-to-death trait was $71 \%$, indicating that these traits are likely to be genetically controlled.

\section{Identification of Host Genetic Loci that Influence Survival Following Pneumonic Bp Infection}

Whole-genome linkage analysis of the survival phenotype using this cohort of animals revealed a significant QTL on chromosome 5 (genome-wide significance of 0.015 , LRS of 24.1 with D alleles contributing to increased survival) encompassing a region of approximately 12 megabases and a significant QTL on chromosome 7 (genome-wide significance of 0.017 , LRS of 23.5 with D alleles contributing to increased survival) encompassing a region of approximately 10 megabases that are both covariant with differential susceptibility/resistance to acute pneumonic melioidosis (Figure 4-1B). 


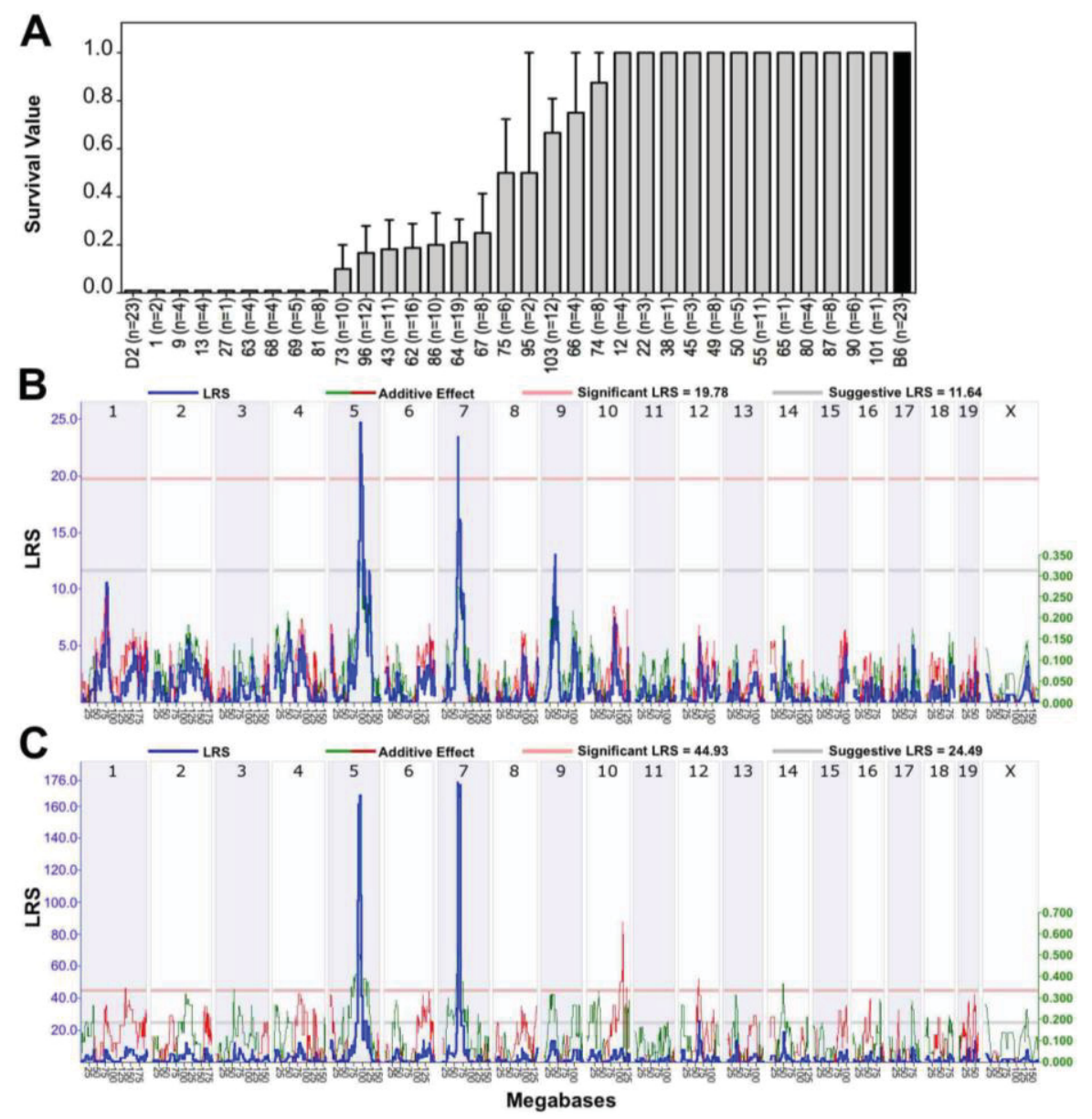

Figure 4-1. Genome-wide linkage analysis of survival following pneumonic challenge with Burkholderia pseudomallei.

A cohort of male mice, which included 32 BXD strains, was infected intranasally with 50-100 CFU of Burkholderia pseudomallei. Infected mice were monitored for survival for up to 11 days post-infection and those that survived infection were given a value of "1" while those that succumbed to infection received a value of "0". Panel A: Log-Rank plot showing the mean \pm SEM of the survival value for each strain. Panels $\mathbf{B}$ and $\mathbf{C}$ :

Standard and weighted interval mapping, respectively, was performed using the in silico resources within GeneNetwork.org to identify genetic loci that correlated with survival. The blue line indicates LRS scores across the entire genome. Thin red and green lines indicate that B6 or D2 alleles increase trait values, respectively. The mouse chromosomes are identified in the upper $\mathrm{x}$-axis, the lower $\mathrm{x}$-axis shows the physical map in mega bases for each chromosome, and the y-axis represents the LRS score. Thick red and grey horizontal lines indicate the genome-wide significance threshold $(\mathrm{p}<0.05)$ or suggestive threshold $(\mathrm{p}<0.63)$, respectively. 
Intriguingly, these loci have an additive allele effect that does not correspond to expectation based on parental strain survival (D2 low, B6 high). Weighted QTL analysis of this dataset identified the loci on chromosomes 5 and 7 as highly significant QTLs (genome-wide significances of 0.011 and 0.009 with LRS scores of 161.7 and 175.9, respectively) (Figure 4-1C). The significant QTLs on chromosomes 5 and 7 were also identified when we used time-to-death of this BXD cohort as a phenotype for QTL analyses (Figure 4-2). It should be noted that further investigation of these two QTL regions using composite interval mapping and haplotype analyses revealed chromosomes 5 and 7 are co-dependent because they exhibit the same pattern of inheritance. As a result, the QTL peak on chromosome 7 is more than likely to be an artifact (discussed in chapter 6).

\section{Identification of Candidate Host Genes that May Contribute to Host Susceptibility/Resistance Following $B p$ Infection}

The significant QTLs on chromosomes 5 and 7 each encompass regions of approximately 10-12 megabases that encode approximately 120 and 70 genes, respectively. We analyzed each of these loci to identify specific candidate genes within the QTL intervals whose function(s) might be important for the survival phenotype. For these candidate gene searches, we considered peak height and bootstrap analyses to define the QTL intervals (Figure 4-3). We then utilized the QTLminer tool [126] in GeneNetwork to identify genes within the QTL that are most likely to contribute to host susceptibility to pneumonic $B p$ infection. QTLminer scores genes on a scale of 0 to 4 based on the following criteria: (1) the gene has a mRNA expression value $\geq 8$ in the lungs in at least one of the expression databases provided on GeneNetwork, (2) the gene is cis-regulated in lung, (3) the gene contains at least 1 nonsynonymous SNP between the parental B6 and D2 mice, and (4) and the gene contains indels in BXD mice. The genes within each QTL that had the highest QTLminer score are listed in Figure 4-3 and in Table 4-1.

\section{Identification of Candidate Genes from Expression Profiling Using RNA-Seq}

Successful incorporation of RNA-Seq data with results of QTL mapping from an AIL can significantly reduce the number of positional candidates within the QTL region(s) [148]. We performed expression profiling on the lung tissue of 5 different BXD RI strains (3 mice/strain) infected with Bp 1026b for 24 hours. The resistant BXD strains used (BXD50 and BXD70) are the most resistant strains we have tested to date (100\% survival with better weight retention when compared to B6 mice). The susceptible BXD strains used (BXD63, BXD09 and BXD27) had an average survival time of 4 days with $100 \%$ mortality (similar to D2 mice). Comparison of RNA expression between the resistant and susceptible mice identified many genes whose expression differed significantly. We used a stringent threshold of $\mathrm{a} \geq 2$-fold change and a $\mathrm{p}$-value of $\leq 0.05$ for our analyses. Clustering based on functional characteristics between the resistant and susceptible strains revealed many of the upregulated genes in the resistant strains were 


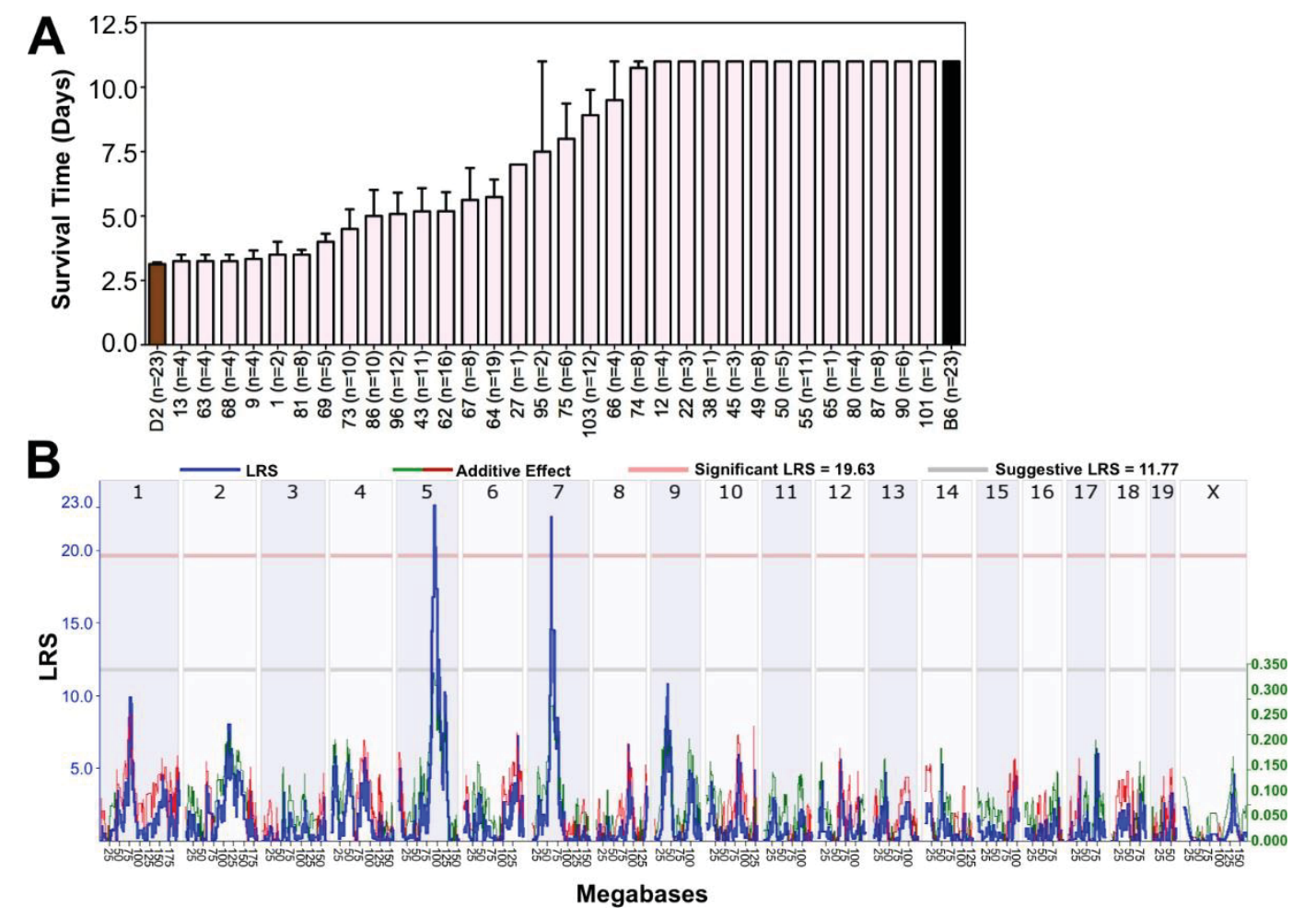

Figure 4-2. Genome-wide linkage analysis of the time-to-death trait following pneumonic challenge with Burkholderia pseudomallei.

A cohort of male mice, which included 32 BXD strains, was infected intranasally with 50-100 CFU of Burkholderia pseudomallei. Infected mice were monitored for survival for up to 11 days post-infection. Mean survival time of each strain is shown in Panel A: Log-Rank plot showing the mean \pm SEM of the survival time for each strain. Panel B: Interval mapping was performed using the in silico resources within GeneNetwork.org to identify genetic loci that correlated with time-to death. The blue line indicates LRS scores across the entire genome. Thin red and green lines indicate that B6 or D2 alleles increase trait values, respectively. The mouse chromosomes are identified in the upper $\mathrm{x}$-axis, the lower $\mathrm{x}$-axis shows the physical map in mega bases for each chromosome, and the y-axis represents the LRS score. Thick red and grey horizontal lines indicate the genome-wide significance threshold $(\mathrm{p}<0.05)$ or suggestive threshold $(\mathrm{p}<0.63)$, respectively. genes on chromosomes 5 and 7 that may have some influence of the host response to pneumonic $B p$ infection. 

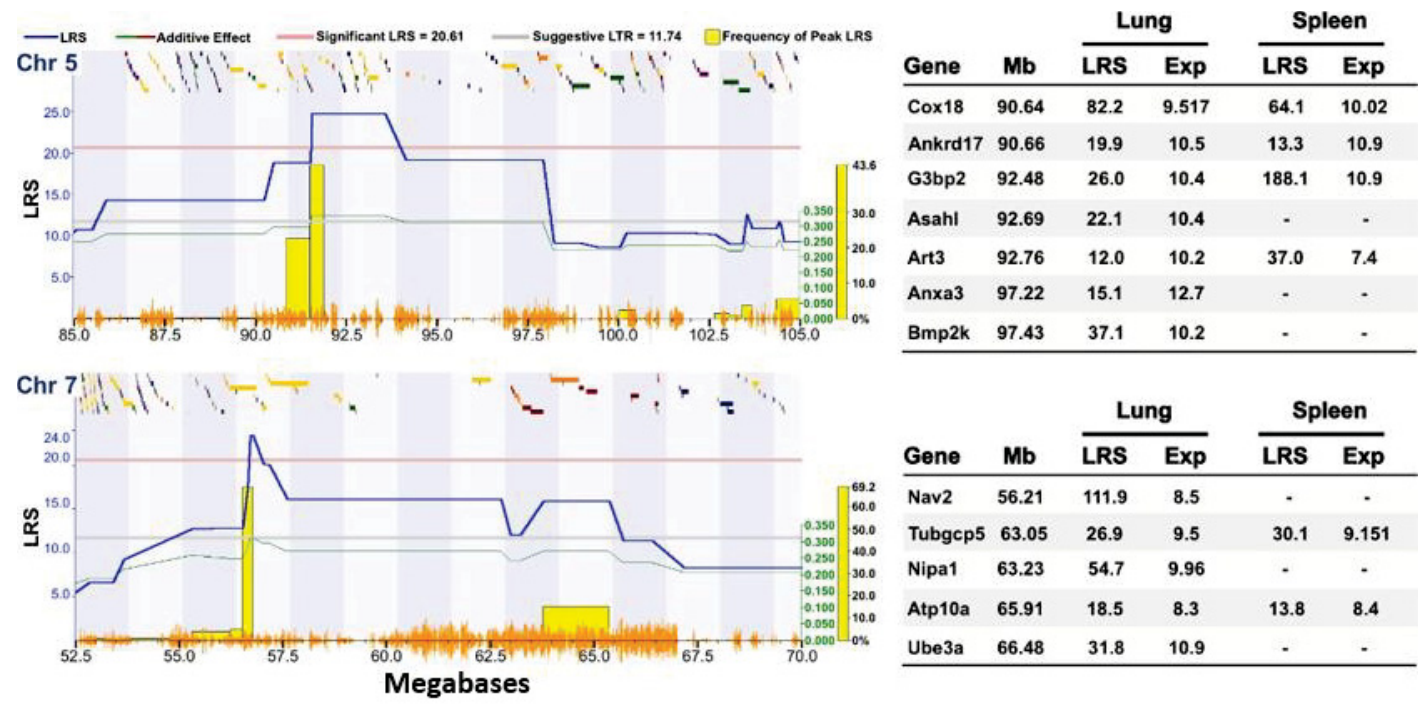

\begin{tabular}{lcccccc} 
& & \multicolumn{2}{c}{ Lung } & & \multicolumn{2}{c}{ Spleen } \\
\cline { 3 - 4 } \cline { 6 - 7 } Gene & Mb & LRS & Exp & & LRS & Exp \\
\hline Nav2 & 56.21 & 111.9 & 8.5 & & - & - \\
Tubgcp5 & 63.05 & 26.9 & 9.5 & & 30.1 & 9.151 \\
Nipa1 & 63.23 & 54.7 & 9.96 & & - \\
Atp10a & 65.91 & 18.5 & 8.3 & & 13.8 & 8.4 \\
Ube3a & 66.48 & 31.8 & 10.9 & & - & - \\
\hline
\end{tabular}

Figure 4-3. Detailed maps of QTLs contributing to survival and candidate genes within these intervals.

Left hand panels: The critical intervals were identified based on bootstrap analysis (frequencies of peak LRS indicated with yellow bars) and peak shapes. The density of SNPs present in the BXD strains is indicated by orange chatter along the $\mathrm{x}$-axis. The multicolored chatter along the top of the graph represent the open reading frames within the interval. The blue line indicates LRS scores across the entire genome. Thin red and green lines indicate that B6 or D2 alleles increase trait values, respectively. The mouse chromosomes are identified in the upper $\mathrm{x}$-axis, the lower $\mathrm{x}$-axis shows the physical map in mega bases for each chromosome, and the y-axis represents the LRS score. Thick red and grey horizontal lines indicate the genome-wide significance threshold $(p<0.05)$ or suggestive threshold $(\mathrm{p}<0.63)$, respectively. Right hand panels: Candidate genes within each interval are indicated along with their LRS score and their relative expression levels in normative tissues. 
Table 4-1. QTLMINER scores for candidate genes within the QTL interval for the survival trait (Chrs 5 and 7): Trait 16330.

\begin{tabular}{|c|c|c|c|c|c|c|c|}
\hline $\begin{array}{c}\text { Gene } \\
\text { Symbol }\end{array}$ & Mb & $\begin{array}{c}\text { Gene } \\
\text { Designation }\end{array}$ & $\begin{array}{c}\text { Biological } \\
\text { Processes/Functions }\end{array}$ & $\begin{array}{l}\text { nsSNPs } \\
\text { (B6 vs. } \\
\text { D2) }\end{array}$ & $\begin{array}{l}\text { InDels } \\
\text { in } \\
\text { BXD } \\
\text { Mice }\end{array}$ & $\begin{array}{l}\text { Cis- } \\
\text { Regulated } \\
\text { in Lung }\end{array}$ & $\begin{array}{l}\text { QTL } \\
\text { Miner } \\
\text { Score } \\
(1-4)\end{array}$ \\
\hline \multicolumn{8}{|c|}{ Chromosome 5} \\
\hline Art3 & 92.76 & $\begin{array}{l}\text { ADP- } \\
\text { ribosyltransferas } \\
\text { e } 3\end{array}$ & $\begin{array}{l}\text { protein amino acid } \\
\text { ADP-ribosylation }\end{array}$ & 103 & 10 & Yes & 4 \\
\hline Ankrd17 & 90.66 & $\begin{array}{l}\text { ankyrin repeat } \\
\text { domain } 17\end{array}$ & $\begin{array}{l}\text { endoderm } \\
\text { development }\end{array}$ & 20 & 11 & Yes & 4 \\
\hline $\mathrm{G} 3 B p 2$ & 92.48 & $\begin{array}{l}\text { GTPase } \\
\text { activating } \\
\text { protein (SH3 } \\
\text { domain) binding } \\
\text { protein 2 }\end{array}$ & $\begin{array}{l}\text { transport, small } \\
\text { GTPase mediated } \\
\text { signal transduction, } \\
\text { mRNA transport }\end{array}$ & 8 & 1 & Yes & 4 \\
\hline Asahl & 92.69 & $\begin{array}{l}\mathrm{N}- \\
\text { acylsphingosine } \\
\text { amidohydrolase } \\
\text { (acid } \\
\text { ceramidase)-like }\end{array}$ & $\begin{array}{l}\text { lipid metabolic } \\
\text { processes }\end{array}$ & 54 & 4 & Yes & 4 \\
\hline Anxa3 & 97.22 & annexin A3 & $\begin{array}{l}\text { positive regulation of } \\
\text { DNA metabolic } \\
\text { processes }\end{array}$ & 7 & 8 & Yes & 4 \\
\hline Bmp2k & 97.43 & $\begin{array}{l}\text { BMP-2- } \\
\text { inducible kinase }\end{array}$ & $\begin{array}{l}\text { protein amino acid } \\
\text { phosphorylation, } \\
\text { regulation of bone } \\
\text { mineralization }\end{array}$ & 6 & 6 & Yes & 4 \\
\hline Cxc19 & 92.75 & $\begin{array}{l}\text { chemokine (C- } \\
\mathrm{X}-\mathrm{C} \text { motif) } \\
\text { ligand } 9\end{array}$ & $\begin{array}{l}\text { inflammatory } \\
\text { responses, immune } \\
\text { responses, cytokine- } \\
\text { cytokine receptor } \\
\text { interaction, } \\
\text { chemokine signaling } \\
\text { pathway, toll-like } \\
\text { receptor signaling } \\
\text { pathway }\end{array}$ & 27 & 4 & Yes & 3 \\
\hline Areg & 91.57 & amphiregulin & $\begin{array}{l}\text { epidermal growth } \\
\text { factor receptor } \\
\text { signaling pathway, } \\
\text { positive regulation of } \\
\text { cell proliferation, } \\
\text { glial cell } \\
\text { proliferation, neuron } \\
\text { projection } \\
\text { development, } \\
\text { positive regulation of } \\
\text { phosphorylation, } \\
\text { negative regulation of } \\
\text { osteoblast } \\
\text { differentiation, } \\
\text { response to glucose, } \\
\text { ErbB signaling } \\
\text { pathway }\end{array}$ & 6 & 0 & Yes & 3 \\
\hline
\end{tabular}


Table 4-1. (Continued).

\begin{tabular}{|c|c|c|c|c|c|c|c|}
\hline $\begin{array}{c}\text { Gene } \\
\text { Symbol }\end{array}$ & Mb & $\begin{array}{c}\text { Gene } \\
\text { Designation }\end{array}$ & $\begin{array}{c}\text { Biological } \\
\text { Processes/Functions }\end{array}$ & $\begin{array}{l}\text { nsSNPs } \\
\text { (B6 vs. } \\
\text { D2) }\end{array}$ & $\begin{array}{l}\text { InDels } \\
\text { in } \\
\text { BXD } \\
\text { Mice } \\
\end{array}$ & $\begin{array}{c}\text { Cis- } \\
\text { Regulated } \\
\text { in Lung }\end{array}$ & $\begin{array}{l}\text { QTL } \\
\text { Miner } \\
\text { Score } \\
(1-4) \\
\end{array}$ \\
\hline Cox 18 & 90.64 & $\begin{array}{l}\text { Cox18 } \\
\text { cytochrome c } \\
\text { oxidase } \\
\text { assembly } \\
\text { homolog }\end{array}$ & $\begin{array}{l}\text { protein insertion into } \\
\text { membrane }\end{array}$ & 15 & 0 & Yes & 3 \\
\hline \multicolumn{8}{|c|}{ Chromosome 7} \\
\hline Ube3a & 66.48 & $\begin{array}{l}\text { ubiquitin protein } \\
\text { ligase } \mathrm{E} 3 \mathrm{~A}\end{array}$ & $\begin{array}{l}\text { protein modification } \\
\text { processes, protein } \\
\text { ubiquitination, } \\
\text { positive regulation of } \\
\text { transcription from } \\
\text { RNA polymerase II } \\
\text { promoter, prostate } \\
\text { gland growth, } \\
\text { ubiquitin-dependent } \\
\text { protein catabolic } \\
\text { processes, positive } \\
\text { regulation of } \\
\text { phosphoinositide 3- } \\
\text { kinase cascade, } \\
\text { sperm ent, Ubiquitin } \\
\text { mediated proteolysis }\end{array}$ & 9 & 13 & Yes & 4 \\
\hline Atp10a & 65.91 & $\begin{array}{l}\text { ATPase, class } \\
\text { V, type } 10 \mathrm{~A}\end{array}$ & $\begin{array}{l}\text { phospholipid } \\
\text { transport, metabolic } \\
\text { processes, ATP } \\
\text { biosynthetic } \\
\text { processes }\end{array}$ & 11 & 15 & Yes & 4 \\
\hline Tubgcp5 & 63.05 & $\begin{array}{l}\text { tubulin, gamma } \\
\text { complex } \\
\text { associated } \\
\text { protein } 5\end{array}$ & $\begin{array}{l}\text { microtubule } \\
\text { cytoskeleton } \\
\text { organization }\end{array}$ & 13 & 8 & Yes & 4 \\
\hline Nipa1 & 63.23 & $\begin{array}{l}\text { non imprinted in } \\
\text { Prader- } \\
\text { Willi/Angelman } \\
\text { syndrome } 1 \\
\text { homolog }\end{array}$ & $\begin{array}{l}\text { transport, ion } \\
\text { transport, magnesium } \\
\text { ion transport }\end{array}$ & 3 & 2 & Yes & 4 \\
\hline Nav2 & 56.21 & $\begin{array}{l}\text { neuron } \\
\text { navigator } 2\end{array}$ & $\begin{array}{l}\text { neuronal } \\
\text { development, neurite } \\
\text { outgrowth }\end{array}$ & 56 & 59 & Yes & 4 \\
\hline
\end{tabular}


involved in processes such as immune response, defense response, regulation of apoptosis, and inflammatory response (Table A-2). The majority of the upregulated genes in the susceptible strains were involved in processes such as vesicle-mediated transport, membrane organization, defense response, and endocytosis (Table A-3).

\section{DISCUSSION}

It has been known for some time that distinct inbred strains of mice display a range of susceptibility to $B p$ infection. In this study, we employed a panel of recombinant inbred BXD genotypes to identify regions of the murine genome that are responsible for variable susceptibility to this bacterial pathogen. Since our trait is more than likely genetically controlled, we performed genome wide linkage analysis using survival and time-to-death following pneumonic infection with $B p 1026 \mathrm{~b}$ to identify host genes involved in the differential progression of melioidosis. We identified two significant QTLs, one on chromosome 5 and the other on chromosome 7 that appear to be involved in the variability of susceptibility to pneumonic $B p$ infection. We utilized the in silico tools in GeneNetwork and global transcription data to identify candidate genes within each of these QTL intervals that are most likely to play a role in the outcome of $B p$ infection.

Most of the high-priority candidate genes identified (using QTLminer) within the QTL on chromosome 5 appear to have a role in immunological processes. For instance, the cox 18 gene encodes a mitochondrial inner membrane protein that is involved with cytochrome $\mathrm{C}$ assembly. It is known that a mutation of Cox 18 results in deficient cytochrome $\mathrm{C}$ oxidase activity that, in turn, eliminates activation of cell surface receptors involved in apoptosis [149], a process that is essential for limiting replication of some intracellular bacterial pathogens $[109,150]$. Another candidate gene in the interval, $G 3 B p 2$, encodes GTPase activating protein-binding protein 2 . This protein is known to

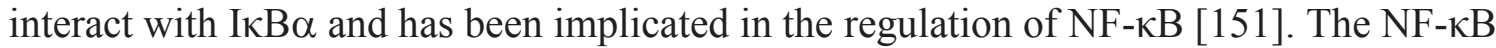
family of transcription factors is a group of evolutionarily conserved proteins involved in lymphoid organogenesis, development of immune cells [152] and the coordination of many aspects of innate and adaptive immunity to infection. Cxcl9 encodes a chemokine whose function(s) have not been clearly defined, but are likely to be important for T cell trafficking [153]. Art3 is one of five genes that encode a family of arginine-specific ADPribosyltransferases, or ARTs. Arts 1 and 2 are known to play a role in the function of immune lymphocytes $[154,155]$. ADP-ribosyltransferase activity has also been detected on the surface of both human neutrophils [156] and monocytes [157] and the activity of these enzymes is elevated in response to LPS treatment. Ankrd17 encodes a protein (ankyrin repeat protein 17) that participates in innate immunity by interacting with several intracellular molecules (RIG-I, MDA5, and VISA) that have a role in sensing the presence of diverse viral RNAs, resulting in positive regulation of RIG-I-like receptormediated immune signaling [158]. Anxa 3 encodes a protein that is known to have a role in bacterial phagocytosis [159], and as such is implicated as a component of the innate immune response. Asahl encodes an $\mathrm{N}$-acylsphingosine amidohydrolase that catalyzes the synthesis and degradation of ceramide into sphingosine and fatty acid. Mutations in this 
gene have been associated with a lysosomal storage disorder known as Farber's disease [160]. This enzyme is involved in apoptosis pathways as well, but it is unclear whether it is directly involved in innate immunity. Amphiregulin (Areg) is a member of the epidermal growth factor family and has an important role in the immune response to nematode infection [161]. Finally, Bmp2k (the gene that encodes BMP-2-inducible kinase) is also found within this QTL. Bone morphogenic proteins (BMPs) have no known role in immune responses, but they are known to play a key role in skeletal development and patterning [162] and have been implicated in lung development, and adult lung homeostasis [163].

Only one of the candidate genes with the highest correlation indices within the QTL on chromosome 7 (Ube3a, Tubgcp5, Nipa1, and Nav2) have an obvious role in host innate immune responses. Ube3a encodes E3 ubiquitin-protein ligase, part of the ubiquitin protein degradation system [164]. Although this process is critical for antigen presentation to $\mathrm{T}$ cells, it likely has no role in innate immune responses. Tubgcp 5 encodes a protein (gamma complex-associated protein 5) that has essential roles in mitotic spindle formation $[165,166]$ and microtubule nucleation and organization [165, 167]. Nipal encodes a protein that plays a role in nervous system development and maintenance [168], and may function as a receptor or magnesium transporter [169], and Nav2 encodes neuron navigator 2, a protein involved in neuronal development, but that likely has no direct role in innate immunity. However, Atp10a encodes a P-type cation transport ATPase that could have an important role in disease susceptibility. In a recent transcriptomic study designed to identify genetic markers that can differentiate between individuals that experience either acute vs. latent Mycobacterium tuberculosis (MTB), Atp 10a was one of three genes (along with Cxcl10 and TlrO) whose expression levels were discriminatory. It remains to be determined whether Atp $10 a$ expression/functionality is responsible for variable susceptibility to MTB.

We went further and cross-referenced candidate genes generated from QTLminer with our RNA-Seq expression data. We checked for genes that fell within our suggestive and/or significant QTL regions for our weight loss (chromosome 4, 7-11 mb, chromosome 2, 179.25-180 mb, and chromosome 17, 9.5-11.5 mb) and survival (chromosome 5, 85-98 $\mathrm{mb}$ and chromosome 7, 56- $67 \mathrm{mb}$ ). This analysis found a few compelling genes that fell within two of our QTL intervals (chromosomes 5 and 7). Genes that were significantly upregulated in the resistant strains include the closely related interferon-gamma inducible genes, $\mathrm{Cxcl9}$, $\mathrm{Cxcl10}$, and $\mathrm{Cxcl11}$, that encode the chemokine (C-X-C motif) ligands 9, 10, and 11, respectively; and $N d n$, which encodes the protein necdin. These genes exhibited a $B p$-infection state fold change of 10, 9, 24, and 4, respectively. Specifically, in humans, $\mathrm{Cxcl9}$, $\mathrm{Cxcl10}$ and $\mathrm{Cxcl11}$ are inflammatory chemokines that mediate the recruitment of T cells, natural killer cells and monocytes/macrophages at the site of infection [170]. These chemokines exert their effects through their cognate G-protein coupled receptor, CXCR3 [170, 171]. Ndn is located in the Prader-Willi Syndrome deletion region and encodes a growth suppressor (necdin) that facilitates the entry of the cell into cell cycle arrest and inhibits cell growth [172]. Furthermore, necdin has been called a multi-functional protein with a potential role in tumor suppression [173]. 
Next, we organized these candidate genes into cis eQTLs and trans eQTLs based on the genomic location of the gene of origin. Cis eQTLs map to the same genomic location as the expressed gene [174] and therefore exerts a direct effect on its function. Conversely, trans eQTLs also known as distant eQTLs, map far away from the location of the expressed gene and therefore has a secondary effect on the trait [77]. Cxcl9, Cxcl11 and $N d n$ are all cis eQTLs and are high priority genes for future validation studies to completely examine their role in the resistance and/or susceptibility to $B p$ infection.

We performed this same cross-reference analysis with genes that were significantly upregulated in the susceptible strains and fell within all of our suggestive and/or significant QTL regions. Similar to the previous analysis, this approach did not identify any genes within the weight loss QTL intervals. However, there were five candidate genes found within our survival QTLs (on chromosomes 5 and 7) when crossreferenced with our expression data. They include, Fam47e (family with sequence similarity 47), whose function has yet to be confirmed, but some reports describe it as having transcription cofactor activity [175]. $\operatorname{Prdm} 8$ (protein domain containing 8) which may play a role in chromatin binding, cell morphology and cytoskeletal organization [176]. Chrna 7 encodes the neuronal acetylcholine receptor subunit alpha-7, a cholinergic receptor that mediates fast signal transmission at synapses and is a member of a superfamily of ligand-gated ion channels [177]. Interestingly, this gene is located in a major susceptibility locus for juvenile myoclonic epilepsy [178] and is near a chromosomal location involved in the genetic transmission of schizophrenia [179]. Other genes include, Snrpal, which encodes the small nuclear ribonuclearprotein polypeptide that function in mRNA processing by binding to RNA and cell cycle regulators [180]. Finally, $\operatorname{Tm} 2 d 3$ encodes TM2 domain containing 3, which may have functional roles in cell death or cell proliferation signalling cascades [181]. Chrna7 is the only cis eQTL from this group of candidate genes identified from our expression data. Infection state differences of these genes ranged from two- to sevenfold in the susceptible mice. In sum, only $\sim 5 \%$ of differentially expressed genes from our expression profiling data reside within our survival/weight loss QTL regions. This observation calls into question the role of the remaining differentially expressed genes corresponding to survival of $B p$ infection. These genes may have a contributing role to survival during a $B p$ infection, although this point is merely speculation. It would be interesting to evaluate whether we observe alternate gene expression changes in various tissues and at different times points, which may help in understanding some of the relationships in gene expression patterns during a $B p$ infection. 


\section{CHAPTER 5. EFFICIENT INACTIVATION OF BURKHOLDERIA PSEUDOMALLEI OR FRANCISELLA TULARENSIS IN INFECTED CELLS FOR SAFE REMOVAL FROM BIOSAFETY LEVEL 3 CONTAINMENT LABORATORIES*}

\section{CHAPTER SUMMARY}

Working with infectious agents that require BSL-3 level containment offers many challenges for researchers. BSL-3 containment laboratories are usually not equipped with expensive specialty equipment that is needed for studies such as flow cytometric analysis, microscopy, and proteomic analyses. Therefore, for most researchers that are working with BSL-3 level infectious agents, removal of samples from BSL-3 labs for these types of studies is necessary, and methods for complete and dependable inactivation of the samples are required. In this report, we carried out a thorough characterization of the effectiveness of paraformaldehyde fixation for inactivation of cell samples infected with the intracellular bacterial agents Burkholderia pseudomallei (Bp) and Francisella tularensis $(F t)$, both of which are Tier 1 select agent pathogens that require BSL-3 containment. We have demonstrated that cells infected with these pathogens are completely inactivated via 5-minute treatment with $4 \%$ paraformaldehyde. Moreover, a 15-minute treatment with $2 \%$ paraformaldehyde completely sterilized both $\mathrm{Bp}$ - and $\mathrm{Ft}$ infected cells. These studies also revealed that $B p$ is significantly more sensitive to paraformaldehyde treatment than Ft. Our findings have clearly demonstrated that a 15minute treatment of $\mathrm{Bp}$ - or $\mathrm{Ft}$-infected cells with $4 \%$ paraformaldehyde solution will allow for safe removal of the cell samples from BSL-3 labs for downstream studies.

\section{INTRODUCTION}

Flow cytometry has become an integral tool for the evaluation of immune responses to various cells during an infection with viral or bacterial agents. Due to the expense of this type of equipment and the technical expertise required for proper operation, flow cytometers/cell sorters are typically found in shared core facilities that employ dedicated operators for analysis of a variety of sample types. This creates many challenges for researchers working with agents requiring biosafety level 3 (BSL-3) containment, since most core flow cytometry facilities are located in laboratories with biosafety level 2 (BSL-2) containment capabilities. Additional factors such as biosecurity play a role when the agents in use are considered select agents, and these security procedures must be maintained until the samples are rendered noninfectious.

\footnotetext{
*Reprinted with permission. Emery, F.D., J.M. Stabenow, and M.A. Miller, Efficient inactivation of Burkholderia pseudomallei or Francisella tularensis in infected cells for safe removal from biosafety level 3 containment laboratories. Pathogens and disease, 2014. 71(2): p. 276-81.
} 
Removal of BSL-3 agents to a lower containment level laboratory requires inactivation of the pathogen to allow for safe manipulation of the sample, and to ensure that biosafety considerations are met for personnel working with these samples [182]. This is of particular concern when dealing with BSL-3 select agents destined for flow cytometric analysis, where the potential for generation of aerosols exists. While biosafety standards have been well described for work with unfixed cells for cell sorting procedures, little guidance can be found for effective inactivation procedures for potentially infectious flow cytometry samples [183, 184]. Previous studies have shown that samples containing high titers of known viruses were resistant to standard inactivation procedures $[185,186]$. These findings have been cited by the International Society for Analytical Cytology (ISAC), which cautions that fixation procedures must be carefully performed to ensure complete inactivation of any potential infectious agents to reduce the health risk to laboratory personnel $[187,188]$. The ISAC also recommends that if samples are fixed, "appropriate methods must be selected to reliably inactivate potentially biohazardous agents," yet no specific methods are recommended [187].

Most fixation procedures for flow cytometry include the use of paraformaldehyde (PFA) solutions at concentrations varying from 1-4\%. Commercially available fixation buffers are typically comprised of a neutral $\mathrm{pH}$-buffered saline solution with $4 \%(\mathrm{w} / \mathrm{v})$ PFA. These methods have been shown to provide effective fixation of lymphoid cells, following immunofluorescent staining of surface markers or intracellular cytokines, that is compatible with flow cytometric analysis (BD Technical Data Sheet, BD Cytofix ${ }^{\mathrm{TM}}$ ). However, the ability of these compounds to provide for inactivation of potentially infectious microorganisms has been focused primarily on clinical samples with low levels of organisms present, and the incubation time for complete inactivation of potentially infectious agents has not been established. Here we evaluate the PFA concentration and incubation time required to completely inactivate Francisella tularensis and Burkholderia pseudomallei within infected cells. Both of these agents are classified as Tier 1 select agents and require BSL-3 containment. We have validated the inactivation kinetics required to demonstrate complete inactivation of these bacteria to allow for removal of samples from a BSL-3 laboratory for flow cytometric analysis using BSL-2 containment practices.

\section{MATERIALS AND METHODS}

\section{Collection and Differentiation of Murine Bone Marrow Cells}

Bone marrow cells were obtained aseptically from femurs and tibias of 9-12 week old C57BL/6J mice using previously described methods [189] and cryogenically stored at $-80^{\circ} \mathrm{C}$ in freezing medium (DMEM [ScienceCell, Carlsbad, Ca.] with 50\% FCS [Sigma Chemical Co., St. Louis, MO] and 10\% DMSO [Sigma Chemical Co., St. Louis, MO]). Frozen bone marrow cells were thawed and differentiated into BMDMs using culture conditions that were established previously [190]. Briefly, after thawing cells were pelleted via centrifugation ( $200 \mathrm{x}$ g for 5 minutes at $\mathrm{RT}^{\circ}$ ), resuspended in $10 \mathrm{~mL}$ bone 
marrow differentiation media (D20/30: DMEM supplemented with 20\% FBS, 30\% L-929 conditioned medium [LCCM], penicillin/streptomycin $[100 \mathrm{U} / \mathrm{mL}$ and $100 \mathrm{mg} / \mathrm{mL}$, respectively, Cellgro, Manassas, VA], 2mM L-glutamine [Cellgro, Manassas, VA] and $50 \mathrm{mg} / \mathrm{mL}$ gentamycin [Sigma, St. Louis, MO]), and seeded in 100-mm-diameter tissue culture dishes (BD Biosciences, San Jose, CA). The cultures were incubated at $37^{\circ} \mathrm{C}$ in a $5 \% \mathrm{CO}_{2}$ atmosphere for four days and then $10 \mathrm{~mL}$ of fresh $\mathrm{D} 20 / 30$ was added and incubated for an additional 3 days to allow cells to adhere to the petri dish. To harvest the BMDM, culture media was removed via aspiration and $10 \mathrm{~mL}$ of cold $0.53 \mathrm{mM}$ EDTA/PBS was added to the plate and incubated at $37^{\circ} \mathrm{C}$ for 15 minutes. The BMDM were detached by gently pipetting the PBS across the dish several times. The BMDM cell suspension was pelleted via centrifugation $\left(200 \mathrm{x}\right.$ g for 5 minutes at $\left.\mathrm{RT}^{\circ}\right)$ then resuspended in BMDM cultivation media (D10/5: DMEM supplemented with 10\% FBS, 5\% LCCM, 2mM L-glutamine). The cells were then counted using a Scepter 2.0 Handheld Automated Cell Counter (EMD Millipore, Billerica, MA).

\section{Bacteria}

Burkholderia pseudomallei, strain 1026b (Bp) was obtained from Biodefense and Emerging Infections Research Resources Repository (BEI Resources, Manassas, VA) and Francisella tularensis tularensis, Schu S4 strain $(F t)$ was obtained from the Centers for Disease Control and Prevention (CDC, Atlanta, GA). Overnight cultures of both bacterial agents were prepared and used to inoculate fresh media. Once the bacteria reached log-phase growth, they were pelleted by centrifugation, resuspended in the appropriate media (see below) supplemented with $20 \%$ glycerol, aliquoted (approximately $100 \mu \mathrm{l} /$ tube), and stored cryogenically at $-80^{\circ} \mathrm{C}$. $B p$ was cultured in unmodified LB broth and $F t$ was cultured in modified Mueller Hinton broth (MMH broth supplemented with $10 \mathrm{~g} / \mathrm{L}$ tryptone, $0.1 \%$ glucose, $0.025 \%$ ferrous pyrophosphate, $0.1 \%$ L-cysteine, and $2.5 \%$ calf serum). Enumeration of these frozen stocks was performed by dilution plating as described below. All work with these two bacterial agents was performed under BSL-3 containment using standard operating procedures that were reviewed and approved by the University of Tennessee Health Science Center (UTHSC) Institutional Biosafety Committee (IBC). All BSL-3 laboratories in the RBL are registered with the select agent Program and all of the work with the select agents was done in a Centers for Disease Control (CDC)-approved facility (UTHSC Regional Biocontainment Laboratory, CDC Registration Number: C20010616-1230).

\section{Infection of Cells with $\mathrm{Bp}$ or $\mathrm{Ft}$}

BMDM were seeded into a 150-mm-diameter non-tissue culture dishes (Sarstedt, Newton, NC) at a density of approximately $5 \times 10 \mathrm{e} 7$ cells per plate and the bacteria (thawed from frozen stocks and diluted) were added to each plate at an MOI of 100. Cell cultures were allowed to incubate for approximately 12-15 hours after infection. After the incubation period, the media was carefully aspirated from the cell monolayers and $10 \mathrm{~mL}$ of $0.53 \mathrm{mM}$ EDTA $/ \mathrm{PBS}$ was added to each petri dish and allowed to incubate at $37^{\circ} \mathrm{C}$ for 
15 minutes. The macrophages were then detached by gently pipetting across the dish several times. The infected cells were pelleted via centrifugation (200x g for 5 min @ $\mathrm{RT}^{\circ}$ ), washed twice with DMEM-20 (DMEM supplemented with 20\% FBS), and then washed in culture medium containing kanamycin to kill remaining extracellular bacteria. Cells were washed two additional times with PBS. The cells were then resuspended in 10 $\mathrm{mL}$ BD-Staining Buffer and then the cells were enumerated using a Scepter Handheld Automated Cell Counter.

\section{Fixation of Infected Cells}

$B p$ - or $F t$-infected cells were distributed into Eppendorf ${ }^{\text {B }}$ tubes at approximately $1 \mathrm{X} 10^{6}$ cells/tube. The cells were pelleted via centrifugation $\left(300 \mathrm{x} \mathrm{g}\right.$ at $4^{\circ} \mathrm{C}$ for $\left.5 \mathrm{~min}\right)$ and then supernatant was aspirated. Cells were then treated with $250 \mu 1$ BD-Cytofix Fixation Buffer (Cytofix, BD Biosciences, cat.no. 554655, San Jose, CA) in undiluted form (4.21\% PFA solution), diluted 1:2 (2.1\% PFA solution), diluted 1:4 (1\% PFA solution), or diluted 1:8 (0.5\% PFA solution) and incubated for the indicated periods of time. Dilutions of Cytofix were performed using BD Pharmingen Stain Buffer (Stain Buffer, BD Biosciences, cat.no. 554655, San Jose, CA). Following the fixation incubation period, the total volume of each sample was increased to $1 \mathrm{ml}$ by addition of Stain Buffer, the cells were pelleted via centrifugation ( $200 \mathrm{xg}$ for $5 \mathrm{~min}$ at $\mathrm{RT}^{\circ}$ ), supernatant was aspirated, and the cells were resuspended in $1 \mathrm{ml}$ of Stain Buffer.

\section{Enumeration of Bacteria}

At each of the indicated time points following Cytofix treatment, suspensions of $B p$ - or $F t$-infected cells that had been treated with Cytofix were subjected to dilution plating, as previously described [108, 109], to enumerate the remaining viable $B p$ or $F t$ in the sample. Briefly, the cell suspensions were plated in duplicate $(100 \mu \mathrm{l}$ of the fixed cell preparation per plate) on either LB agar (Bp) or BHI agar $(F t)$ plates using an Eddy Jet spiral plater (Neutec Group, Inc., Farmingdale, NY). Plates were incubated at $37^{\circ} \mathrm{C}$ in a static incubator for 24-48 hours and then colonies were counted using a Flash \& Go automated colony counter (Neutec Group, Inc., Farmingdale, NY) to determine the bacterial burdens $(\mathrm{CFU} / \mathrm{mL})$.

\section{RESULTS}

To evaluate the ability of PFA to kill the intracellular bacterial pathogens Burkholderia pseudomallei (Bp) strain 1026b and Francisella tularensis tularensis (Ft) strain Schu S4 during fixation of infected cells, we performed time course studies in which infected murine macrophages were treated with a range of concentrations of paraformaldehyde solution (0.5-4\%). Murine BMDMs were infected with each of the pathogens at an MOI of 100 and cultured for 12-15 hrs to allow bacterial replication in infected cells. After the cells were harvested, washed and enumerated, they were 
distributed into O-ringed centrifuge tubes $\left(5 \times 10^{5}\right.$ cells/tube $)$ and pelleted via centrifugation, supernatant aspirated away, and then the cells were resuspended in PFA solution $(0.5,1.0,2.1$, or $4.21 \%)$. Dilution plating was performed at each treatment time point $(1,5,10,15,30$, and 45 minutes as well as $1,4,8$, and $24 \mathrm{hrs})$ to determine how many viable bacteria remained in each fixed cell sample (Table 5-1 and Table 5-2). A 5minute treatment with BD-Cytofix (4.21\% paraformaldehyde) killed all $B p$

(Figure 5-1A) and $\mathrm{Ft}$ (Figure 5-1B), while 2.1\% PFA treatment required 15 minutes to completely sterilize the infected cell samples. Treatment with $1 \%$ or $0.5 \%$

paraformaldehyde failed to completely sterilize infected cell samples even after a 24-hour treatment period (Figure 5-1, Table 5-1 and Table 5-2).

Because the lower detection limit of the dilution plating method is approximately $20 \mathrm{CFU}$, we performed parallel experiments in which PFA-treated samples of infected cells were added to $10 \mathrm{~mL}$ of broth culture medium (LB broth for $B p$-infected cell cultures and $\mathrm{MH}$ broth for $F t$-infected cells) and incubated at $37^{\circ} \mathrm{C}$ for 72 hours in a shaking incubator. Optical density readings (OD@600nm) taken prior to and following incubation to confirm that treatment for 5 minutes (or more) with 4\% PFA or for 15 minutes (or more) with $2 \%$ PFA completely sterilized samples of $B p$ - or $F t$-infected cells (data not shown).

Analysis of the data generated for the $1 \%$ and $2.1 \%$ paraformaldehyde treatment groups revealed that $B p$ is significantly more sensitive to paraformaldehyde treatment than Ft (Figure 5-2). Over the treatment time course, the burden of viable $B p$ following treatment with $1 \%$ and $2.1 \%$ paraformaldehyde solution was significantly lower than that of $F t(\mathrm{p}<0.0001$ and $\mathrm{p}<0.0039$, respectively). Moreover, although the reduction of viable $F t$ was slightly greater than that of $B p$ following 15 minute treatment with $0.5 \%$ paraformaldehyde, $B p$ was much more sensitive to treatment with higher concentrations of paraformaldehyde solution (Table 5-3 and Table 5-4). For instance, a 15-minute treatment with $1 \%$ paraformaldehyde resulted in a $6.6 \pm 1.72$-fold reduction of viable $B p$ numbers compared to only a $0.97 \pm 0.22$ fold reduction of viable Ft. A 10 -minute treatment with $2.1 \%$ paraformaldehyde resulted in a $260.6 \pm 149.8$-fold reduction of viable $B p$ but only a $4.57 \pm 0.69$-fold reduction of viable $F t$, while a 1-minute treatment with $4.21 \%$ paraformaldehyde solution resulted in a $1555 \pm 865.7$-fold reduction of viable $B p$ numbers but only a $35.2 \pm 5.01$-fold reduction of viable $F t$ numbers

(Table 5-3 and Table 5-4).

\section{DISCUSSION}

The BMBL clearly states that removal of research samples from BSL-3 containment for downstream studies (e.g. flow cytometric analysis, microscopy, proteomic analyses, etc.) at lower biosafety levels requires reliable standard operating procedures (SOPs) for complete infectious agent inactivation [191]. Although one could reasonably assume that standard fixation or other inactivation procedures involving various chemical agents would effectively inactivate most organisms, validation of the 
Table 5-1. Number of Burkholderia pseudomallei following paraformaldehyde fixation of infected cell samples (1st 15 minutes of timecourse).

\begin{tabular}{ccccc}
\hline Treatment & 1 Minute & 5 Minutes & 10 Minutes & 15 Minutes \\
\hline Untreated & $119,333 \pm 14,224$ & $113,333 \pm 5,686$ & $99,567 \pm 2,676$ & $94,700 \pm 985$ \\
$\mathbf{0 . 5 \%}$ PFA & $91,900 \pm 7,539$ & $84,800 \pm 200$ & $81,267 \pm 2,098$ & $79,233 \pm 3,355$ \\
$\mathbf{1 . 0 \%}$ PFA & $52,967 \pm 3,742$ & $37,967 \pm 4,438$ & $35,133 \pm 4,329$ & $12,900 \pm 2,946$ \\
$\mathbf{2 . 1 \%}$ PFA & $42,667 \pm 907$ & $12,230 \pm 8,128$ & $538 \pm 419$ & 0 \\
$\mathbf{4 . 2 \%}$ PFA & $89 \pm 33$ & 0 & 0 & 0 \\
\hline
\end{tabular}

PFA- paraformaldehyde

Table 5-2. Number of Francisella tularensis following paraformaldehyde fixation of infected cell samples (1st 15 minutes of timecourse).

\begin{tabular}{ccccc}
\hline Treatment & 1 Minute & 5 Minutes & 10 Minutes & 15 Minutes \\
\hline Untreated & $4,437 \pm 325$ & $4,290 \pm 251$ & $4,433 \pm 125$ & $4,517 \pm 278$ \\
$\mathbf{0 . 5} \%$ PFA & $4,290 \pm 251$ & $4,320 \pm 375$ & $3,663 \pm 134$ & $3,483 \pm 672$ \\
$\mathbf{1 . 0} \%$ PFA & $2,783 \pm 50$ & $1,940 \pm 251$ & $1,810 \pm 26$ & $1,753 \pm 57$ \\
$\mathbf{2 . 1 \%}$ PFA & $1,983 \pm 533$ & $1,427 \pm 93$ & $890 \pm 15$ & 0 \\
$\mathbf{4 . 2 \%}$ PFA & $141 \pm 32$ & 0 & 0 & 0 \\
\hline
\end{tabular}

PFA- paraformaldehyde 


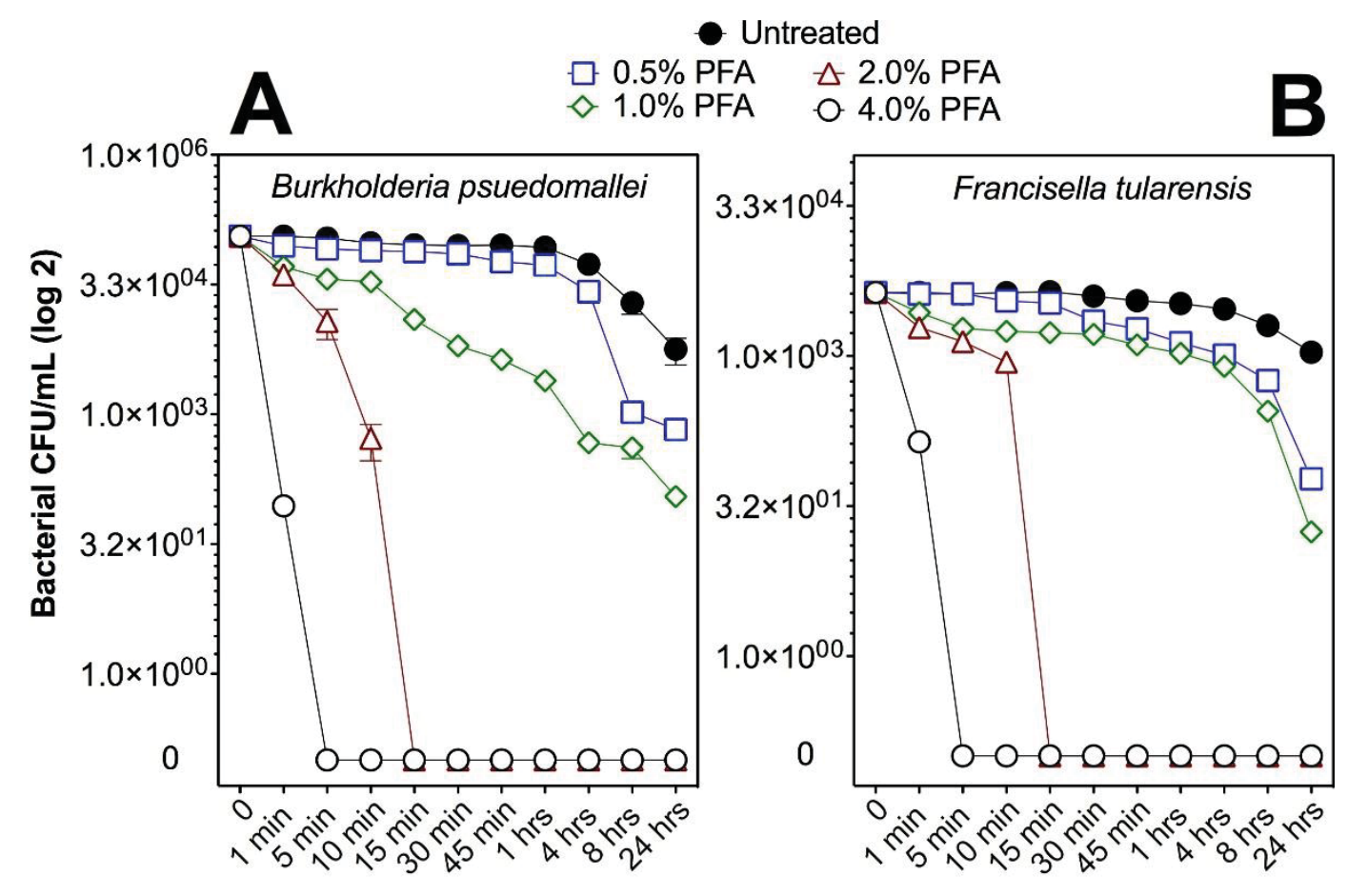

Treatment Time

Figure 5-1. Paraformaldehyde fixation conditions for killing of Burkholderia pseudomallei and Francisella tularensis Schu S4 in infected cell samples.

Murine BMDMs infected with (Panel A) Burkholderia pseudomallei 1026b or (Panel B) Francisella tularensis Schu S4 (5 x $10^{6}$ cells/sample) were treated with the indicated concentrations of paraformaldehyde for either 1, 5, 10, 15, 30, or $45 \mathrm{~min}$ and 1, 4, 8, and $24 \mathrm{hrs}$. At the end of the treatment period live bacteria were enumerated by dilution plating. All data points represent the mean \pm SEM of triplicate samples. Statistical analysis was performed using a 2-way ANOVA and revealed that each of the PFA treatments resulted in significant reduction of viable bacteria compared to untreated controls $(* * *$ indicates $\mathrm{p}<0.001)$. The results shown are representative of three separate experiments of similar design. 


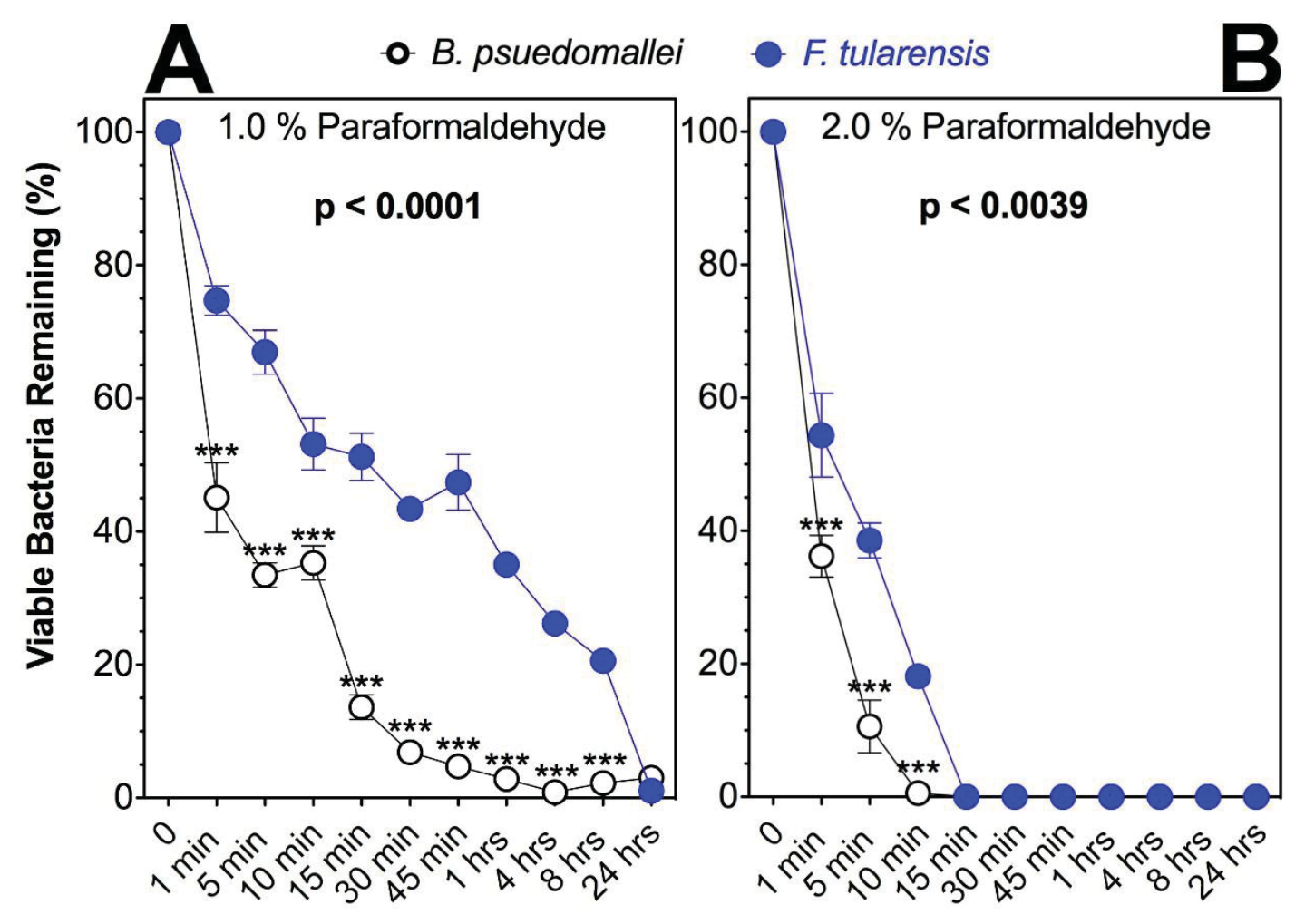

Treatment Time

Figure 5-2. Burkholderia psuedomallei is more sensitive than Francisella tularensis to paraformaldehyde treatment.

Murine BMDMs infected with either B. pseudomallei or F. tularensis were treated with the indicated concentrations of paraformaldehyde for either $1,5,10,15,30$, or $45 \mathrm{~min}$ and $1,4,8$, and $24 \mathrm{hrs}$ and then surviving bacteria were enumerated via dilution plating. Data points represent the percentage of the starting number of CFU (untreated control sample at that time point) that survived paraformaldehyde treatment and are presented as the mean \pm SEM of results with triplicate samples. Statistical analysis was performed using a 2-way ANOVA and the indicated p-values reflect differences attributable to the bacterium over the time course. Bonferroni posttests were also performed and significant differences at each time point are indicated $(* * *$ indicates $p<0.001)$. The results shown are representative of three separate experiments of similar design. 
Table 5-3. Fold reduction of viable Burkholderia pseudomallei following paraformaldehyde fixation of infected cell samples.

\begin{tabular}{ccccc}
\hline Treatment & 1 Minute & 5 Minutes & 10 Minutes & 15 Minutes \\
\hline 0.5\% PFA & $0.31 \pm 0.023$ & $0.34 \pm 0.07$ & $0.23 \pm 0.04$ & $0.20 \pm 0.06$ \\
$\mathbf{1 . 0} \%$ PFA & $1.27 \pm 0.41$ & $2.0 \pm 0.27$ & $1.87 \pm 0.39$ & $6.60 \pm 1.72$ \\
$\mathbf{2 . 1 \%}$ PFA & $1.80 \pm 0.39$ & $15.95 \pm 17.4$ & $260.6 \pm 149.8$ & - \\
$\mathbf{4 . 2 \%}$ PFA & $1555 \pm 865.7$ & - & - & - \\
\hline
\end{tabular}

PFA- paraformaldehyde

Table 5-4. Fold reduction of viable Francisella tularensis following paraformaldehyde fixation of infected cell samples.

\begin{tabular}{ccccc}
\hline Treatment & 1 Minute & 5 Minutes & 10 Minutes & 15 Minutes \\
\hline $\mathbf{0 . 5 \%}$ PFA & $0.04 \pm 0.08$ & $0.25 \pm 0.11$ & $0.35 \pm 0.05$ & $0.38 \pm 0.06$ \\
$\mathbf{1 . 0 \%}$ PFA & $0.34 \pm 0.07$ & $0.50 \pm 0.13$ & $0.9 \pm 0.24$ & $0.97 \pm 0.22$ \\
$\mathbf{2 . 1 \%}$ PFA & $0.89 \pm 0.37$ & $1.62 \pm 0.32$ & $4.57 \pm 0.69$ & - \\
$\mathbf{4 . 2 \%}$ PFA & $35.2 \pm 5.01$ & - & - & - \\
\hline
\end{tabular}

PFA- paraformaldehyde 
method is required with each infectious agent to satisfy these requirements. Moreover, the selected method for deactivation must also be compatible with the downstream analyses that will be performed on the inactivated sample. The use of published inactivation methods must also be validated for each laboratory to ensure that the procedures are followed correctly and complete inactivation can be achieved. The lack of standardized protocols, including the kinetics of the methods, is problematic to researchers working with BSL-3 agents and often requires development of methods that meet the inactivation requirement while maintaining the integrity of the sample matrix for subsequent analysis.

There are a variety of published studies that detail inactivation techniques for Francisella tularensis. A study by Clemens and associates described the use of 4\% PFA in PBS overnight as an effective treatment for inactivation of Ft [192]. A different group successfully utilized three different treatments $(2 \%$ PFA for $1 \mathrm{hr}$, heat-inactivation at $60^{\circ} \mathrm{C}$ for $16 \mathrm{hrs}$, or UV irradiation $\left[7,500 \mu \mathrm{J} / \mathrm{cm} 3\right.$ at RT $\left.{ }^{\circ}\right]$ ) to inactivate $F t$ [193]. Other published studies reported that $F t$ is susceptible to heat-inactivation [194, 195] or that inanimate surfaces contaminated with $F t$ can be sterilized by a combination of $10 \%$ bleach treatment followed by $70 \%$ ethanol [196]. However, in each of these reports the inactivation treatment was performed on bacteria alone, not on infected cells. Moreover, among these inactivation methods, only PFA treatment is compatible with any of the potential downstream analyses of infected cells. There is one published report that described inactivation of $F t$-infected cells using 3-8 \% PFA treatment for 30 minutes [197]. However, this paper does not contain any primary data related to the efficacy of PFA inactivation, but instead only cites guidance from a 2006 CDC website report that is no longer available.

There is also a paucity of published information relating to the inactivation of Burkholderia pseudomallei. One published study showed that $B p$ in liquid samples could be inactivated by treatment with a combination of $\mathrm{pH}$, heat, and salinity [198]. Another report revealed that $B p$ on environmental surfaces could be inactivated by treatment for 15 minutes with 6\% PFA [199]. O'Connell and colleagues have published studies designed to evaluate the effectiveness of chlorine-based disinfection (in water treatment systems) for inactivation of $B p$ [200]. One of the most interesting findings in this report related to the significant variability observed in the sensitivity of different $B p$ strains to chlorine-based disinfection. These findings reinforced the idea that inactivation methods should be validated for each infectious agent. We have been unable to find any published studies that define inactivation parameters for $B p$-infected cells that would be compatible with downstream flow cytometric analysis.

The findings provided in this report are the first that clearly establish a procedure that can be used to reliably and completely disinfect mammalian cells that have been infected with the BSL-3 agents $F t$ and Bp, allowing for their removal from BSL-3 containment for downstream flow cytometric analyses using BSL-2 practices. Paraformaldehyde treatment was chosen for the current studies because: (1) is the most commonly used fixation treatment for flow cytometry samples, (2) it is known to have negligible effects on fluorescence properties or forward scatter/side scatter characteristics 
of antibody labeled cells (Lal, et al., 1988), and (3) because there are commercial sourcesof paraformaldehyde solutions that are designed specifically for fixation of cells for flow cytometric analysis. Here we report that fixation for 5 minutes with a $4.21 \%$ PFA solution is capable of complete sterilization of cell suspensions that have been infected with either Ft or Bp. Moreover, a 15-minute treatment of Ft or Bp-infected cells with a $2.1 \%$ PFA solution results in complete inactivation of the sample. Our findings also indicated that treatment of either $F t$ - or $B p$-infected cells with concentrations of PFA that are lower than $2.1 \%(1 \%$ and $0.5 \%)$ is likely to result in incomplete disinfection of the samples. Based on these findings, we conclude that a 15 minute treatment of Ft- or $B p$-infected mammalian cells with $4.21 \%$ paraformaldehyde is an appropriate SOP for inactivation of these two infectious agents, allowing for removal of fixed cells samples from BSL-3 containment. Interestingly, we also found that $B p$ is significantly more sensitive than Ft to PFA treatment. Although this finding did not impact the establishment of the inactivation SOP, it did provide further evidence that infectious agents display a range of sensitivities to chemical inactivation, underscoring the need for independent testing and validation of inactivation SOPs for each agent. It is important to note that these studies were performed exclusively on single cell suspensions of $B p$ or $F t$ infected cells. It is likely that sterilization of $B p$ or $F t$-infected tissues (that have not been homogenized into single cell suspensions) would require longer exposure times than those described in this report. 


\section{CHAPTER 6. DISCUSSION AND CONCLUSIONS}

\section{DISCUSSION}

$B p$ is the cause of the frequently fatal infectious disease melioidosis. Little is known about the influence of specific genes or genetic backgrounds in humans that contribute to the susceptibility or resistance to $B p$ infections. Therefore, the identification of key host genetic factors that control resistance or susceptibility to $B p$ is of much importance. For these studies, we used a forward genetics approach to identify genomic regions influencing infection-state phenotypes seen during a $B p$ infection. The results from our studies demonstrate that the BXD RI strain panel and the GeneNetwork Database are powerful genetic resources for analyzing the differential susceptibility to a $B p$ infection. It has shown to be an efficient methodology which to examine infectious disease susceptibility genes in a host utilizing an expanded set of RI strains. To our knowledge, this study is the first report that uses a forward genetics approach to discover genes that underlie resistance and/or susceptibility to this pathogen.

Our data indicate that genetic regulation of survival, time-to-death and weight loss during a $B p$ infection is a complex phenomenon, whereby many genes exert their effects on these traits. We observed significant differences in survival, time-to-death and weight loss kinetics in the parental mice and across the different BXD strains following pneumonic infection with $B p 1026$ b. This observed variability was expected based on the genetic diversity of the parental mice and the BXD strain family. We hypothesize that the observed differences in weight loss kinetics and survival amongst these strains can be attributed to the genetic variation resulting in varying levels of qualitative and quantitative profiles of the host defense. Furthermore, our heritability analyses for these phenotypes indicate there is a major influence of genetic background to these traits.

Genome wide linkage analysis using these phenotypes identified several host loci associated with the observed differential response to $B p$, and it is apparent that these traits are likely controlled by several loci encompassing many genes. According to our linkage analysis, weight retention during a $B p$ infection is controlled by QTLs on chromosomes $2,4,12$, and 17 in a time-dependent manner. This indicates that host loci within these QTLs may be important for the host response in a transient and dynamic fashion during melioidosis. However, a principle component analysis for weight loss at all days supports a single chromosomal locus on chromosome 12 that accounts for $>70 \%$ of the total weight loss variability in the cohort. This means that loci identified on days 1 and 2 contribute $30 \%$ or less to the variation in weight loss kinetics indicating chromosome 12 is likely to be the single primary factor responsible for differential weight loss following $B p$ infection. Interestingly, a recently reported genome wide study of host response to H1N1 influenza infection also identified multiple QTLs (different from those identified here) that appear to control weight loss kinetics in a time-dependent fashion [73]. This study concluded that much of the initial weight loss was transient and associated with the stress of anesthesia prior to intranasal instillation. Meanwhile, our genome wide linkage analysis of survival (and time-to-death) generated two significant QTLs, one on 
chromosome 5 and the other on chromosome 7 . It is worth noting that the lack of overlap in loci contributing to survival compared to weight loss kinetics suggested that the weight loss and survival traits are independently controlled. A network diagram generated using the Network graphing feature of GeneNetwork confirmed that there was little correlation between weight loss kinetics and either the survival or time-to-death phenotypes (Figure 6-1).

The in silico tools in GeneNetwork allowed us to identify candidate genes within the six previously identified QTL intervals that may be casual for resistance or susceptibility to a $B p$ infection. In total, there are 335 positional candidate genes located within these intervals. We were able to narrow down the total number of genes using QTLminer to 46 high scoring (score of 3 or 4) candidates using additional information such as normal gene expression levels in target organs, cis-regulation of the gene in the lung and number of nonsynonymous SNPs or indels between the parental B6 and D2 genotypes. High scoring candidate genes within these intervals are involved in a wide range of pathways that could be important for mounting an effective immune response including, calcium homeostasis, cell stress responses, protein degradation and recycling, extracellular matrix and actin reorganization, apoptosis, bacterial phagocytosis, immune cell recruitment, tissue repair, lung homeostasis, cell cycle regulation and nervous system development.

It has been suggested that variation in gene expression is an important contributor to the genetic architecture of complex traits [148]. To get a glimpse into the infectionstate gene regulation that may contribute to increased or decreased survival during a $B p$ infection, we performed host transcriptomic profiling using RNA-seq on the lung tissue of a small cohort of resistant (BXD -50, -70) and susceptible (BXD -09, -63, -70) BXD strains infected with $B p 1026 \mathrm{~b}$ for 24 hours. This analysis revealed a very large number of host genes that were upregulated in the resistant or susceptible strains during a $B p$ infection. A gene ontology analysis provided insight into the common themes and biological significance of this large pool of data. Analysis outputs consistently demonstrated that the early host response in resistant strains, enriched for genes involved in the immediate immune responses, which include response to IFN-gamma, leukocyte activation, response to cytokine, and induction of apoptosis. The molecular function of the majority of genes upregulated in the resistant strains were involved in binding, which included antigen binding, chemokine receptor binding, and $\mathrm{MHC}$ class 1 and $1 \mathrm{~b}$ protein binding. This cluster of genes significantly upregulated in the resistant strains represent a group of genes designated as "common host immune response", and might signify a general "alarm signal" for inflammatory infections [201]. Based on the function of genes upregulated in the resistant strains we can infer that these genes allow activation of defense programs and control of intracellular bacterial replication. Meanwhile, the early host response in the susceptible strains enriched for genes involved in a variety of processes including vesicle-mediated transport, membrane organization, defense response and phagocytosis. Interestingly, there were genes also upregulated in the susceptible strains 24 hours post-infection that function in a response to hypoxia, which could be associated with the stress of anesthesia prior to intranasal installation. In fact, the timing of this transcript increase also correlates to the appearance of the transient weight loss 


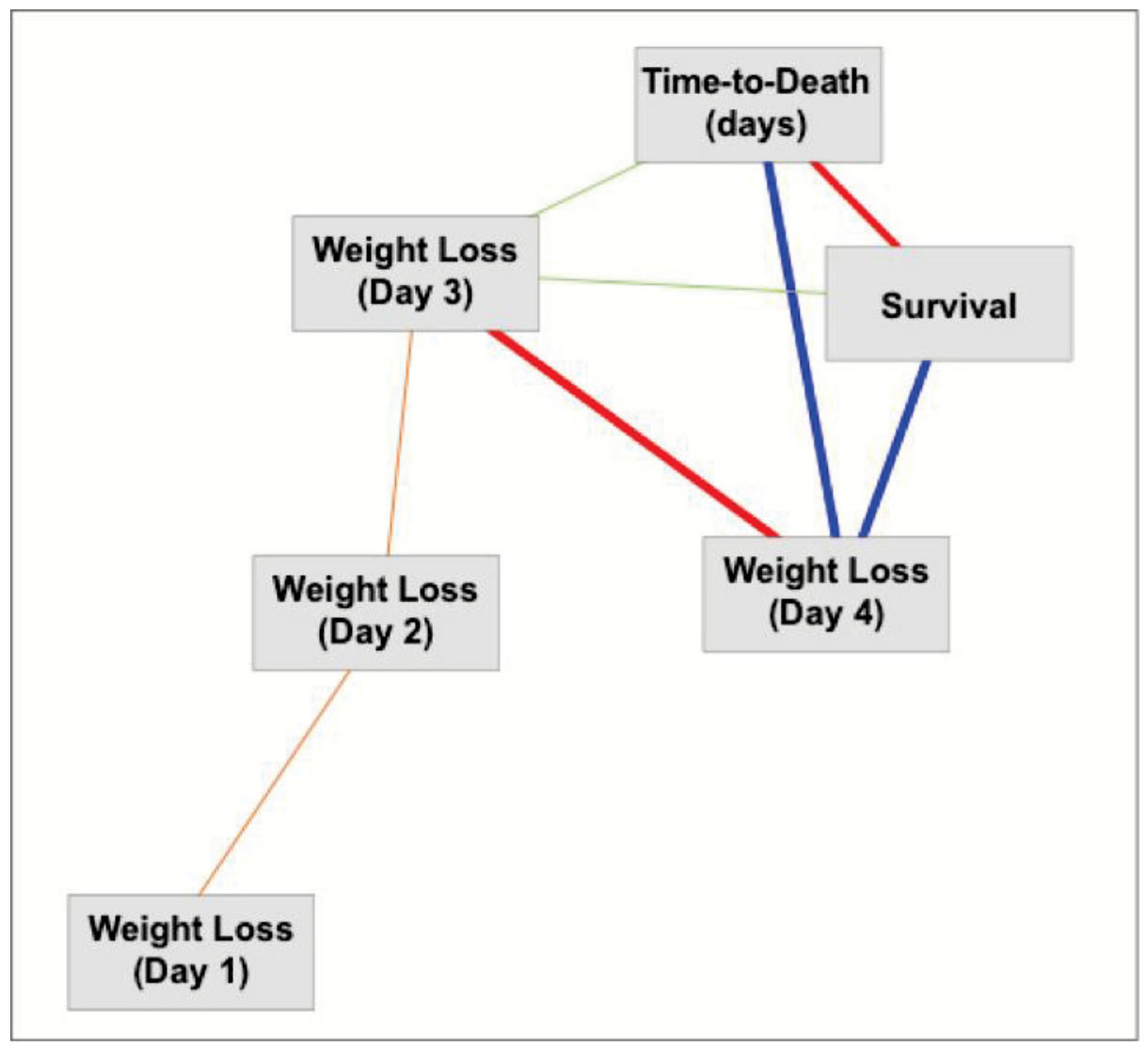

Figure 6-1. Correlation network for the survival, time-to-death, and weight loss phenotypes following pneumonic $B$. pseudomallei infection.

The color of the lines connecting the $B$. pseudomallei disease-state traits indicate the following correlation indices: red line / 0.7 to 1.0 , orange line / 0.5 to 0.7 , green line / 0.5 to -0.7 , and blue line / -0.7 to -1.0 . 
QTLs that we hypothesize may have been a result of the effects of anesthesia prior to the $B p$ infection, similar to observations seen in the previously mentioned H1N1 study by Nedelko et. al. [73]. There were also a large number of genes that function in vesiclemediated transport, which could function in many pathways including pathways that modulate the host defense response. Moreover, seeing as though $B p$ enters the host cell in a vesicle (endosome), these genes can also be implicated in increasing the permissiveness of $B p$ replication in establishing an intracellular colonization niche since our previous studies have illustrated that overwhelming bacterial loads are typical in the susceptible parental strain (D2).

We went a step further and integrated the results of our RNA-Seq data with results from our QTL mapping studies. We mined this data to only incorporate genes that fell within any of our significant/suggestive QTL intervals. Using this approach, we were able to reduce the number of candidates from 46 genes residing throughout six QTL regions, to 10 high priority candidate genes on two QTLs (Chrs. 5 and 7) that were differentially expressed between the susceptible and resistant strains. Most notably, this analysis revealed a cluster of closely related interferon-gamma inducible genes, Cxcl9, Cxcl10, and Cxcl11, that encode the chemokine (C-X-C motif) ligands 9, 10, and 11, respectively and $N d n$, which encodes the protein necdin (cell growth suppressor), all which were significantly up regulated in the resistant strains. Other genes generated from this analysis include Fam $47 e$ (family with sequence similarity 47), Prdm8 (protein domain containing 8), Chrna7 (neuronal acetylcholine receptor subunit alpha-7), Snrpal (small nuclear ribonuclearprotein polypeptide), $\operatorname{Tm} 2 d 3$ (TM2 domain containing 3), and Gm20457 (not yet characterized), which were all significantly upregulated in the susceptible strains. These genes were further narrowed down to 4 potential candidate genes based on the genomic location of the gene of origin (cis vs. trans eQTLs). Cxcl9, Cxcl11, Ndn, and Chrna 7 are all cis eQTLs that map to the same location as the expressed gene and therefore exert a direct effect on its function. Functional studies should commence with these genes as cis eQTLs generally have strong effect sizes and it is easier to validate and interpret their affect on the trait [202] when compared to trans eQTLs. Collectively, these results provided additional leverage for prioritization of candidate genes for further interrogation.

The CXCL cluster of genes within our significant QTL region on chromosome 5 is of particular interest based on their known biological function and their obvious role in immunity. Cxcl9 [also known as MIG, (monokine-induced by IFN-gamma)] and Cxcl11 [I-TAC, (T cell alpha chemoattractant)] are interferon-gamma inducible chemokines that play a role in orchestrating immune cell accumulation ( $\mathrm{T}$ cells, natural killer cells, and monocytes/macrophages) and activation during an inflammatory response [203]. They function through receptor dependent interactions through their cognate G-protein coupled receptor CXCR3 [170, 203]. Previous studies have illustrated that neutralization of these chemokines increases host susceptibility, thus the results of our gene expression profiling suggest that high expression of $\mathrm{Cxcl}$ and -11 is associated with increased survival since both are highly expressed in the resistant strains with an infection-state increase of 10 and 24 , respectively. Future experiments would incorporate functional studies to validate these candidate genes and explore their specific role during a $B p$ infection. For instance, 
we could use many traditional techniques such as Reverse-Transcriptase PCR (RT-PCR), Real-time PCR (qPCR), ELISA, and RNA silencing, as previously described [47]. Specifically, infection-state expression levels of the candidate genes, can be measured via RT-PCR and qPCR and differential protein expression can be measured by ELISA (or western blotting). Another ideal approach would be to use knockout mice or dampen the expression of the candidate genes using techniques such as RNA silencing in cells or animals that express a functional form of the gene. In addition, the use of congenic strains would be a valuable resource in analyzing our complex traits [204]. Congenic mice are genetically engineered to carry a targeted mutation where a small portion of the donor (mouse) genome is placed on a recipient mouse strain, allowing a defined chromosomal region to be assayed. In using these molecular techniques and others, we can begin to identify the functional roles of candidate genes that are responsible for observed differential infection-state phenotypes in mice during a $B p$ infection.

In conclusion, there have been a number of studies that have identified host loci that are covariant with susceptibility to viral, bacterial, and even parasitic infectious agents. No clear pattern has emerged from these studies, and in fact, collectively their findings indicate that host-pathogen interactions are extremely complex. Some of these studies have identified single host loci that are responsible for disease susceptibility, while others have determined that susceptibility to disease involves multiple host loci. For instance, it has been documented that a single gene ( $\mathrm{Scl} 2)$ controls the predisposition for development of cutaneous lesions following infection with Leishmania mexicana [115]. It has also been shown that susceptibility to murine cytomegalovirus is controlled by a single host loci that encodes an NK cell activating receptor $[118,119]$ and that a single gene (Car2) serves as the susceptibility locus for Theiler's virus-induced demyelinating disease [120]. In contrast, similar studies have revealed that susceptibility to influenza virus infection is a multigenic trait, and that different arrays of host loci control susceptibility to distinct strains of influenza [73, 123]. Studies of susceptibility to bacterial pathogens have also yielded divergent results. A set of studies by Miyairi and associates revealed that susceptibility to Chlamydia psittaci is a simple trait that is controlled by a single host locus that encodes p47 GTPases [74, 100]. Another study revealed that differential susceptibility to group A Steptococci is also controlled by a single host genetic locus [122]. In contrast, a study by Yadav and colleagues [121] and the present study revealed that susceptibility to the bacterial pathogens Yersina pestis and $B p$, respectively, involve multiple host loci. In fact, the only clear similarity between these two studies was that two of the weaker QTLs involved in susceptibility to Yersinia overlap with the QTL on chromosome 5 that was identified in the current studies on $B p$. These similarities could be coincidental, but they could also indicate some strong similarities in the interactions of hosts with these two highly virulent intracellular bacterial pathogens. 


\section{FUTURE STUDIES}

\section{Chromosomes 5 and 7 Are Co-Dependent}

Whole genome linkage analysis of our survival phenotype revealed two significant QTLs on chromosomes 5 and 7. The significant/suggestive regions of these two chromosomes have roughly the same pattern of inheritance of B6 and D2 haplotypes from the 32-BXD strain cohort used in the initial analysis. In other words, our significant and suggestive intervals on chromosomes 5 and 7 are effectively one region of the genome from a statistical point of view. GN incorporates a feature called composite interval mapping, which can detect secondary QTLs and decipher if two loci are codependent or independent. Composite interval mapping revealed that these two loci are co-dependent based on the loss of both QTLs when we controlled for loci within or near the significant/suggestive QTL intervals for chromosomes 5 and 7.

While previous studies were completed using randomly selected BXD strains, to resolve the co-dependency between chromosomes 5 and 7, we have begun adding specifically selected strains to the previous analysis. These specifically selected strains were chosen based on the results of a haplotype analysis that was completed using GN. The haplotype analysis identified BXD genotypes (that were not used in the preliminary studies) that have differing haplotypes (either B6 or D2) on chromosomes 5 and 7 in our regions of interest. Same as previous studies, disease-state phenotypes (survival, time-todeath and weight loss) were measured using the selected BXD strains. Recently, we have added three new BXD strains (BXD -44, -79, -100) to this analysis and interval mapping revealed a highly significant QTL on chromosome 5 (Figure 6-2). The QTL peak on chromosome 7 from our initial analysis was a presumed artifact attributable to the similar pattern of inheritance in the initial BXD cohort and addition of these strains with differing haplotypes, significantly decreased the QTL on chromosome 7. We will continue to add specifically selected BXD strains to this study to increase the precision of QTL analysis and significantly reduce the number of candidate genes.

\section{The Additive Allele Effect for Survival QTL Analysis}

Future studies will focus on an interesting phenomenon observed during our survival QTL analysis involving the additive allele effect. The additive allele effect is an estimate of the change in the average phenotype that would be produced by substituting a D2 or B6 single allele, thereby increasing trait values $[205,206]$. When observing a QTL map generated by GN, the thin red and green lines indicate that B6 or D2 alleles increase trait values, respectively, and the additive values are located on the far right of the QTL map [205]. QTL maps of our survival phenotype display a thin green line, which is indicative of a D2 allele increasing the survival trait in the suggestive/significant QTL interval on chromosomes 5; but this observation does not conform to what we observe for survival at the parental level. Based on our QTL maps, B6 should be a highly sensitive strain and D2 should be a highly resistant strain. We postulate that something dramatic 

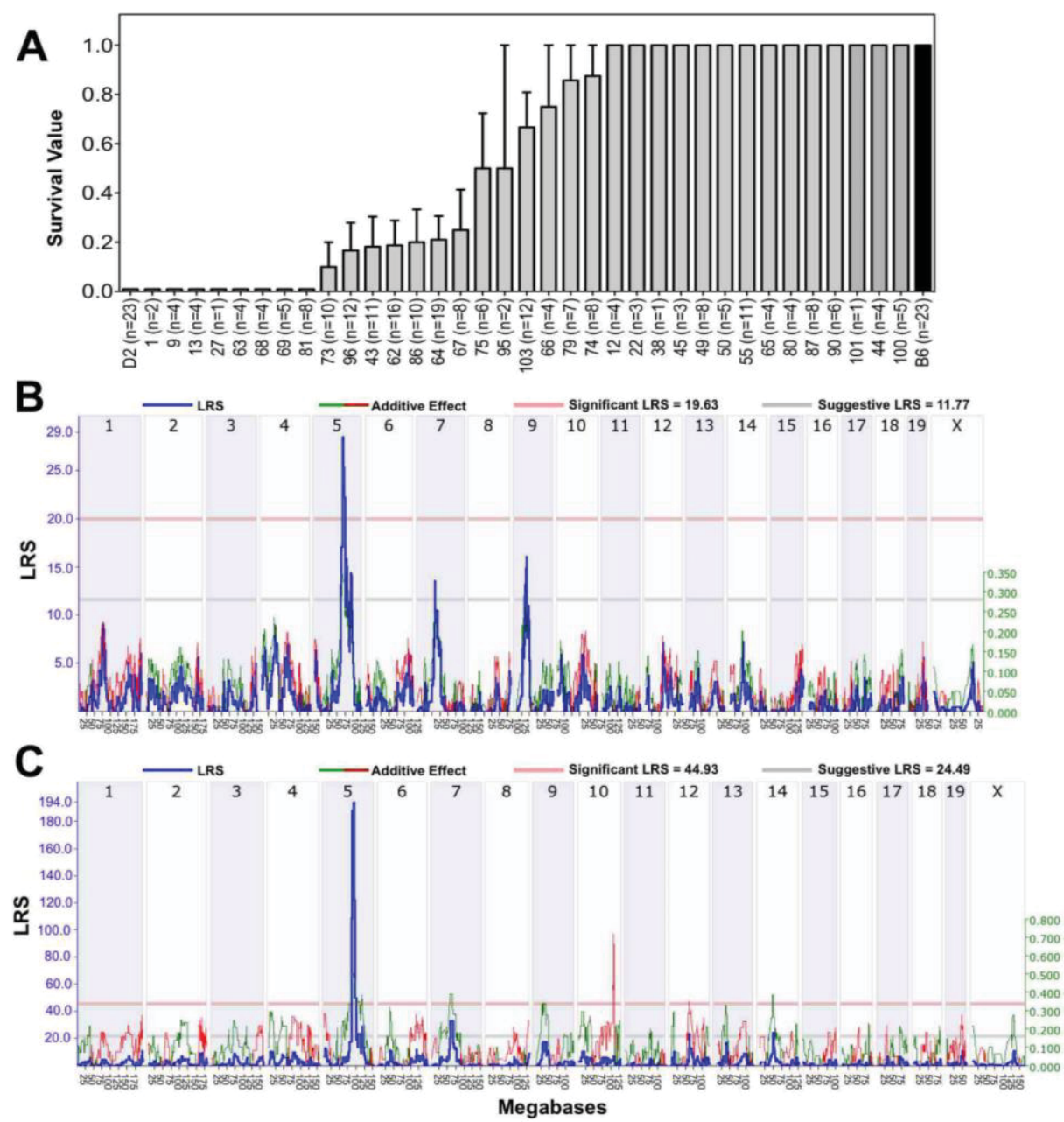

Figure 6-2. Refined QTL analysis with addition of three new BXD genotypes: Genome-wide linkage analysis of survival following pneumonic challenge with Burkholderia pseudomallei.

A cohort of male mice, which included 35 BXD strains, was infected intranasally with 50-100 CFU of Burkholderia pseudomallei. Infected mice were monitored for survival for up to 11 days post-infection and those that survived infection were given a value of "1" while those that succumbed to infection received a value of "0". Panel A: Log-Rank plot showing the mean \pm SEM of the survival value for each strain. Panels B and C:

Standard and weighted interval mapping, respectively, was performed using the in silico resources within GeneNetwork.org to identify genetic loci that correlated with survival. The blue line indicates LRS scores across the entire genome. Thin red and green lines indicate that B6 or D2 alleles increase trait values, respectively. The mouse chromosomes are identified in the upper $\mathrm{x}$-axis, the lower $\mathrm{x}$-axis shows the physical map in mega bases for each chromosome, and the y-axis represents the LRS score. Thick red and grey horizontal lines indicate the genome-wide significance threshold $(\mathrm{p}<0.05)$ or suggestive threshold $(p<0.63)$, respectively. 
has happened in this region of the genome in one of the parent strains that has caused a reverse in the polarity. However, it is unlikely that both strains were subject to a serious mutation that would cause this type of reverse in polarity. Undeniably, this phenomenon raises the following question: In the last 20 years, has there been a serious mutation in D2 that has made it more sensitive to $B p$ or has there been a mutation in B6 that has made it highly resistant to $B p$ ? A haplotype analysis revealed that mice with a B allele within our QTL intervals on chromosome 5 succumb to $B p$ infection, while mice with a D allele display an increased survival phenotype to the infection.

One way to begin dissecting this interesting observation is to perform $B p$ survival studies with C57BL/6NJ (B6NJ) mice. Using B6NJ mice will allow us to test the idea that there has been a novel or spontaneous mutation in the B6 strain that has permitted them to survive $B p$ infections. In 1951, The Jackson Laboratory sent B6 mice (at F32 generation) to the National Institutes of Health, where they were maintained and bred independently for decades [207]. B6NJ is now considered a subline of C57BL/6. As such, if a recent mutation is the cause of the increased survivability in the B6 mice, then the B6NJ strains would be devoid of this mutation and exhibit a decreased survival phenotype. Conversely, this same study could be carried out with D2 mice using DBA/1 J (D1). D2 and D1 differ at a large number of loci (including the MHC $H 2$ haplotype).

\section{CONCLUSIONS}

The mapping of host resistance and susceptibility loci in the BXD RI population uncovered several QTLs and potential candidate genes that may be critical for host defense during melioidosis. The data presented in this dissertation provides an intriguing glimpse into the genetic basis of the differential susceptibility to a $B p$ infection. Our data indicate that genetic regulation of survival, time-to-death and weight loss during a $B p$ infection is a complex phenomenon, whereby many genes exert their effects on these traits. Weight loss QTLs displayed a time-dependent profile indicating host loci within these QTLs may be important for the host response in a transient and dynamic fashion. Furthermore, linkage analysis of survival (and time-to-death) generated two significant QTLs, but we were able to narrow down these QTL regions to chromosome 5 only using specifically selected BXD strains. We examined these QTL regions and identified several possible candidate genes that may be important for host response to $B p$ infections. These studies will lay the groundwork in increasing our understanding of the interactions between $B p$ and its genetically diverse hosts. 


\section{LIST OF REFERENCES}

1. Christopher L. Hatcher, L.A.M., Alfredo G. Torres, Recent Advances in

Burkholderia mallei and B. pseudomallei Research. Current Trop Med Rep, 2015.

2. Coenye, T. and P. Vandamme, Diversity and significance of Burkholderia species occupying diverse ecological niches. Environmental microbiology, 2003. 5(9): p. 719-29.

3. Wiersinga, W.J., B.J. Currie, and S.J. Peacock, Melioidosis. The New England journal of medicine, 2012. 367(11): p. 1035-44.

4. Deshazer, D., Virulence of clinical and environmental isolates of Burkholderia oklahomensis and Burkholderia thailandensis in hamsters and mice. FEMS microbiology letters, 2007. 277(1): p. 64-9.

5. Sim, S.H., et al., The core and accessory genomes of Burkholderia pseudomallei: implications for human melioidosis. PLoS pathogens, 2008. 4(10): p. e1000178.

6. Holden, M.T., et al., Genomic plasticity of the causative agent of melioidosis, Burkholderia pseudomallei. Proceedings of the National Academy of Sciences of the United States of America, 2004. 101(39): p. 14240-5.

7. Wiersinga, W.J., et al., Melioidosis: insights into the pathogenicity of Burkholderia pseudomallei. Nature reviews. Microbiology, 2006. 4(4): p. 272-82.

8. Peacock, S.J., Melioidosis. Current opinion in infectious diseases, 2006. 19(5): p. 421-8.

9. Tuanyok, A., et al., Genomic islands from five strains of Burkholderia pseudomallei. BMC genomics, 2008. 9: p. 566.

10. Tumapa, S., et al., Burkholderia pseudomallei genome plasticity associated with genomic island variation. BMC genomics, 2008. 9: p. 190.

11. Wiersinga, W.J., et al., Melioidosis: insights into the pathogenicity of Burkholderia pseudomallei. Nat Rev Microbiol, 2006. 4(4): p. 272-82.

12. Currie, B.J., Advances and remaining uncertainties in the epidemiology of Burkholderia pseudomallei and melioidosis. Trans R Soc Trop Med Hyg, 2008. 102(3): p. 225-7.

13. Currie, B.J., et al., The epidemiology of melioidosis in Australia and Papua New Guinea. Acta tropica, 2000. 74(2-3): p. 121-7. 
14. Douglas, M.W., et al., Epidemiology of community-acquired and nosocomial bloodstream infections in tropical Australia: a 12-month prospective study. Tropical medicine \& international health : TM \& IH, 2004. 9(7): p. 795-804.

15. Lazar Adler, N.R., et al., The molecular and cellular basis of pathogenesis in melioidosis: how does Burkholderia pseudomallei cause disease? FEMS microbiology reviews, 2009. 33(6): p. 1079-99.

16. Brett, P.J. and D.E. Woods, Pathogenesis of and immunity to melioidosis. Acta tropica, 2000. 74(2-3): p. 201-10.

17. Peacock, S.J., Melioidosis. Curr Opin Infect Dis, 2006. 19(5): p. 421-8.

18. Valade, E., et al., [Melioidosis: an emerging tropical disease]. Medecine tropicale : revue du Corps de sante colonial, 2009. 69(5): p. 437-45.

19. Management of Accidental Laboratory Exposure to Burkholderia pseudomallei and B. mallei. Available from: http://wwwnc.cdc.gov/eid/article/14/7/071501 article.

20. Partrick R. Murray, K.S.R., Michael A. Pfaller, Medical Microbiology. 7th ed. 2012: Elsevier Saunders.

21. White, N.J., Melioidosis. Lancet, 2003. 361(9370): p. 1715-22.

22. Currie, B.J., et al., Endemic melioidosis in tropical northern Australia: a 10-year prospective study and review of the literature. Clinical infectious diseases : an official publication of the Infectious Diseases Society of America, 2000. 31(4): p. 981-6.

23. Peacock, S.J., et al., Management of accidental laboratory exposure to Burkholderia pseudomallei and B. mallei. Emerging infectious diseases, 2008. 14(7): p. e2.

24. Yee, K.C., et al., Melioidosis, the great mimicker: a report of 10 cases from Malaysia. The Journal of tropical medicine and hygiene, 1988. 91(5): p. 249-54.

25. Fisher, D.A. and P.N. Harris, Melioidosis: refining management of a tropical time bomb. Lancet, 2014. 383(9919): p. 762-4.

26. Ngauy, V., et al., Cutaneous melioidosis in a man who was taken as a prisoner of war by the Japanese during World War II. Journal of clinical microbiology, 2005. 43(2): p. 970-2.

27. Clayton, A.J., R.S. Lisella, and D.G. Martin, Melioidosis: a serological survey in military personnel. Military medicine, 1973. 138(1): p. 24-6. 
28. Cheng, A.C. and B.J. Currie, Melioidosis: epidemiology, pathophysiology, and management. Clinical microbiology reviews, 2005. 18(2): p. 383-416.

29. Kenny, D.J., et al., In vitro susceptibilities of Burkholderia mallei in comparison to those of other pathogenic Burkholderia spp. Antimicrobial agents and chemotherapy, 1999. 43(11): p. 2773-5.

30. Sookpranee, T., et al., Pseudomonas pseudomallei, a common pathogen in Thailand that is resistant to the bactericidal effects of many antibiotics. Antimicrobial agents and chemotherapy, 1991. 35(3): p. 484-9.

31. Ashdown, L.R., In vitro activities of the newer beta-lactam and quinolone antimicrobial agents against Pseudomonas pseudomallei. Antimicrobial agents and chemotherapy, 1988. 32(9): p. 1435-6.

32. McEniry, D.W., S.H. Gillespie, and D. Felmingham, Susceptibility of Pseudomonas pseudomallei to new beta-lactam and aminoglycoside antibiotics. The Journal of antimicrobial chemotherapy, 1988. 21(2): p. 171-5.

33. Moore, R.A., et al., Efflux-mediated aminoglycoside and macrolide resistance in Burkholderia pseudomallei. Antimicrobial agents and chemotherapy, 1999. 43(3): p. 465-70.

34. Yamamoto, T., et al., In vitro susceptibilities of Pseudomonas pseudomallei to 27 antimicrobial agents. Antimicrobial agents and chemotherapy, 1990. 34(10): p. 2027-9.

35. Hall, W.H. and R.E. Manion, Antibiotic susceptibility of Pseudomonas pseudomallei. Antimicrobial agents and chemotherapy, 1973. 4(2): p. 193-5.

36. Chau, P.Y., et al., In vitro susceptibility of strains of Pseudomonas pseudomallei isolated in Thailand and Hong Kong to some newer beta-lactam antibiotics and quinolone derivatives. The Journal of infectious diseases, 1986. 153(1): p. 167-70.

37. Trunck, L.A., et al., Molecular basis of rare aminoglycoside susceptibility and pathogenesis of Burkholderia pseudomallei clinical isolates from Thailand. PLoS neglected tropical diseases, 2009. 3(9): p. e519.

38. Rholl, D.A., et al., Molecular Investigations of PenA-mediated beta-lactam Resistance in Burkholderia pseudomallei. Frontiers in microbiology, 2011. 2: p. 139.

39. Maharjan, B., et al., Recurrent melioidosis in patients in northeast Thailand is frequently due to reinfection rather than relapse. Journal of clinical microbiology, 2005. 43(12): p. 6032-4.

40. Chaowagul, W., et al., Relapse in melioidosis: incidence and risk factors. The Journal of infectious diseases, 1993. 168(5): p. 1181-5. 
41. Jane, L., et al., Burkholderia pseudomallei osteomyelitis: An unusual cause of fever in a returned traveller. The Australasian medical journal, 2012. 5(2): p. 1413.

42. Suputtamongkol, Y., et al., Risk factors for melioidosis and bacteremic melioidosis. Clinical infectious diseases : an official publication of the Infectious Diseases Society of America, 1999. 29(2): p. 408-13.

43. Chen, Y.L., et al., The concentrations of ambient Burkholderia pseudomallei during typhoon season in endemic area of melioidosis in Taiwan. PLoS neglected tropical diseases, 2014. 8(5): p. e2877.

44. Chaowagul, W., et al., Melioidosis: a major cause of community-acquired septicemia in northeastern Thailand. The Journal of infectious diseases, 1989. 159(5): p. 890-9.

45. Horby, P., et al., The role of host genetics in susceptibility to influenza: a systematic review. PLoS One, 2012. 7(3): p. e33180.

46. Liu, B., et al., Model of differential susceptibility to mucosal Burkholderia pseudomallei infection. Infection and immunity, 2002. 70(2): p. 504-11.

47. Miyairi, I., et al., The 447 GTPases Iigp2 and Irgb10 regulate innate immunity and inflammation to murine Chlamydia psittaci infection. J Immunol, 2007. 179(3): p. 1814-24.

48. Chapman, S.J. and A.V. Hill, Human genetic susceptibility to infectious disease. Nature reviews. Genetics, 2012. 13(3): p. 175-88.

49. Dharakul, T., et al., HLA-DR and -DQ associations with melioidosis. Hum Immunol, 1998. 59(9): p. 580-6.

50. Nuntayanuwat, S., et al., Polymorphism in the promoter region of tumor necrosis factor-alpha gene is associated with severe meliodosis. Hum Immunol, 1999. 60(10): p. 979-83.

51. Srivastava, B., et al., Host genetic background strongly influences the response to influenza a virus infections. PloS one, 2009. 4(3): p. e4857.

52. Markova, N., V. Kussovski, and T. Radoucheva, Killing of Pseudomonas pseudomallei by polymorphonuclear leukocytes and peritoneal macrophages from chicken, sheep, swine and rabbits. Zentralblatt fur Bakteriologie : international journal of medical microbiology, 1998. 288(1): p. 103-10.

53. Brett, P.J. and D.E. Woods, Structural and immunological characterization of Burkholderia pseudomallei O-polysaccharide-flagellin protein conjugates. Infection and immunity, 1996. 64(7): p. 2824-8. 
54. Manzeniuk, I.N., et al., [Burkholderia mallei and Burkholderia pseudomallei. Study of immuno- and pathogenesis of glanders and melioidosis. Heterologous vaccines]. Antibiotiki i khimioterapiia = Antibiotics and chemoterapy [sic] / Ministerstvo meditsinskoi i mikrobiologicheskoi promyshlennosti SSSR, 1999. 44(6): p. 21-6.

55. Emery, F.D., et al., Genetic control of weight loss during pneumonic Burkholderia pseudomallei infection. Pathogens and disease, 2014. 71(2): p. 24964.

56. Leakey, A.K., G.C. Ulett, and R.G. Hirst, BALB/c and C57Bl/6 mice infected with virulent Burkholderia pseudomallei provide contrasting animal models for the acute and chronic forms of human melioidosis. Microbial pathogenesis, 1998. 24(5): p. 269-75.

57. Leakey, A.K., G.C. Ulett, and R.G. Hirst, BALB/c and C57Bl/6 mice infected with virulent Burkholderia pseudomallei provide contrasting animal models for the acute and chronic forms of human melioidosis. Microb Pathog, 1998. 24(5): p. 269-75.

58. Ulett, G.C., N. Ketheesan, and R.G. Hirst, Cytokine gene expression in innately susceptible BALB/c mice and relatively resistant C57BL/6 mice during infection with virulent Burkholderia pseudomallei. Infect Immun, 2000. 68(4): p. 2034-42.

59. Hoppe, I., Characterization of a murine model of melioidosis: comparison of different strains of mice. Infect Immun, 1999. 67(6): p. 2891-900.

60. Ulett, G.C., N. Ketheesan, and R.G. Hirst, Cytokine gene expression in innately susceptible BALB/c mice and relatively resistant C57BL/6 mice during infection with virulent Burkholderia pseudomallei. Infection and immunity, 2000. 68(4): p. 2034-42.

61. Hoppe, I., et al., Characterization of a murine model of melioidosis: comparison of different strains of mice. Infection and immunity, 1999. 67(6): p. 2891-900.

62. Cheng, A.C., D.A. Dance, and B.J. Currie, Bioterrorism, Glanders and melioidosis. Euro Surveill, 2005. 10(3): p. E1-2; author reply E1-2.

63. Registry, N.S.A.; Available from: http://www.selectagents.gov/select $\% 20$ agents $\% 20$ and $\% 20$ toxins $\% 20$ list.html.

64. Gilad, J., et al., Burkholderia mallei and Burkholderia pseudomallei as bioterrorism agents: national aspects of emergency preparedness. Isr Med Assoc J, 2007. 9(7): p. 499-503.

65. HHS and USDA Select Agents and Toxins 7 CFR Part 331, 9 CFR Part 121, 42 CFR Part 73. 2012. 
66. Wiersinga, W.J. and T. van der Poll, Immunity to Burkholderia pseudomallei. Current opinion in infectious diseases, 2009. 22(2): p. 102-8.

67. Chantratita, N., et al., Screen of whole blood responses to flagellin identifies TLR5 variation associated with outcome in melioidosis. Genes and immunity, 2014. 15(2): p. 63-71.

68. Nuntayanuwat, S., et al., Polymorphism in the promoter region of tumor necrosis factor-alpha gene is associated with severe meliodosis. Human immunology, 1999. 60(10): p. 979-83.

69. Civelek, M. and A.J. Lusis, Systems genetics approaches to understand complex traits. Nature reviews. Genetics, 2014. 15(1): p. 34-48.

70. Sieberts, S.K. and E.E. Schadt, Moving toward a system genetics view of disease. Mammalian genome : official journal of the International Mammalian Genome Society, 2007. 18(6-7): p. 389-401.

71. Lynch, R.M., et al., Identifying genetic loci and spleen gene coexpression networks underlying immunophenotypes in BXD recombinant inbred mice. Physiological genomics, 2010. 41(3): p. 244-53.

72. Boivin, G.A., et al., Mapping of clinical and expression quantitative trait loci in a sex-dependent effect of host susceptibility to mouse-adapted influenza $H 3 N 2 / H K / 1 / 68$. Journal of immunology, 2012. 188(8): p. 3949-60.

73. Nedelko, T., et al., Distinct gene loci control the host response to influenza H1N1 virus infection in a time-dependent manner. BMC genomics, 2012. 13: p. 411.

74. Miyairi, I., et al., Host genetics and Chlamydia disease: prediction and validation of disease severity mechanisms. PloS one, 2012. 7(3): p. e33781.

75. Andreux, P.A., et al., Systems genetics of metabolism: the use of the BXD murine reference panel for multiscalar integration of traits. Cell, 2012. 150(6): p. 128799.

76. Williams, R.W., et al., The genetic structure of recombinant inbred mice: highresolution consensus maps for complex trait analysis. Genome biology, 2001. 2(11): p. RESEARCH0046.

77. Chesler, E.J., et al., Complex trait analysis of gene expression uncovers polygenic and pleiotropic networks that modulate nervous system function. Nature genetics, 2005. 37(3): p. 233-42.

78. Mouse Cross Information. 20042012 [cited 201518 May 2015]; Available from: http://www.genenetwork.org/mouseCross.html. 
79. Broman, K.W., The genomes of recombinant inbred lines. Genetics, 2005. 169(2): p. 1133-46.

80. Bailey, D.W., Recombinant-inbred strains. An aid to finding identity, linkage, and function of histocompatibility and other genes. Transplantation, 1971. 11(3): p. $325-7$.

81. Bailey, D.W., Recombinant Inbred Strains. An aid to finding identity linkage, and function of histocompatibility and other genes. Transplantation, 1971. 11: p. 325327.

82. Taylor, B.A., Recombinant inbred strains: use in gene mapping. Origins fo Inbred Mice, ed. H. Morse. Vol. 3. 1978: New York Academic Press.

83. Silver, L.M., Mouse genetics : concepts and applications. 1995, New York: Oxford University Press. xiii, 362 p.

84. Peirce, J.L., et al., A new set of BXD recombinant inbred lines from advanced intercross populations in mice. BMC genetics, 2004. 5: p. 7.

85. Molecular Biology of the Toxic Response. 1 ed, ed. K.W. Alvaro Puga. 1998: CRC Press. 581.

86. Philip, V.M., et al., Genetic analysis in the Collaborative Cross breeding population. Genome research, 2011.21(8): p. 1223-38.

87. The Jackson Laboratory: Recombinant Inbred (RI) Strains. 20122012 [cited 201515 May 2015]; Available from: www.jax.org/smsr/ristrain.html.

88. Flint, J., Mapping quantitative traits and strategies to find quantitative trait genes. Methods, 2011. 53(2): p. 163-74.

89. www.GeneNetwork.org.

90. Laboratory, T.J. The Jackson Laboratory Mouse DNA Resource. JAX NOTES ISSUE, 499, Fall 20052005 [cited 201515 May 2015]; 499:[Available from: http://jaxmice.jax.org/jaxnotes/archive/499b.html.

91. Shifman, S., et al., A high-resolution single nucleotide polymorphism genetic map of the mouse genome. PLoS biology, 2006. 4(12): p. e395.

92. Darvasi, A. and M. Soller, Advanced intercross lines, an experimental population for fine genetic mapping. Genetics, 1995. 141(3): p. 1199-207.

93. Yang, H., et al., A customized and versatile high-density genotyping array for the mouse. Nature methods, 2009. 6(9): p. 663-6. 
94. Mackay, T.F., E.A. Stone, and J.F. Ayroles, The genetics of quantitative traits: challenges and prospects. Nature reviews. Genetics, 2009. 10(8): p. 565-77.

95. Newbury, A.J. and G.D. Rosen, Genetic, morphometric, and behavioral factors linked to the midsagittal area of the corpus callosum. Front Genet, 2012. 3: p. 91.

96. Nadeau, J.H. and A.M. Dudley, Genetics. Systems genetics. Science, 2011. 331(6020): p. 1015-6.

97. Lander, E.S. and D. Botstein, Mapping mendelian factors underlying quantitative traits using RFLP linkage maps. Genetics, 1989. 121(1): p. 185-99.

98. Wayne, C.M.M.a.M., Quantitative Trait Locus (QTL) Analysis. Scitable by Nature Education, 2008. 1(208).

99. Meuwissen, T.H., B.J. Hayes, and M.E. Goddard, Prediction of total genetic value using genome-wide dense marker maps. Genetics, 2001. 157(4): p. 1819-29.

100. Miyairi, I., et al., The 447 GTPases Iigp2 and Irgb10 regulate innate immunity and inflammation to murine Chlamydia psittaci infection. Journal of immunology, 2007. 179(3): p. 1814-24.

101. Ehlers, C.L., et al., A comparison of selected quantitative trait loci associated with alcohol use phenotypes in humans and mouse models. Addiction biology, 2010. 15(2): p. 185-99.

102. Grisel, J.E., Quantitative trait locus analysis. Alcohol research \& health : the journal of the National Institute on Alcohol Abuse and Alcoholism, 2000. 24(3): p. 169-74.

103. Chesler, E.J., et al., WebQTL: rapid exploratory analysis of gene expression and genetic networks for brain and behavior. Nature neuroscience, 2004. 7(5): p. 4856.

104. Chesler, E.J. and R.W. Williams, Brain gene expression: genomics and genetics. International review of neurobiology, 2004. 60: p. 59-95.

105. Morahan, G. and R.W. Williams, Systems genetics: the next generation in genetics research? Novartis Foundation symposium, 2007. 281: p. 181-8; discussion 188-91, 208-9.

106. Druka, A., et al., Towards systems genetic analyses in barley: Integration of phenotypic, expression and genotype data into GeneNetwork. BMC Genet, 2008. 9: p. 73. 
107. Emery, F.D., J.M. Stabenow, and M.A. Miller, Efficient inactivation of Burkholderia pseudomallei or Francisella tularensis in infected cells for safe removal from biosafety level 3 containment laboratories. Pathogens and disease, 2014. 71(2): p. 276-81.

108. Jayakar, H.R., et al., A galU mutant of Francisella tularensis is attenuated for virulence in a murine pulmonary model of tularemia. BMC microbiology, 2011. 11: p. 179.

109. Ceballos-Olvera, I., et al., Inflammasome-dependent pyroptosis and IL-18 protect against Burkholderia pseudomallei lung infection while IL-1beta is deleterious. PLoS pathogens, 2011. 7(12): p. e1002452.

110. Miller, M.A., et al., Visualization of murine intranasal dosing efficiency using luminescent Francisella tularensis: effect of instillation volume and form of anesthesia. PloS one, 2012. 7(2): p. e31359.

111. Currie, B.J., Advances and remaining uncertainties in the epidemiology of Burkholderia pseudomallei and melioidosis. Transactions of the Royal Society of Tropical Medicine and Hygiene, 2008. 102(3): p. 225-7.

112. Cheng, A.C., et al., Melioidosis in northern Australia, 2001-02. Communicable diseases intelligence quarterly report, 2003. 27(2): p. 272-7.

113. Cheng, A.C., D.A. Dance, and B.J. Currie, Bioterrorism, Glanders and melioidosis. Euro surveillance : bulletin Europeen sur les maladies transmissibles = European communicable disease bulletin, 2005. 10(3): p. E1-2; author reply E12.

114. Gilad, J., et al., Burkholderia mallei and Burkholderia pseudomallei as bioterrorism agents: national aspects of emergency preparedness. The Israel Medical Association journal : IMAJ, 2007. 9(7): p. 499-503.

115. Roberts, M., J. Alexander, and J.M. Blackwell, Genetic analysis of Leishmania mexicana infection in mice: single gene ( $\mathrm{Scl}-2)$ controlled predisposition to cutaneous lesion development. Journal of immunogenetics, 1990. 17(1-2): p. 89100.

116. Horby, P., et al., An updated systematic review of the role of host genetics in susceptibility to influenza. Influenza and other respiratory viruses, 2013. 7 Suppl 2: p. 37-41.

117. Horby, P., et al., What is the evidence of a role for host genetics in susceptibility to influenza A/H5N1? Epidemiology and infection, 2010. 138(11): p. 1550-8.

118. Cheng, T.P., et al., Ly49h is necessary for genetic resistance to murine cytomegalovirus. Immunogenetics, 2008. 60(10): p. 565-73. 
119. Lee, S.H., et al., Susceptibility to mouse cytomegalovirus is associated with deletion of an activating natural killer cell receptor of the C-type lectin superfamily. Nature genetics, 2001. 28(1): p. 42-5.

120. Melvold, R.W., et al., Identification of a locus on mouse chromosome 3 involved in differential susceptibility to Theiler's murine encephalomyelitis virus-induced demyelinating disease. Journal of virology, 1990. 64(2): p. 686-90.

121. Yadav, J.S., et al., Multigenic control and sex bias in host susceptibility to sporeinduced pulmonary anthrax in mice. Infection and immunity, 2011. 79(8): p. 3204-15.

122. Abdeltawab, N.F., et al., An unbiased systems genetics approach to mapping genetic loci modulating susceptibility to severe streptococcal sepsis. PLoS pathogens, 2008. 4(4): p. e1000042.

123. Boon, A.C., et al., Host genetic variation affects resistance to infection with a highly pathogenic H5N1 influenza A virus in mice. Journal of virology, 2009. 83(20): p. 10417-26.

124. Alberts, R., et al., Genome-wide analysis of the mouse lung transcriptome reveals novel molecular gene interaction networks and cell-specific expression signatures. Respiratory research, 2011. 12: p. 61.

125. Ulett, G.C., et al., A model of immunity to Burkholderia pseudomallei: unique responses following immunization and acute lethal infection. Microbes and infection / Institut Pasteur, 2005. 7(11-12): p. 1263-75.

126. Alberts, R. and K. Schughart, QTLminer: identifying genes regulating quantitative traits. BMC bioinformatics, 2010. 11: p. 516.

127. Cao, S., J.K. Iyer, and V. Lin, Identification of tetratricopeptide repeat domain 9 , a hormonally regulated protein. Biochemical and biophysical research communications, 2006. 345(1): p. 310-7.

128. Choi, Y.A., et al., Secretome analysis of human BMSCs and identification of SMOC1 as an important ECM protein in osteoblast differentiation. Journal of proteome research, 2010. 9(6): p. 2946-56.

129. Lawrance-Owen, A.J., et al., Genetic association suggests that SMOC1 mediates between prenatal sex hormones and digit ratio. Human genetics, 2013. 132(4): p. 415-21.

130. Okada, I., et al., SMOC1 is essential for ocular and limb development in humans and mice. American journal of human genetics, 2011. 88(1): p. 30-41. 
131. Turkmen, S., et al., CA8 mutations cause a novel syndrome characterized by ataxia and mild mental retardation with predisposition to quadrupedal gait. PLoS genetics, 2009. 5(5): p. e1000487.

132. Srikanth, S., et al., Junctate is a Ca2+-sensing structural component of Orail and stromal interaction molecule 1 (STIM1). Proceedings of the National Academy of Sciences of the United States of America, 2012. 109(22): p. 8682-7.

133. Okamura, S., et al., p53DINP1, a p53-inducible gene, regulates p53-dependent apoptosis. Molecular cell, 2001. 8(1): p. 85-94.

134. Sancho, A., et al., DOR/Tp53inp2 and Tp53inp1 constitute a metazoan gene family encoding dual regulators of autophagy and transcription. PloS one, 2012. 7(3): p. e34034.

135. Seillier, M., et al., TP53INP1, a tumor suppressor, interacts with LC3 and ATG8family proteins through the LC3-interacting region (LIR) and promotes autophagy-dependent cell death. Cell death and differentiation, 2012. 19(9): p. 1525-35.

136. Baillat, D., et al., Integrator, a multiprotein mediator of small nuclear RNA processing, associates with the C-terminal repeat of RNA polymerase II. Cell, 2005. 123(2): p. 265-76.

137. Kotani, T., et al., Human G-proteins, ObgH1 and Mtg1, associate with the large mitochondrial ribosome subunit and are involved in translation and assembly of respiratory complexes. Nucleic acids research, 2013. 41(6): p. 3713-22.

138. Hirano, Y., et al., Human small G proteins, ObgH1, and ObgH2, participate in the maintenance of mitochondria and nucleolar architectures. Genes to cells : devoted to molecular \& cellular mechanisms, 2006. 11(11): p. 1295-304.

139. Suchanek, M., et al., The mammalian oxysterol-binding protein-related proteins (ORPs) bind 25-hydroxycholesterol in an evolutionarily conserved pocket. The Biochemical journal, 2007. 405(3): p. 473-80.

140. Olzmann, J.A. and L.S. Chin, Parkin-mediated K63-linked polyubiquitination: $a$ signal for targeting misfolded proteins to the aggresome-autophagy pathway. Autophagy, 2008. 4(1): p. 85-7.

141. Chen, D., et al., Parkin mono-ubiquitinates Bcl-2 and regulates autophagy. The Journal of biological chemistry, 2010. 285(49): p. 38214-23.

142. Narendra, D., et al., Parkin is recruited selectively to impaired mitochondria and promotes their autophagy. The Journal of cell biology, 2008. 183(5): p. 795-803. 
143. Li, J., et al., Association study of the single nucleotide polymorphisms of PARK2 and PACRG with leprosy susceptibility in Chinese population. European journal of human genetics : EJHG, 2012. 20(5): p. 488-9.

144. Aberg, K., et al., Human QKI, a potential regulator of $m R N A$ expression of human oligodendrocyte-related genes involved in schizophrenia. Proceedings of the National Academy of Sciences of the United States of America, 2006. 103(19): p. 7482-7.

145. Mays, E.E. and E.A. Ricketts, Melioidosis: recrudescence associated with bronchogenic carcinoma twenty-six years following initial geographic exposure. Chest, 1975. 68(2): p. 261-3.

146. Mackowiak, P.A. and J.W. Smith, Septicemic melioidosis. Occurrence following acute influenza A six years after exposure in Vietnam. JAMA, 1978. 240(8): p. 764-6.

147. Chodimella, U., et al., Septicemia and suppuration in a Vietnam veteran. Hosp Pract (Minneap), 1997. 32(5): p. 219-21.

148. Lionikas, A., et al., Resolving candidate genes of mouse skeletal muscle QTL via RNA-Seq and expression network analyses. BMC genomics, 2012. 13: p. 592.

149. Souza, R.L., et al., Cloning and characterization of COX18, a Saccharomyces cerevisiae PET gene required for the assembly of cytochrome oxidase. J Biol Chem, 2000. 275(20): p. 14898-902.

150. Ying, S., et al., Premature apoptosis of Chlamydia-infected cells disrupts chlamydial development. The Journal of infectious diseases, 2008. 198(10): p. 1536-44.

151. Prigent, M., et al., IkappaBalpha and IkappaBalpha /NF-kappa B complexes are retained in the cytoplasm through interaction with a novel partner, RasGAP SH3binding protein 2. The Journal of biological chemistry, 2000. 275(46): p. 36441-9.

152. Wong, E.T. and V. Tergaonkar, Roles of NF-kappaB in health and disease: mechanisms and therapeutic potential. Clin Sci (Lond), 2009. 116(6): p. 451-65.

153. Ogawa, N., et al., Involvement of the interferon-gamma-induced T cell-attracting chemokines, interferon-gamma-inducible 10-kd protein (CXCL10) and monokine induced by interferon-gamma (CXCL9), in the salivary gland lesions of patients with Sjogren's syndrome. Arthritis and rheumatism, 2002. 46(10): p. 2730-41.

154. Wang, J., et al., Regulation of cytotoxic T cells by ecto-nicotinamide adenine dinucleotide (NAD) correlates with cell surface GPI-anchored/arginine ADPribosyltransferase. Journal of immunology, 1994. 153(9): p. 4048-58. 
155. Liu, Z.X., Y. Yu, and G. Dennert, A cell surface ADP-ribosyltransferase modulates $T$ cell receptor association and signaling. The Journal of biological chemistry, 1999. 274(25): p. 17399-401.

156. Donnelly, L.E., et al., Arginine-specific mono(ADP-ribosyl)transferase activity on the surface of human polymorphonuclear neutrophil leucocytes. The Biochemical journal, 1996. 315 ( Pt 2): p. 635-41.

157. Grahnert, A., et al., Mono-ADP-ribosyltransferases in human monocytes: regulation by lipopolysaccharide. The Biochemical journal, 2002. 362(Pt 3): p. 717-23.

158. Wang, Y., et al., Ankrd17 positively regulates RIG-I-like receptor (RLR)-mediated immune signaling. European journal of immunology, 2012. 42(5): p. 1304-15.

159. Larsson, M., et al., Role of annexins in endocytosis of antigens in immature human dendritic cells. Immunology, 1997. 92(4): p. 501-11.

160. Chedrawi, A.K., et al., Novel V97G ASAH1 mutation found in Farber disease patients: unique appearance of the disease with an intermediate severity, and marked early involvement of central and peripheral nervous system. Brain \& development, 2012. 34(5): p. 400-4.

161. Zaiss, D.M., et al., Amphiregulin, a TH2 cytokine enhancing resistance to nematodes. Science, 2006. 314(5806): p. 1746.

162. Hoffmann, A. and G. Gross, BMP signaling pathways in cartilage and bone formation. Critical reviews in eukaryotic gene expression, 2001. 11(1-3): p. 2345.

163. Sountoulidis, A., et al., Activation of the Canonical Bone Morphogenetic Protein (BMP) Pathway during Lung Morphogenesis and Adult Lung Tissue Repair. PloS one, 2012. 7(8): p. e41460.

164. Ube3a. Available from: http://www.ncbi.nlm.nih.gov/gene/7337.

165. Xiong, Y. and B.R. Oakley, In vivo analysis of the functions of gamma-tubulincomplex proteins. Journal of cell science, 2009. 122(Pt 22): p. 4218-27.

166. Berl R. Oakley, et al., $\gamma$-tubulin is a component of the spindle pole body that is essential for microtubule function in Aspergillus nidulans. Cell, 1990. 61(7): p. 1289-1301.

167. Murphy, S.M., et al., GCP5 and GCP6: two new members of the human gammatubulin complex. Molecular biology of the cell, 2001. 12(11): p. 3340-52.

168. Entrez Gene: NIPA1 non imprinted in Prader-Willi/Angelman syndrome 1. 
169. Goytain, A., et al., NIPA1(SPG6), the basis for autosomal dominant form of hereditary spastic paraplegia, encodes a functional $M g 2+$ transporter. The Journal of biological chemistry, 2007. 282(11): p. 8060-8.

170. Torraca, V., et al., The CXCR3-CXCL11 signaling axis mediates macrophage recruitment and dissemination of mycobacterial infection. Disease models \& mechanisms, 2015. 8(3): p. 253-69.

171. Rosenblum, J.M., et al., CXC chemokine ligand (CXCL) 9 and CXCL10 are antagonistic costimulation molecules during the priming of alloreactive $T$ cell effectors. Journal of immunology, 2010. 184(7): p. 3450-60.

172. Jay, P., et al., The human necdin gene, NDN, is maternally imprinted and located in the Prader-Willi syndrome chromosomal region. Nature genetics, 1997. 17(3): p. 357-61.

173. Chapman, E.J. and M.A. Knowles, Necdin: a multi functional protein with potential tumor suppressor role? Molecular carcinogenesis, 2009. 48(11): p. 97581.

174. Chen, L., et al., Single nucleotide polymorphisms affect both cis- and transeQTLs. Genomics, 2009. 93(6): p. 501-8.

175. Fam47e. Gene Cards 2014 31Mar15 6Jun15]; Available from: http://www.genecards.org/cgi-bin/carddisp.pl?gene=FAM47E.

176. Prdm8. 2002 27May15 6Jun15]; Available from: http://www.uniprot.org/uniprot/Q8NEN9.

177. Chini, B., et al., Molecular cloning and chromosomal localization of the human alpha 7-nicotinic receptor subunit gene (CHRNA7). Genomics, 1994. 19(2): p. 379-81.

178. Taske, N.L., et al., Evaluation of the positional candidate gene CHRNA7 at the juvenile myoclonic epilepsy locus (EJM2) on chromosome 15q13-14. Epilepsy research, 2002. 49(2): p. 157-72.

179. Bakanidze, G., et al., Association of the Nicotinic Receptor alpha7 Subunit Gene (CHRNA7) with Schizophrenia and Visual Backward Masking. Frontiers in psychiatry, 2013. 4: p. 133.

180. Williams, S.G. and K.B. Hall, Binding affinity and cooperativity control $U 2 B^{\prime \prime} /$ snRNA/U2A' RNP formation. Biochemistry, 2014. 53(23): p. 3727-37.

181. TM2D3. 12May15 6Jun15]; Available from: http://www.ncbi.nlm.nih.gov/gene/80213. 
182. Richmond, J.Y. and R.W. McKinney, eds. Biosafety in Microbiological and Biomedical Laboratories (U.S. Department of Health and Human Services, Centers for Disease Control and Prevention, and the National Institutes of Health). 5th Edition ed. 2012, U.S. Government Printing Office: Washington, D.C.

183. Alvarez-Barrientos, A., et al., Applications of flow cytometry to clinical microbiology. Clinical microbiology reviews, 2000. 13(2): p. 167-95.

184. Kimman, T.G., E. Smit, and M.R. Klein, Evidence-based biosafety: a review of the principles and effectiveness of microbiological containment measures. Clinical microbiology reviews, 2008. 21(3): p. 403-25.

185. Aloisio, C.H. and J.K. Nicholson, Recovery of infectious human immunodeficiency virus from cells treated with $1 \%$ paraformaldehyde. Journal of immunological methods, 1990. 128(2): p. 281-5.

186. Ericson, J.G., et al., Effects of whole blood lysis and fixation on the infectivity of human T-lymphotropic virus type 1 (HTLV-I). Cytometry, 1994. 18(1): p. 49-54.

187. Schmid, I., et al., International Society for Analytical Cytology biosafety standard for sorting of unfixed cells. Cytometry. Part A : the journal of the International Society for Analytical Cytology, 2007. 71(6): p. 414-37.

188. Schmid, I., et al., Standard safety practices for sorting of unfixed cells. Current protocols in cytometry / editorial board, J. Paul Robinson, managing editor ... [et al.], 2007. Chapter 3: p. Unit3 6.

189. Marim, F.M., et al., A method for generation of bone marrow-derived macrophages from cryopreserved mouse bone marrow cells. PLoS One, 2010. 5(12): p. e15263.

190. Englen, M.D., et al., Granulocyte/macrophage colony-stimulating factor is expressed and secreted in cultures of murine L929 cells. Journal of immunological methods, 1995. 184(2): p. 281-3.

191. CDC, Biosafety in microbiological and biomedical laboratories (BMBL), 5th Edition. Section IV-Laboratory Biosafety Level Criteria, p. 30-59. 5th Edition ed. Section IV_-Laboratory Biosafety Level Criteria. 2009, Washington, D.C.: U.S. Department of Health and Human Services.

192. Clemens, D.L., B.Y. Lee, and M.A. Horwitz, Virulent and avirulent strains of Francisella tularensis prevent acidification and maturation of their phagosomes and escape into the cytoplasm in human macrophages. Infection and immunity, 2004. 72(6): p. 3204-17. 
193. Baron, S.D., R. Singh, and D.W. Metzger, Inactivated Francisella tularensis live vaccine strain protects against respiratory tularemia by intranasal vaccination in an immunoglobulin A-dependent fashion. Infection and immunity, 2007. 75(5): p. 2152-62.

194. Anda, P., et al., Waterborne outbreak of tularemia associated with crayfish fishing. Emerging infectious diseases, 2001. 7(3 Suppl): p. 575-82.

195. Ehrlich, R. and S. Miller, Survival of airborne Pasteurella tularensis at different atmospheric temperatures. Applied microbiology, 1973. 25(3): p. 369-72.

196. Dennis, D.T., et al., Tularemia as a biological weapon: medical and public health management. JAMA : the journal of the American Medical Association, 2001. 285(21): p. 2763-73.

197. Agrati, C., et al., Rapid and biologically safe procedures for the evaluation of antigen-specific $T$ cell response to microbial pathogens that may be used in the BSL-3 and BSL-4 environment. Applied Biosafety, 2008. 13(1): p. 27-30.

198. Robertson, J., et al., The survival of Burkholderia pseudomallei in liquid media. The American journal of tropical medicine and hygiene, 2010. 82(1): p. 88-94.

199. Shams, A.M., et al., Survival of Burkholderia pseudomallei on Environmental Surfaces. Applied and environmental microbiology, 2007. 73(24): p. 8001-4.

200. O'Connell, H.A., et al., Variability of Burkholderia pseudomallei strain sensitivities to chlorine disinfection. Applied and environmental microbiology, 2009. 75(16): p. 5405-9.

201. Chin, C.Y., D.M. Monack, and S. Nathan, Genome wide transcriptome profiling of a murine acute melioidosis model reveals new insights into how Burkholderia pseudomallei overcomes host innate immunity. BMC genomics, 2010. 11: p. 672.

202. Pandey, A.K. and R.W. Williams, Genetics of gene expression in CNS. International review of neurobiology, 2014. 116: p. 195-231.

203. Crawford, M.A., et al., Interferon-inducible CXC chemokines directly contribute to host defense against inhalational anthrax in a murine model of infection. PLoS pathogens, 2010. 6(11): p. e1001199.

204. Laboratory, T.J. Recombinant congenic mice. 20022 August 2015]; Available from: http://research.jax.org/grs/type/recombcong.html.

205. GeneNetwork Glossary of Terms and Features. 06Jun15]; Available from: http://www.genenetwork.org/glossary.html.

206. Shin, D.L., et al., Segregation of a spontaneous Klrd1 (CD94) mutation in DBA/2 mouse substrains. G3, 2015. 5(2): p. 235-9. 
207. C57BL/6NJ. 2008 8Jun15]; Available from: http://jaxmice.jax.org/strain/005304.html. 


\section{APPENDIX. SUPPLEMENTARY FIGURES AND TABLES}

Table A-1. BXD strain group sizes from day 1 through day 4.

\begin{tabular}{|c|c|c|c|c|c|c|c|}
\hline \multicolumn{2}{|c|}{ Day \#1 } & \multicolumn{2}{|c|}{ Day \#2 } & \multicolumn{2}{|c|}{ Day \#3 } & \multicolumn{2}{|c|}{ Day \#4 } \\
\hline $\begin{array}{l}\text { Mouse } \\
\text { Strain }\end{array}$ & $\begin{array}{c}\mathrm{n}=\# \text { of } \\
\text { mice }\end{array}$ & $\begin{array}{l}\text { Mouse } \\
\text { Strain }\end{array}$ & $\begin{array}{c}n=\# \text { of } \\
\text { mice }\end{array}$ & $\begin{array}{c}\text { Mouse } \\
\text { Strain }\end{array}$ & $\begin{array}{c}\mathrm{n}=\# \text { of } \\
\text { mice }\end{array}$ & $\begin{array}{l}\text { Mouse } \\
\text { Strain }\end{array}$ & $\begin{array}{c}\mathrm{n}=\# \text { of } \\
\text { mice }\end{array}$ \\
\hline C57BL/6J & $n=23$ & C57BL/6J & $n=23$ & C57BL/6J & $n=23$ & C57BL/6J & $n=23$ \\
\hline DBA & $n=23$ & DBA & $n=23$ & $*$ DBA & $n=22$ & *DBA & $n=3$ \\
\hline BXD 27 & $n=1$ & BXD 27 & $n=1$ & BXD 27 & $n=1$ & BXD 27 & $n=1$ \\
\hline BXD 22 & $n=3$ & BXD 22 & $n=3$ & BXD 22 & $n=3$ & BXD 22 & $n=3$ \\
\hline BXD 90 & $n=6$ & BXD 90 & $n=6$ & BXD 90 & $n=6$ & BXD 90 & $n=6$ \\
\hline BXD 55 & $n=11$ & BXD 55 & $n=11$ & BXD 55 & $n=11$ & BXD 55 & $n=11$ \\
\hline BXD 49 & $n=8$ & BXD 49 & $n=8$ & BXD 49 & $n=8$ & BXD 49 & $n=8$ \\
\hline BXD 81 & $n=8$ & BXD 81 & $n=8$ & BXD 81 & $n=8$ & *BXD 81 & $n=4$ \\
\hline BXD 73 & $n=10$ & BXD 73 & $n=10$ & BXD 73 & $n=10$ & *BXD 73 & $n=6$ \\
\hline BXD 87 & $n=8$ & BXD 87 & $n=8$ & BXD 87 & $n=8$ & BXD 87 & $n=8$ \\
\hline BXD 95 & $n=2$ & BXD 95 & $n=2$ & BXD 95 & $n=2$ & BXD 95 & $n=2$ \\
\hline BXD 103 & $n=12$ & BXD 103 & $n=12$ & *BXD 103 & $n=11$ & *BXD 103 & $n=10$ \\
\hline BXD 9 & $n=6$ & BXD 9 & $n=6$ & *BXD 9 & $n=5$ & *BXD 9 & $n=3$ \\
\hline BXD 45 & $n=3$ & BXD 45 & $n=3$ & BXD 45 & $n=3$ & BXD 45 & $n=3$ \\
\hline BXD 75 & $n=6$ & BXD 75 & $n=6$ & BXD 75 & $n=6$ & BXD 75 & $n=6$ \\
\hline BXD 50 & $n=5$ & BXD 50 & $n=5$ & BXD 50 & $n=5$ & BXD 50 & $n=5$ \\
\hline BXD 63 & $n=4$ & BXD 63 & $n=4$ & BXD 63 & $n=4$ & *BXD 63 & $n=1$ \\
\hline BXD 101 & $n=1$ & BXD 101 & $n=1$ & BXD 101 & $n=1$ & BXD 101 & $n=1$ \\
\hline BXD 65 & $n=1$ & BXD 65 & $n=1$ & BXD 65 & $n=1$ & BXD 65 & $n=1$ \\
\hline BXD 96 & $n=12$ & BXD 96 & $n=12$ & BXD 96 & $n=12$ & *BXD 96 & $n=9$ \\
\hline BXD 74 & $n=8$ & BXD 74 & $n=8$ & BXD 74 & $n=8$ & BXD 74 & $n=8$ \\
\hline BXD 80 & $n=4$ & BXD 80 & $n=4$ & BXD 80 & $n=4$ & BXD 80 & $n=4$ \\
\hline BXD 67 & $n=8$ & BXD 67 & $n=8$ & BXD 67 & $n=8$ & *BXD 67 & $n=5$ \\
\hline BXD 64 & $n=19$ & BXD 64 & $n=19$ & BXD 64 & $n=19$ & *BXD 64 & $n=14$ \\
\hline BXD 86 & $n=10$ & BXD 86 & $n=10$ & BXD 86 & $n=10$ & *BXD 86 & $n=2$ \\
\hline BXD 13 & $n=4$ & BXD 13 & $n=4$ & BXD 13 & $n=4$ & *BXD 13 & $n=1$ \\
\hline BXD 12 & $n=4$ & BXD 12 & $n=4$ & BXD 12 & $n=4$ & BXD 12 & $n=4$ \\
\hline BXD 43 & $n=11$ & BXD 43 & $n=11$ & BXD 43 & $n=11$ & * BXD 43 & $n=8$ \\
\hline BXD 1 & $n=2$ & BXD 1 & $n=2$ & BXD 1 & $n=2$ & *BXD 1 & $n=1$ \\
\hline BXD 62 & $n=16$ & BXD 62 & $n=16$ & BXD 62 & $n=16$ & *BXD 62 & $n=12$ \\
\hline BXD 69 & $n=5$ & BXD 69 & $n=5$ & BXD 69 & $n=5$ & *BXD 69 & $n=4$ \\
\hline
\end{tabular}


Table A-1. (Continued).

\begin{tabular}{|c|c|c|c|c|c|c|c|}
\hline \multicolumn{2}{|c|}{ Day \#1 } & \multicolumn{2}{|c|}{ Day \#2 } & \multicolumn{2}{|c|}{ Day \#3 } & \multicolumn{2}{|c|}{ Day \#4 } \\
\hline $\begin{array}{l}\text { Mouse } \\
\text { Strain }\end{array}$ & $\begin{array}{c}\mathrm{n}=\# \text { of } \\
\text { mice }\end{array}$ & $\begin{array}{l}\text { Mouse } \\
\text { Strain }\end{array}$ & $\begin{array}{c}n=\# \text { of } \\
\text { mice }\end{array}$ & $\begin{array}{l}\text { Mouse } \\
\text { Strain }\end{array}$ & $\begin{array}{c}\mathrm{n}=\# \text { of } \\
\text { mice }\end{array}$ & $\begin{array}{l}\text { Mouse } \\
\text { Strain }\end{array}$ & $\begin{array}{c}\mathrm{n}=\# \text { of } \\
\text { mice }\end{array}$ \\
\hline BXD 66 & $\mathrm{n}=4$ & BXD 66 & $\mathrm{n}=4$ & BXD 66 & $n=4$ & BXD 66 & $\mathrm{n}=4$ \\
\hline BXD 68 & $n=4$ & BXD 68 & $n=4$ & BXD 68 & $n=4$ & *BXD 68 & $n=1$ \\
\hline BXD 38 & $n=1$ & BXD 38 & $n=1$ & BXD 38 & $n=1$ & BXD 38 & $n=1$ \\
\hline
\end{tabular}

Red asterisk (*) indicates that at least one mouse from that genotype succumbed to infection. 

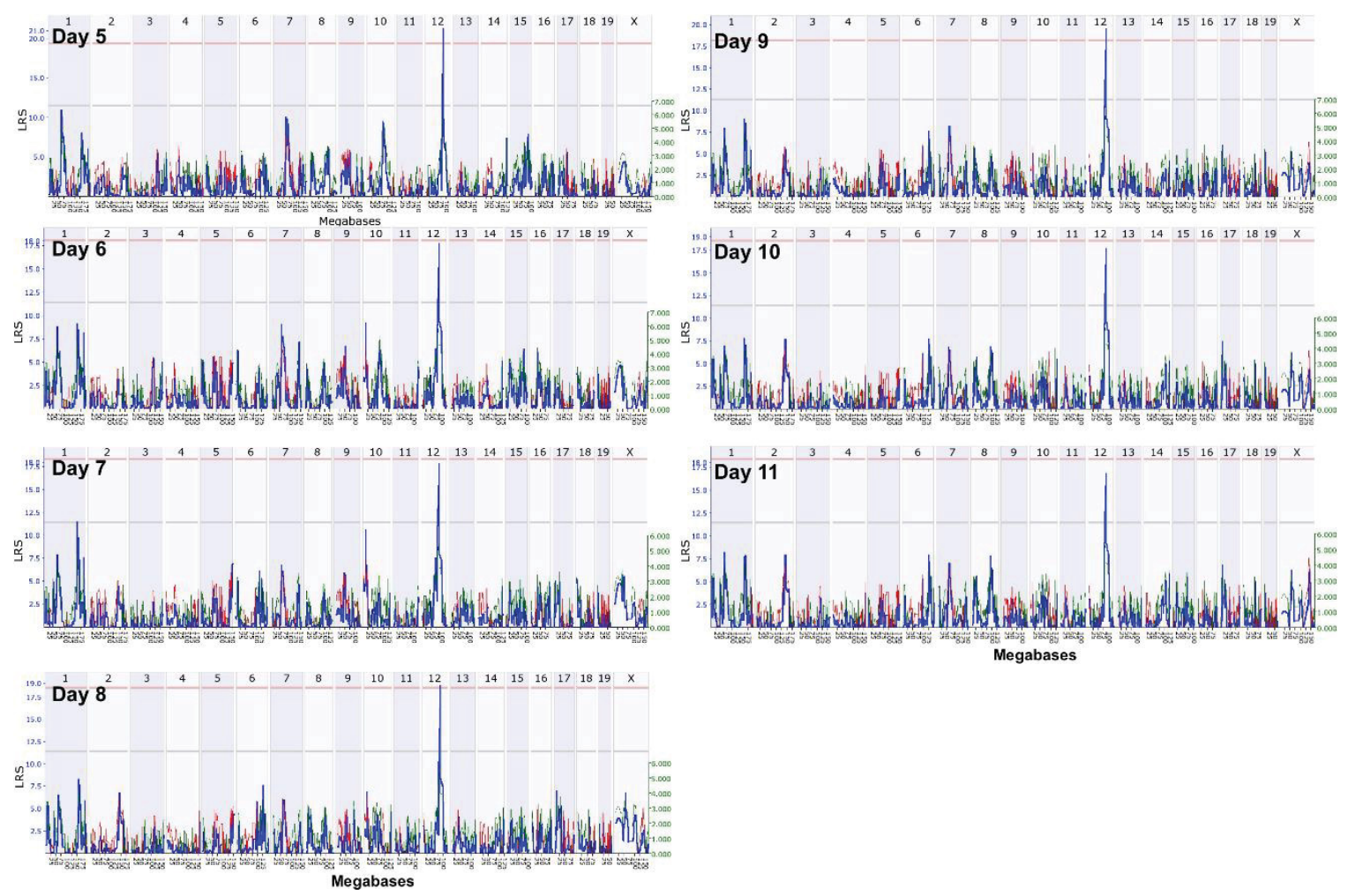

Figure A-1. Genome-wide linkage analysis for percentage weight loss on days 5-11 post- $B p$ infection.

Genome-wide interval maps of percentage weight loss of all BXD genotypes and parental strains at each time point are shown as indicated. Days 5, 8 and 9 show a significant QTL on chromosome 12 while days 6, 7, 10,11 show a suggestive QTL on chromosome 12. The blue line indicates LRS scores across the entire genome. Thin red and green lines indicate that B6 or D2 alleles increase trait values, respectively. The mouse chromosomes are identified in the upper $\mathrm{x}$-axis, the lower $\mathrm{x}$-axis shows the physical map in mega bases for each chromosome, and the y-axis represents the LRS score. Thick red and grey horizontal lines indicate the genome-wide significance threshold $(\mathrm{p}<0.05)$ or suggestive threshold $(\mathrm{p}<0.63)$, respectively. 
Table A-2. Pathway analysis (Gene Ontology (GO) Description) using genes whose expression is significantly upregulated in resistant BXD mice (BXD50 and BXD70).

\begin{tabular}{|c|c|c|c|c|}
\hline GO-Description & Count & $\%$ & P-Value & Benjamini \\
\hline immune response & 56 & 14.1 & $3.60 \mathrm{E}-28$ & $5.80 \mathrm{E}-25$ \\
\hline defense response & 32 & 8.1 & $5.50 \mathrm{E}-10$ & $2.90 \mathrm{E}-07$ \\
\hline response to wounding & 21 & 5.3 & $1.20 \mathrm{E}-05$ & $2.10 \mathrm{E}-03$ \\
\hline response to organic substance & 19 & 4.8 & $8.50 \mathrm{E}-03$ & $3.10 \mathrm{E}-01$ \\
\hline regulation of cell proliferation & 19 & 4.8 & $1.50 \mathrm{E}-02$ & $4.30 \mathrm{E}-01$ \\
\hline regulation of apoptosis & 18 & 4.5 & $3.70 \mathrm{E}-02$ & $6.00 \mathrm{E}-01$ \\
\hline regulation of programmed cell death & 18 & 4.5 & 4.10E-02 & $6.20 \mathrm{E}-01$ \\
\hline regulation of cell death & 18 & 4.5 & 4.30E-02 & $6.20 \mathrm{E}-01$ \\
\hline inflammatory response & 16 & 4 & $2.90 \mathrm{E}-05$ & $4.60 \mathrm{E}-03$ \\
\hline response to virus & 15 & 3.8 & $1.50 \mathrm{E}-10$ & $1.20 \mathrm{E}-07$ \\
\hline antigen processing and presentation & 14 & 3.5 & $9.90 \mathrm{E}-09$ & $4.00 \mathrm{E}-06$ \\
\hline $\begin{array}{l}\text { positive regulation of immune } \\
\text { system process }\end{array}$ & 14 & 3.5 & $1.70 \mathrm{E}-04$ & $1.60 \mathrm{E}-02$ \\
\hline behavior & 14 & 3.5 & $4.80 \mathrm{E}-02$ & $6.40 \mathrm{E}-01$ \\
\hline innate immune response & 12 & 3 & $6.20 \mathrm{E}-06$ & $1.40 \mathrm{E}-03$ \\
\hline $\begin{array}{l}\text { positive regulation of immune } \\
\text { response }\end{array}$ & 11 & 2.8 & $2.80 \mathrm{E}-04$ & $2.30 \mathrm{E}-02$ \\
\hline $\begin{array}{l}\text { positive regulation of response to } \\
\text { stimulus }\end{array}$ & 11 & 2.8 & $3.10 \mathrm{E}-03$ & $1.60 \mathrm{E}-01$ \\
\hline positive regulation of apoptosis & 11 & 2.8 & $2.10 \mathrm{E}-02$ & $5.00 \mathrm{E}-01$ \\
\hline $\begin{array}{l}\text { positive regulation of programmed } \\
\text { cell death }\end{array}$ & 11 & 2.8 & $2.20 \mathrm{E}-02$ & $5.10 \mathrm{E}-01$ \\
\hline positive regulation of cell death & 11 & 2.8 & $2.30 \mathrm{E}-02$ & $5.10 \mathrm{E}-01$ \\
\hline $\begin{array}{l}\text { regulation of lymphocyte mediated } \\
\text { immunity }\end{array}$ & 10 & 2.5 & $3.80 \mathrm{E}-06$ & $1.00 \mathrm{E}-03$ \\
\hline $\begin{array}{l}\text { regulation of leukocyte mediated } \\
\text { immunity }\end{array}$ & 10 & 2.5 & $7.00 \mathrm{E}-06$ & $1.40 \mathrm{E}-03$ \\
\hline $\begin{array}{l}\text { regulation of immune effector } \\
\text { process }\end{array}$ & 10 & 2.5 & $4.60 \mathrm{E}-05$ & $6.10 \mathrm{E}-03$ \\
\hline $\begin{array}{l}\text { positive regulation of multicellular } \\
\text { organismal process }\end{array}$ & 10 & 2.5 & $4.20 \mathrm{E}-03$ & $1.90 \mathrm{E}-01$ \\
\hline lymphocyte activation & 10 & 2.5 & $1.10 \mathrm{E}-02$ & $3.70 \mathrm{E}-01$ \\
\hline leukocyte activation & 10 & 2.5 & $2.50 \mathrm{E}-02$ & $5.20 \mathrm{E}-01$ \\
\hline locomotory behavior & 10 & 2.5 & 4.10E-02 & $6.20 \mathrm{E}-01$ \\
\hline cell activation & 10 & 2.5 & 4.70E-02 & $6.40 \mathrm{E}-01$ \\
\hline regulation of cytokine production & 9 & 2.3 & $5.30 \mathrm{E}-03$ & $2.30 \mathrm{E}-01$ \\
\hline
\end{tabular}


Table A-2. (Continued).

\begin{tabular}{|c|c|c|c|c|}
\hline GO-Description & Count & $\%$ & P-Value & Benjamini \\
\hline induction of programmed cell death & 9 & 2.3 & $1.50 \mathrm{E}-02$ & $4.30 \mathrm{E}-01$ \\
\hline induction of apoptosis & 9 & 2.3 & $1.50 \mathrm{E}-02$ & 4.30E-01 \\
\hline $\begin{array}{l}\text { positive regulation of signal } \\
\text { transduction }\end{array}$ & 9 & 2.3 & $1.80 \mathrm{E}-02$ & $4.60 \mathrm{E}-01$ \\
\hline response to endogenous stimulus & 9 & 2.3 & $2.50 \mathrm{E}-02$ & $5.20 \mathrm{E}-01$ \\
\hline $\begin{array}{l}\text { positive regulation of cell } \\
\text { communication }\end{array}$ & 9 & 2.3 & $2.90 \mathrm{E}-02$ & $5.40 \mathrm{E}-01$ \\
\hline regulation of cell killing & 8 & 2 & $1.20 \mathrm{E}-06$ & $3.90 \mathrm{E}-04$ \\
\hline $\begin{array}{l}\text { regulation of leukocyte mediated } \\
\text { cytotoxicity }\end{array}$ & 8 & 2 & $1.20 \mathrm{E}-06$ & $3.90 \mathrm{E}-04$ \\
\hline $\begin{array}{l}\text { regulation of adaptive immune } \\
\text { response based on somatic } \\
\text { recombination of immune receptors } \\
\text { built from immunoglobulin } \\
\text { superfamily domains }\end{array}$ & 8 & 2 & $9.00 \mathrm{E}-05$ & $9.70 \mathrm{E}-03$ \\
\hline $\begin{array}{l}\text { regulation of adaptive immune } \\
\text { response }\end{array}$ & 8 & 2 & $9.00 \mathrm{E}-05$ & $9.70 \mathrm{E}-03$ \\
\hline $\mathrm{T}$ cell activation & 8 & 2 & $6.90 \mathrm{E}-03$ & $2.70 \mathrm{E}-01$ \\
\hline immune effector process & 8 & 2 & $1.10 \mathrm{E}-02$ & $3.60 \mathrm{E}-01$ \\
\hline positive regulation of transport & 8 & 2 & $1.30 \mathrm{E}-02$ & $4.10 \mathrm{E}-01$ \\
\hline regulation of lymphocyte activation & 8 & 2 & $2.10 \mathrm{E}-02$ & $5.00 \mathrm{E}-01$ \\
\hline regulation of leukocyte activation & 8 & 2 & $2.90 \mathrm{E}-02$ & $5.50 \mathrm{E}-01$ \\
\hline regulation of cell activation & 8 & 2 & $3.00 \mathrm{E}-02$ & $5.50 \mathrm{E}-01$ \\
\hline $\begin{array}{l}\text { regulation of protein modification } \\
\text { process }\end{array}$ & 8 & 2 & $3.90 \mathrm{E}-02$ & $6.20 \mathrm{E}-01$ \\
\hline response to hormone stimulus & 8 & 2 & $3.90 \mathrm{E}-02$ & $6.20 \mathrm{E}-01$ \\
\hline $\begin{array}{l}\text { antigen processing and presentation } \\
\text { of peptide antigen }\end{array}$ & 7 & 1.8 & $4.70 \mathrm{E}-05$ & $5.80 \mathrm{E}-03$ \\
\hline $\begin{array}{l}\text { positive regulation of leukocyte } \\
\text { mediated immunity }\end{array}$ & 7 & 1.8 & $1.00 \mathrm{E}-04$ & $1.00 \mathrm{E}-02$ \\
\hline $\begin{array}{l}\text { positive regulation of lymphocyte } \\
\text { mediated immunity }\end{array}$ & 7 & 1.8 & $1.00 \mathrm{E}-04$ & $1.00 \mathrm{E}-02$ \\
\hline $\begin{array}{l}\text { positive regulation of immune } \\
\text { effector process }\end{array}$ & 7 & 1.8 & $2.30 \mathrm{E}-04$ & $2.00 \mathrm{E}-02$ \\
\hline lipoprotein metabolic process & 7 & 1.8 & $3.30 \mathrm{E}-03$ & $1.70 \mathrm{E}-01$ \\
\hline regulation of $\mathrm{T}$ cell activation & 7 & 1.8 & $1.80 \mathrm{E}-02$ & $4.60 \mathrm{E}-01$ \\
\hline $\begin{array}{l}\text { regulation of protein amino acid } \\
\text { phosphorylation }\end{array}$ & 7 & 1.8 & $2.90 \mathrm{E}-02$ & $5.40 \mathrm{E}-01$ \\
\hline positive regulation of cell killing & 6 & 1.5 & $6.30 \mathrm{E}-05$ & $7.20 \mathrm{E}-03$ \\
\hline $\begin{array}{l}\text { positive regulation of adaptive immune } \\
\text { response based on somatic recombination } \\
\text { of immune receptors built from } \\
\text { immunoglobulin superfamily domains }\end{array}$ & 6 & 1.5 & $4.40 \mathrm{E}-04$ & $3.20 \mathrm{E}-02$ \\
\hline
\end{tabular}


Table A-2. (Continued).

\begin{tabular}{|c|c|c|c|c|}
\hline GO-Description & Count & $\%$ & P-Value & Benjamini \\
\hline $\begin{array}{l}\text { positive regulation of adaptive } \\
\text { immune response }\end{array}$ & 6 & 1.5 & $4.40 \mathrm{E}-04$ & $3.20 \mathrm{E}-02$ \\
\hline $\begin{array}{l}\text { positive regulation of cytokine } \\
\text { production }\end{array}$ & 6 & 1.5 & $6.60 \mathrm{E}-03$ & $2.70 \mathrm{E}-01$ \\
\hline $\begin{array}{l}\text { negative regulation of immune } \\
\text { system process }\end{array}$ & 6 & 1.5 & $1.50 \mathrm{E}-02$ & $4.30 \mathrm{E}-01$ \\
\hline adaptive immune response & 6 & 1.5 & $2.20 \mathrm{E}-02$ & $5.10 \mathrm{E}-01$ \\
\hline $\begin{array}{l}\text { adaptive immune response based on } \\
\text { somatic recombination of immune } \\
\text { receptors built from } \\
\text { immunoglobulin superfamily } \\
\text { domains }\end{array}$ & 6 & 1.5 & $2.20 \mathrm{E}-02$ & $5.10 \mathrm{E}-01$ \\
\hline $\begin{array}{l}\text { negative regulation of multicellular } \\
\text { organismal process }\end{array}$ & 6 & 1.5 & $4.30 \mathrm{E}-02$ & $6.30 \mathrm{E}-01$ \\
\hline $\begin{array}{l}\text { regulation of } \mathrm{T} \text { cell mediated } \\
\text { cytotoxicity }\end{array}$ & 5 & 1.3 & $3.90 \mathrm{E}-05$ & $5.70 \mathrm{E}-03$ \\
\hline $\begin{array}{l}\text { regulation of } \mathrm{T} \text { cell mediated } \\
\text { immunity }\end{array}$ & 5 & 1.3 & $3.20 \mathrm{E}-04$ & $2.50 \mathrm{E}-02$ \\
\hline $\begin{array}{l}\text { antigen processing and presentation } \\
\text { of exogenous antigen }\end{array}$ & 5 & 1.3 & $1.90 \mathrm{E}-03$ & $1.10 \mathrm{E}-01$ \\
\hline $\begin{array}{l}\text { positive regulation of defense } \\
\text { response }\end{array}$ & 5 & 1.3 & $2.30 \mathrm{E}-02$ & $5.00 \mathrm{E}-01$ \\
\hline $\begin{array}{l}\text { antigen processing and presentation } \\
\text { via } \mathrm{MHC} \text { class } \mathrm{Ib}\end{array}$ & 4 & 1 & $2.30 \mathrm{E}-04$ & $1.90 \mathrm{E}-02$ \\
\hline $\begin{array}{l}\text { positive regulation of } \mathrm{T} \text { cell } \\
\text { mediated cytotoxicity }\end{array}$ & 4 & 1 & $5.30 \mathrm{E}-04$ & $3.70 \mathrm{E}-02$ \\
\hline $\begin{array}{l}\text { positive regulation of } \mathrm{T} \text { cell } \\
\text { mediated immunity }\end{array}$ & 4 & 1 & $1.70 \mathrm{E}-03$ & $1.10 \mathrm{E}-01$ \\
\hline $\begin{array}{l}\text { regulation of interleukin-12 } \\
\text { production }\end{array}$ & 4 & 1 & $2.70 \mathrm{E}-03$ & $1.50 \mathrm{E}-01$ \\
\hline $\begin{array}{l}\text { antigen processing and presentation } \\
\text { of peptide antigen via MHC class I }\end{array}$ & 4 & 1 & $3.90 \mathrm{E}-03$ & $1.90 \mathrm{E}-01$ \\
\hline $\begin{array}{l}\text { regulation of natural killer cell } \\
\text { mediated cytotoxicity }\end{array}$ & 4 & 1 & $6.20 \mathrm{E}-03$ & $2.60 \mathrm{E}-01$ \\
\hline $\begin{array}{l}\text { regulation of natural killer cell } \\
\text { mediated immunity }\end{array}$ & 4 & 1 & $6.20 \mathrm{E}-03$ & $2.60 \mathrm{E}-01$ \\
\hline $\begin{array}{l}\text { antigen processing and presentation } \\
\text { of exogenous peptide antigen }\end{array}$ & 4 & 1 & $9.20 \mathrm{E}-03$ & $3.30 \mathrm{E}-01$ \\
\hline $\begin{array}{l}\text { regulation of interferon-gamma } \\
\text { production }\end{array}$ & 4 & 1 & $2.30 \mathrm{E}-02$ & $5.10 \mathrm{E}-01$ \\
\hline response to cytokine stimulus & 4 & 1 & $2.30 \mathrm{E}-02$ & $5.10 \mathrm{E}-01$ \\
\hline $\begin{array}{l}\text { negative regulation of mononuclear } \\
\text { cell proliferation }\end{array}$ & 4 & 1 & $2.90 \mathrm{E}-02$ & $5.40 \mathrm{E}-01$ \\
\hline $\begin{array}{l}\text { negative regulation of leukocyte } \\
\text { proliferation }\end{array}$ & 4 & 1 & $2.90 \mathrm{E}-02$ & $5.40 \mathrm{E}-01$ \\
\hline $\begin{array}{l}\text { negative regulation of lymphocyte } \\
\text { proliferation }\end{array}$ & 4 & 1 & $2.90 \mathrm{E}-02$ & $5.40 \mathrm{E}-01$ \\
\hline
\end{tabular}


Table A-2. (Continued).

\begin{tabular}{|c|c|c|c|c|}
\hline GO-Description & Count & $\%$ & P-Value & Benjamini \\
\hline cell growth & 4 & 1 & $3.30 \mathrm{E}-02$ & $5.70 \mathrm{E}-01$ \\
\hline $\begin{array}{l}\text { positive regulation of cytokine } \\
\text { biosynthetic process }\end{array}$ & 4 & 1 & 4.60E-02 & $6.40 \mathrm{E}-01$ \\
\hline $\begin{array}{l}\text { antigen processing and presentation } \\
\text { of endogenous peptide antigen }\end{array}$ & 3 & 0.8 & $2.10 \mathrm{E}-03$ & $1.20 \mathrm{E}-01$ \\
\hline $\begin{array}{l}\text { positive regulation of glucose } \\
\text { transport }\end{array}$ & 3 & 0.8 & $7.20 \mathrm{E}-03$ & $2.80 \mathrm{E}-01$ \\
\hline $\begin{array}{l}\text { positive regulation of glucose } \\
\text { import }\end{array}$ & 3 & 0.8 & $7.20 \mathrm{E}-03$ & $2.80 \mathrm{E}-01$ \\
\hline $\begin{array}{l}\text { positive regulation of interleukin- } 12 \\
\text { biosynthetic process }\end{array}$ & 3 & 0.8 & $7.20 \mathrm{E}-03$ & $2.80 \mathrm{E}-01$ \\
\hline $\begin{array}{l}\text { regulation of interleukin-12 } \\
\text { biosynthetic process }\end{array}$ & 3 & 0.8 & $1.20 \mathrm{E}-02$ & $3.80 \mathrm{E}-01$ \\
\hline $\begin{array}{l}\text { regulation of fibroblast growth } \\
\text { factor receptor signaling pathway }\end{array}$ & 3 & 0.8 & $1.80 \mathrm{E}-02$ & $4.60 \mathrm{E}-01$ \\
\hline $\begin{array}{l}\text { regulation of peptidyl-serine } \\
\text { phosphorylation }\end{array}$ & 3 & 0.8 & $1.80 \mathrm{E}-02$ & $4.60 \mathrm{E}-01$ \\
\hline cytokine metabolic process & 3 & 0.8 & $2.90 \mathrm{E}-02$ & $5.50 \mathrm{E}-01$ \\
\hline defense response to virus & 3 & 0.8 & $3.30 \mathrm{E}-02$ & $5.70 \mathrm{E}-01$ \\
\hline $\begin{array}{l}\text { cell structure disassembly during } \\
\text { apoptosis }\end{array}$ & 3 & 0.8 & $3.30 \mathrm{E}-02$ & $5.70 \mathrm{E}-01$ \\
\hline $\begin{array}{l}\text { positive regulation of natural killer } \\
\text { cell mediated immunity }\end{array}$ & 3 & 0.8 & $3.30 \mathrm{E}-02$ & $5.70 \mathrm{E}-01$ \\
\hline $\begin{array}{l}\text { positive regulation of natural killer } \\
\text { cell mediated cytotoxicity }\end{array}$ & 3 & 0.8 & 3.30E-02 & $5.70 \mathrm{E}-01$ \\
\hline $\begin{array}{l}\text { positive regulation of interferon- } \\
\text { gamma production }\end{array}$ & 3 & 0.8 & 4.10E-02 & $6.10 \mathrm{E}-01$ \\
\hline $\begin{array}{l}\text { negative regulation of neurological } \\
\text { system process }\end{array}$ & 3 & 0.8 & 4.60E-02 & $6.40 \mathrm{E}-01$ \\
\hline $\begin{array}{l}\text { antigen processing and presentation } \\
\text { of endogenous peptide antigen via } \\
\text { MHC class Ib }\end{array}$ & 2 & 0.5 & $3.80 \mathrm{E}-02$ & $6.10 \mathrm{E}-01$ \\
\hline
\end{tabular}

Count - number of genes from list involved in GO Description; \% - percentage of all genes in list; P-value - modified Fisher Exact p-value for enrichment; Benjamini - false discovery rate corrected $\mathrm{P}$-values. 
Table A-3. Pathway analysis (Gene Ontology (GO) Description) using genes whose expression is significantly upregulated in susceptible BXD mice (BXD9, BXD63 and BXD27).

\begin{tabular}{|c|c|c|c|c|}
\hline GO-Description & Count & $\%$ & P-Value & Benjamini \\
\hline vesicle-mediated transport & 16 & 6.2 & $1.80 \mathrm{E}-04$ & $6.80 \mathrm{E}-02$ \\
\hline membrane organization & 14 & 5.4 & $9.20 \mathrm{E}-06$ & $5.20 \mathrm{E}-03$ \\
\hline defense response & 13 & 5 & $3.80 \mathrm{E}-03$ & $5.80 \mathrm{E}-01$ \\
\hline endocytosis & 12 & 4.7 & $7.00 \mathrm{E}-06$ & $7.90 \mathrm{E}-03$ \\
\hline membrane invagination & 12 & 4.7 & 7.00E-06 & 7.90E-03 \\
\hline response to wounding & 10 & 3.9 & $1.40 \mathrm{E}-02$ & $8.40 \mathrm{E}-01$ \\
\hline intracellular transport & 10 & 3.9 & $4.80 \mathrm{E}-02$ & $9.00 \mathrm{E}-01$ \\
\hline ion homeostasis & 9 & 3.5 & $1.50 \mathrm{E}-02$ & 8.30E-01 \\
\hline translation & 9 & 3.5 & $2.40 \mathrm{E}-02$ & $9.00 \mathrm{E}-01$ \\
\hline chemical homeostasis & 9 & 3.5 & $4.80 \mathrm{E}-02$ & $8.90 \mathrm{E}-01$ \\
\hline cellular ion homeostasis & 8 & 3.1 & $2.50 \mathrm{E}-02$ & $8.90 \mathrm{E}-01$ \\
\hline $\begin{array}{l}\text { cellular chemical } \\
\text { homeostasis }\end{array}$ & 8 & 3.1 & 2.80E-02 & 8.90E-01 \\
\hline $\begin{array}{l}\text { positive regulation of } \\
\text { multicellular organismal } \\
\text { process }\end{array}$ & 7 & 2.7 & $9.10 \mathrm{E}-03$ & 7.80E-01 \\
\hline inflammatory response & 7 & 2.7 & $3.80 \mathrm{E}-02$ & 8.80E-01 \\
\hline $\begin{array}{l}\text { defense response to } \\
\text { bacterium }\end{array}$ & 6 & 2.3 & $6.70 \mathrm{E}-03$ & $7.20 \mathrm{E}-01$ \\
\hline response to bacterium & 6 & 2.3 & $2.90 \mathrm{E}-02$ & $8.80 \mathrm{E}-01$ \\
\hline phagocytosis & 4 & 1.6 & $1.60 \mathrm{E}-02$ & $8.20 \mathrm{E}-01$ \\
\hline response to hypoxia & 4 & 1.6 & $3.30 \mathrm{E}-02$ & $8.80 \mathrm{E}-01$ \\
\hline response to oxygen levels & 4 & 1.6 & $3.40 \mathrm{E}-02$ & $8.80 \mathrm{E}-01$ \\
\hline $\begin{array}{l}\text { regulation of cAMP } \\
\text { metabolic process }\end{array}$ & 4 & 1.6 & $3.70 \mathrm{E}-02$ & $8.80 \mathrm{E}-01$ \\
\hline $\begin{array}{l}\text { regulation of cyclic } \\
\text { nucleotide metabolic } \\
\text { process }\end{array}$ & 4 & 1.6 & 4.60E-02 & $9.00 \mathrm{E}-01$ \\
\hline $\begin{array}{l}\text { regulation of nucleotide } \\
\text { metabolic process }\end{array}$ & 4 & 1.6 & 4.90E-02 & $8.90 \mathrm{E}-01$ \\
\hline $\begin{array}{l}\text { inflammatory response to } \\
\text { antigenic stimulus }\end{array}$ & 3 & 1.2 & $2.40 \mathrm{E}-03$ & $5.00 \mathrm{E}-01$ \\
\hline cell killing & 3 & 1.2 & $1.30 \mathrm{E}-02$ & $8.40 \mathrm{E}-01$ \\
\hline $\begin{array}{l}\text { positive regulation of } \\
\text { phagocytosis }\end{array}$ & 3 & 1.2 & $2.60 \mathrm{E}-02$ & $8.80 \mathrm{E}-01$ \\
\hline regulation of phagocytosis & 3 & 1.2 & $3.00 \mathrm{E}-02$ & $8.70 \mathrm{E}-01$ \\
\hline $\begin{array}{l}\text { antibody-dependent cellular } \\
\text { cytotoxicity }\end{array}$ & 2 & 0.8 & 4.30E-02 & $9.00 \mathrm{E}-01$ \\
\hline type IIa hypersensitivity & 2 & 0.8 & 4.30E-02 & $9.00 \mathrm{E}-01$ \\
\hline type II hypersensitivity & 2 & 0.8 & 4.30E-02 & $9.00 \mathrm{E}-01$ \\
\hline
\end{tabular}


Table A-3. (Continued).

Count - number of genes from list involved in GO Description; \% - percentage of all genes in list; P-value - modified Fisher Exact p-value for enrichment; Benjamini - false discovery rate corrected $\mathrm{P}$-values. 


\section{VITA}

Felicia Diant'e Emery was born in 1983 in Baton Rouge, LA. She graduated from Baton Rouge Magnet High School in 2001 and later, from Louisiana State University in 2006 with of Bachelor of Science in Biological Sciences. After graduation, she began teaching high school Biology and Physical Science in the East Baton Rouge Parish School System. In 2009, Felicia enrolled in a Masters program at Southern University in Baton Rouge, LA and graduated with a Master of Science degree in Biology in May 2010. In the fall of 2010, she entered the Integrated Program in Biomedical Sciences (IPBS) in the Microbial pathogenesis, Immunology and Inflammation Track at The University of Tennessee Health Science Center. Under the guidance of Dr. Mark A. Miller (Microbiology, Immunology and Biochemistry), Felicia has worked on identifying host genetic elements that contribute to differential immune susceptibility during pneumonic Burkholderia pseudomallei $(B p)$ infection in BXD mice using a forward genetics approach. Felicia successfully defended her Ph.D. dissertation in June 2015. She will begin an undergraduate microbiology teaching position in August 2015. 